\title{
Life in the midst of scarcity: adaptations to nutrient availability in Saccharomyces cerevisiae
}

\author{
Bart Smets • Ruben Ghillebert $\cdot$ Pepijn De Snijder • Matteo Binda \\ Erwin Swinnen · Claudio De Virgilio $\cdot$ Joris Winderickx
}

\begin{abstract}
Cells of all living organisms contain complex signal transduction networks to ensure that a wide range of physiological properties are properly adapted to the environmental conditions. The fundamental concepts and individual building blocks of these signalling networks are generally well-conserved from yeast to man; yet, the central role that growth factors and hormones play in the regulation of signalling cascades in higher eukaryotes is executed by nutrients in yeast. Several nutrient-controlled pathways, which regulate cell growth and proliferation, metabolism and stress resistance, have been defined in yeast. These pathways are integrated into a signalling network, which ensures that yeast cells enter a quiescent, resting phase $\left(G_{0}\right)$ to survive periods of nutrient scarceness and that they rapidly resume growth and cell proliferation when nutrient conditions become favourable again. A series of well-conserved nutrient-sensory protein kinases perform key roles in this signalling network: i.e. Snf1, PKA, Tor1 and Tor2, Sch9 and Pho85-Pho80. In this review, we provide a comprehensive overview on the current understanding of the signalling processes
\end{abstract}

B. Smets and R. Ghillebert contributed equally and should be considered co-first authors.

B. Smets · R. Ghillebert · P. De Snijder · E. Swinnen

J. Winderickx $(\bowtie)$

Laboratory of Functional Biology, Katholieke Universiteit

Leuven, Kasteelpark Arenberg 31, Box 2433,

3001 Heverlee, Belgium

e-mail: Joris.winderickx@bio.kuleuven.be

M. Binda $\cdot$ C. De Virgilio

Division of Biochemistry, Department of Medicine,

University of Fribourg, 1700 Fribourg, Switzerland mediated via these kinases with a particular focus on how these individual pathways converge to signalling networks that ultimately ensure the dynamic translation of extracellular nutrient signals into appropriate physiological responses.

Keywords Nutrient sensing - Signal transduction · Yeast $\cdot$ TOR $\cdot$ PKA $\cdot$ Sch9

\section{Introduction}

All living organisms have evolved complex signal transduction networks that ensure the fast and optimal adaptation of cellular metabolism to changes in the environmental conditions. Since signal transduction components and mechanisms are highly conserved among all eukaryotes, the unicellular eukaryote Saccharomyces cerevisiae, or budding yeast, is often used as a model organism to study cell signalling. For $S$. cerevisiae cells, the constantly fluctuating nutrient content of the environment is a key determinant of cell cycle progression and growth, stress resistance and metabolism. The nutrient-induced signalling network enables yeast both to optimally profit from rich nutrient conditions by stimulating cell proliferation and to survive periods of nutrient scarceness by inducing the entry into a quiescent, resting phase, called the stationary phase $\left(\mathrm{G}_{0}\right)$ (Winderickx et al. 2003; Roosen et al. 2004; Zaman et al. 2008). In general, a nutrient is sensed by the signalling network (i) externally, via a receptor protein in the plasma membrane, which after binding of the nutrient adopts a new conformation that activates a downstream signalling cascade, or (ii) internally, after uptake of the nutrient, possibly followed by its metabolism, thereby causing a change in its intracellular concentration which, in 
turn, modulates downstream signalling (Forsberg and Ljungdahl 2001; Holsbeeks et al. 2004).

Yeast can use a wide variety of substances as a nutrient source. Nevertheless, some nutrients are preferred over others and nutrient metabolism is regulated in such a way that the preferred nutrient source is consumed first. Especially, the carbon source has a high impact on S. cerevisiae metabolism. In contrast to most yeast species, $S$. cerevisiae cells will, given that all other essential nutrients are present in adequate amounts, preferably ferment glucose and other rapidly fermentable sugars to ethanol and acetate, although respiration would be energetically more favourable. It is believed that this phenomenon, called the Crabtree effect, gives yeast cells a competitive advantage, as the ethanol produced during fermentation inhibits growth of other micro-organisms. When glucose becomes limiting yeast will enter the diauxic shift, during which metabolism shifts from fermentation to respiration to allow usage of ethanol and acetate, which have accumulated during the fermentative growth phase. Finally, also when these carbon sources have been exhausted, cells will enter the stationary phase $\left(\mathrm{G}_{0}\right)$. Importantly, when another essential nutrient becomes limiting before glucose, yeast cells directly enter the stationary phase without passing through all other growth phases (Fig. 1). This review will focus on the most important nutrient kinases, i.e. Snf1, PKA, Tor1 and Tor2, Sch9 and Pho85-Pho80, and clarify their roles in adaptation to the specific nutrient-induced stress conditions.

\section{Nutrient-induced signalling in S. cerevisiae}

The main glucose repression pathway

The main glucose repression or catabolite repression pathway controls the adaptation of yeast carbon metabolism to the availability of glucose in the medium. In the presence of glucose, the central component of this pathway, the serine/threonine protein kinase Snf1 is inactivated, resulting in the transcriptional repression of genes that are not needed during fermentative growth on glucose, i.e. genes encoding for enzymes involved in gluconeogenesis, the Krebs cycle, respiration and the uptake and metabolism of alternative carbon sources (Fig. 2) (Ronne 1995; Gancedo 1998; Hedbacker and Carlson 2008).

\section{Structure and regulation of the Snf1 kinase}

The Snf1 kinase belongs to the well-conserved Snf1/AMPactivated protein kinase (AMPK) family (Woods et al. 1994; Hardie 2007). As the other members of this family, yeast Snf1 functions in a heterotrimeric complex, comprising a catalytic $\alpha$ subunit (Snf1), a scaffolding as well as

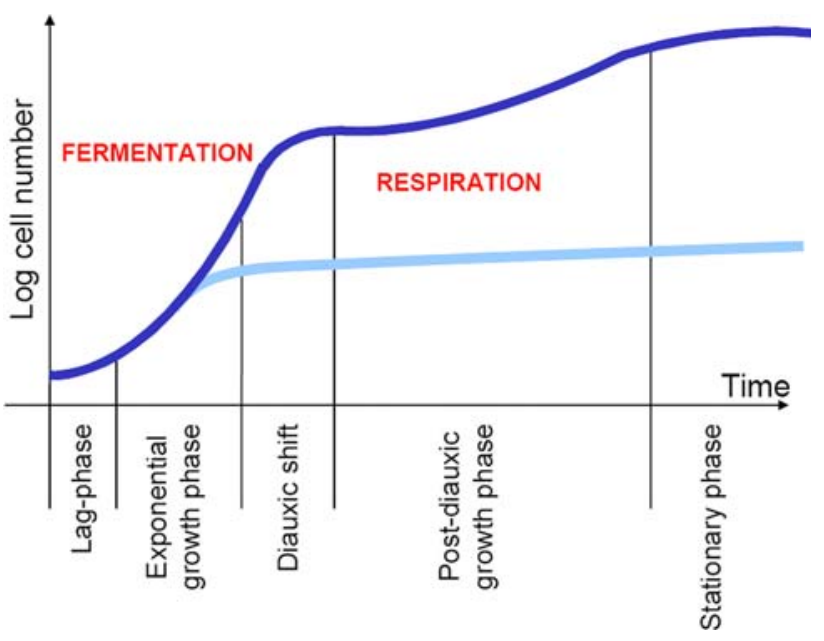

Fig. 1 Typical growth profile of a fermentative batch culture of $S$. cerevisiae. A schematic representation of the increase in cell number and cell density of a batch culture of $S$. cerevisiae inoculated in rich medium containing the rapidly fermentable sugar glucose as carbon source (dark line). After a short adaptive lag phase, yeast consumes glucose during the exponential fermentative growth phase. When the glucose becomes limiting, yeast cells enter the diauxic shift and shift from a fermentative to a respiratory metabolism. In the post-diauxic growth phase, the cells resume growth using ethanol, acetate and other products produced during glucose fermentation as carbon source. Finally, when these carbon sources are exhausted, the cells enter a quiescent state, the stationary phase $\left(\mathrm{G}_{0}\right)$, with the ultimate goal of surviving the starvation period. When exponentially growing yeast cells are transferred to medium containing glucose but missing an essential nutrient such as nitrogen or phosphate, they arrest growth and enter the $\mathrm{G}_{0}$ state due to nutrient deprivation (light line)

regulatory $\beta$ subunit (Gal83, Sip1 or Sip2) and a regulatory $\gamma$ subunit (Snf4) (Celenza and Carlson 1989; Celenza et al. 1989; Yang et al. 1994; Jiang and Carlson 1997; McCartney et al. 2005). The Snf1 kinase complex is controlled through multiple mechanisms. When high levels of glucose are present, an auto-inhibitory interaction between the $\mathrm{N}$-terminal catalytic domain and the C-terminal regulatory domain of Snf1 inactivates the protein kinase. This autoinhibition is relieved when glucose levels drop, which correlates with an increased interaction between the $\gamma$ subunit Snf4 and the Snf1 regulatory domain (Jiang and Carlson 1996).

Additionally, full activation of Snf1 requires phosphorylation of a conserved threonine residue (Thr210) in the activation loop of the Snf1 catalytic domain (Estruch et al. 1992; Wilson et al. 1996; McCartney and Schmidt 2001). Three upstream kinases, Sak1, Elm1 and Tos3, are responsible for phosphorylation of this threonine residue (Sutherland et al. 2003). These kinases appear to be functionally redundant, since only the absence of all three causes a snfl $\Delta$ mutant phenotype. Nevertheless, it was reported that their role in Snf1 activation is determined by the combination of the $\beta$ subunit present in the kinase complex and the growth/stress conditions tested 


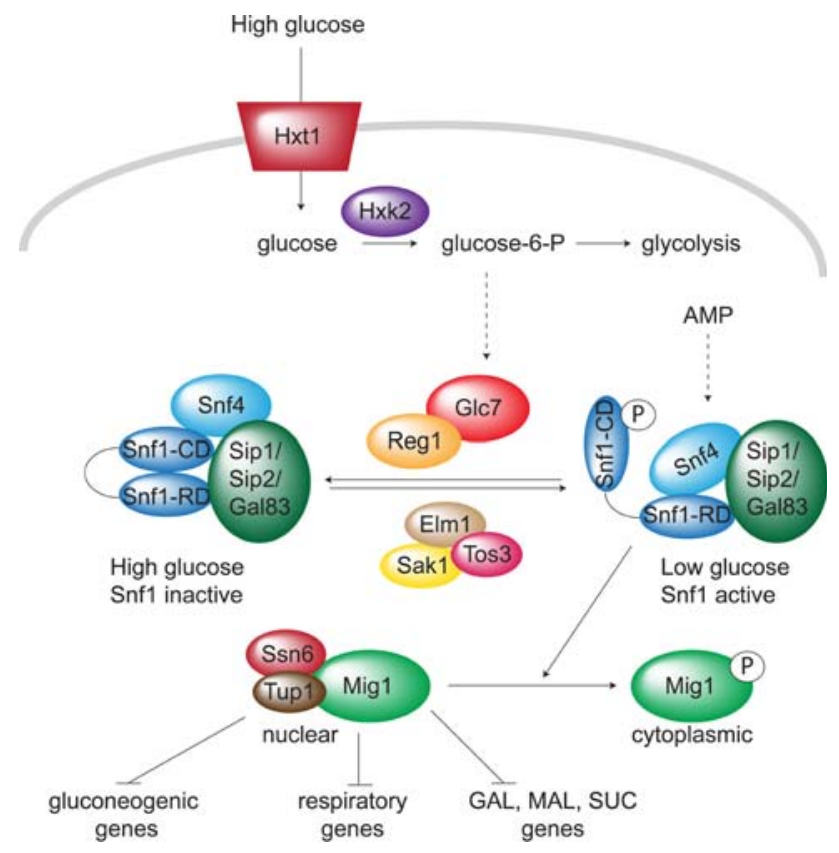

Fig. 2 The main glucose repression pathway in S. cerevisiae. In the presence of high levels of glucose, the Snf1 kinase complex is inactive due to an auto-inhibitory interaction between the catalytic domain (CD) and the regulatory domain (RD) of Snf1. Activation of Snf1 upon glucose exhaustion requires the phosphorylation of $\mathrm{Thr}^{210}$ in the activation loop of the catalytic domain of Snf1 and the binding of Snf4 to the regulatory domain of Snf1, which is necessary to lift Snf1 auto-inhibition. The phosphorylation status of the threonine residue is controlled by the upstream kinases Sak1, Elm1 and Tos3 and the Glc7-Reg1 phosphatase complex. Activated Snf1 phosphorylates Mig1, thereby stimulating the translocation of the repressor to the cytoplasm, which relieves several gene families of glucose repression. The glucose signal that controls Snf1 activity is possibly transduced via Hxk2 to Glc7-Reg1 and via a sensing of the AMP/ ATP ratio by Snf4. Arrows and bars represent positive and negative interactions, respectively. Dashed lines represent putative or indirect interactions. See text for further details

(Hedbacker et al. 2004; Kim et al. 2005; McCartney et al. 2005). Dephosphorylation of Snf1 is mediated by the protein phosphatase complex Glc7-Reg1 (Ludin et al. 1998; Sanz et al. 2000; McCartney and Schmidt 2001). Glc7 is the catalytic subunit of the phosphatase complex, whereas Reg1 is the regulatory subunit that targets the phosphatase to Snf1 since it can bind to the catalytic domain of the protein kinase. In yeast cells, lacking a proper Glc7-Reg1 function, the Snf1 kinase complex is constitutively active resulting in loss of glucose repression (Niederacher and Entian 1991; Tung et al. 1992; Tu and Carlson 1994, 1995; Huang et al. 1996; Hong et al. 2005). However, gluconeogenic genes remain repressed in a reg14 strain, while genes involved in the utilization of alternative carbon sources are derepressed (Schuller 2003). The interaction between Glc7-Reg1 and the Snf1 kinase complex is stimulated upon glucose resupplementation, which was proposed to facilitate the fast dephosphorylation and subsequent inactivation of Snf1 by the phosphatase complex (Sanz et al. 2000). In support of such a crucial role for the phosphatase in the regulation of Snf1 activity, it was recently reported that the dephosphorylation rate of Snf1 is more subject to glucose regulation than the phosphorylation rate (Rubenstein et al. 2008). However, it also appears that the catalytic activity of the Glc7-Reg1 phosphatase itself is not controlled by glucose, but rather Snf1 itself, in such a way that the ability of the Snf1 activation loop to act as a substrate for Glc7-Reg1 is adapted to glucose availability (Rubenstein et al. 2008).

Finally, also the subcellular localization of the Snf1 kinase complex is regulated and depends on the $\beta$ subunit. During growth on glucose medium, all Snf1 complexes are localized in the cytoplasm. However, upon glucose limitation, the Snf1-Sip1 complex translocates to the vacuole and the Snf1-Gal83 complex goes into the nucleus, whereas the Snf1-Sip2 complex remains in the cytoplasm (Vincent et al. 2001). Certainly, the regulation of the nucleocytoplasmic distribution of Snf1-Gal83 is important, as Snf1 has such a great impact on gene expression. Although in a snfl $\Delta$ mutant Gal83 exhibits a glucoseregulated nuclear accumulation, it was shown that the relocalization of the Snf1-Gal83 complex to the nucleus requires both Gal83 as well as an active Snf1 catalytic subunit (Hedbacker et al. 2004; Hedbacker and Carlson 2006). Cytoplasmic retention of inactive Snf1-Gal83 complexes is probably necessary to maintain accessibility of the complex to the Snf1-activating kinases.

\section{Downstream targets of Snf1}

The most important Snf1 target is the transcriptional repressor Mig1. In the presence of glucose, Mig1 is localized in the nucleus and inhibits the expression of many glucose-repressed genes by binding to their promoter in association with the corepressor complex Cyc8/Ssn6-Tup1 (Nehlin and Ronne 1990; Keleher et al. 1992; Lundin et al. 1994; Treitel and Carlson 1995). Glucose exhaustion induces phosphorylation of Mig1 by the activated Snf1 complex, which abolishes the interaction between Mig1 and the repressor complex, causing a relief of glucose repression (Treitel et al. 1998; Smith et al. 1999; Papamichos-Chronakis et al. 2004). Phosphorylation of Mig1 triggers at the same time its interaction with the nuclear export factor Msn5, resulting in nuclear exclusion of Mig1 (De Vit et al. 1997; De Vit and Johnston 1999).

The transcriptional activators Cat8 and Sip4 are two additional effectors of Snf1 that control the expression of gluconeogenic genes in response to glucose exhaustion (Hedges et al. 1995; Lesage et al. 1996; Randez-Gil et al. 1997). Both the expression and activity of these factors are strictly regulated. The gene encoding Cat8 is subject to 
Mig1-dependent repression under high-glucose conditions (Hedges et al. 1995), and once synthesized upon glucose exhaustion, the protein must first be phosphorylated by Snf1 to obtain its transcriptional activity (Rahner et al. 1996; Randez-Gil et al. 1997). Cat8 induces transcription of SIP4 (Vincent and Carlson 1998), and subsequent Snf1dependent phosphorylation of Sip4 then leads to proper induction of gluconeogenic genes by both Cat8 and Sip4 (Hiesinger et al. 2001).

Apart from carbon metabolism, Snf1 affects several other processes via the regulation of transcription factors as well. In particular, the activity of Msn2/4 and Hsf1, transcriptional activators involved in general stress responses, and of Gln3, a transcriptional activator of genes induced upon nitrogen depletion, was shown to be modulated by Snf1 (Bertram et al. 2002; Mayordomo et al. 2002; Hahn and Thiele 2004). Furthermore, Snf1 does also influence transcription in a more indirect manner. As histone kinase, it phosphorylates $\operatorname{Ser}^{10}$ in histone H3, thereby stimulating chromatin remodelling in concert with the Gcn5 acetyltransferase, and recruiting co-activators and the TATAbinding protein to the promoter of genes like INOI, encoding inositol 1-phosphate synthase, and HXT4, which encodes one of the high-affinity glucose transporters (Lo et al. 2001; van Oevelen et al. 2006).

\section{Transducing the glucose signal to Snf1}

An important issue about the glucose repression pathway that remains unclear is how the glucose signal is exactly transduced to the Snf1 kinase complex or its regulators: the kinases Sak1, Elm1 and Tos3 and the phosphatase complex Glc7-Reg1. At the moment, two major hypotheses exist. In mammalian cells, the AMP-activated protein kinase (AMPK), homologue of Snf1, is activated by AMP that binds to the $\gamma$ subunit. It was, therefore, proposed that the AMP/ATP ratio or the AMP levels in yeast also act as a signal for Snf1 activation, since they reflect the rate of glucose phosphorylation and are well correlated with Snf1 activity under a variety of growth conditions (Wilson et al. 1996). Early studies reported that Snf1 could not be activated by AMP in vitro (Mitchelhill et al. 1994; Woods et al. 1994) but, more recently, it turned out that mutations in Snf4, at sites which in AMPK contribute to AMP binding and regulation, do relieve glucose inhibition of Snf1 (Momcilovic et al. 2008).

In a second model, the role of sensor and transducer of the glucose signal is attributed to hexokinase 2 (Hxk2), which acts in the first step of glycolysis phosphorylating glucose on C6. Two other hexokinases, Hxk1 and Glk1, can also catalyse this reaction, but Hxk2 is believed to be the crucial hexokinase during growth on glucose, since Hxk1 and Glk1 are themselves subject to glucose repression (De Winde et al. 1996). It was reported that in a $h x k 2 \Delta$ mutant, the glucose repression of several genes was severely reduced (Zimmermann and Scheel 1977; Entian 1980; Entian and Zimmermann 1980), the interaction between Snf1 and Snf4 was increased (Jiang and Carlson 1996; Sanz et al. 2000) and that Snf1 still phosphorylated Mig1 in the presence of glucose (Treitel et al. 1998; Ahuatzi et al. 2007). Early reports suggested that the role of Hxk2 in glucose repression was limited to its metabolic role (Ma et al. 1989; Rose et al. 1991). More recently, however, mutants were isolated with a distinct effect on catalytic activity and glucose signalling (Hohmann et al. 1999; Kraakman et al. 1999b; Mayordomo and Sanz 2001), indicative for a more specific role of Hxk2 in glucose repression. Since it was shown that overexpression of REG1 rescued defects in glucose repression due to deletion of HXK2 (Sanz et al. 2000), one hypothesis states that Hxk2 exerts its regulatory role in glucose signalling via stimulation of the Glc7-Reg1 phosphatase complex. However, no direct interaction between Reg1 and Hxk2 could be detected (Sanz et al. 2000), and other findings indicate that Hxk2 interferes further downstream with the glucose repression pathway. A small portion of Hxk2 is located within the nucleus and appears to interact with the transcriptional repressor Mig1 (Herrero et al. 1998; Randez-Gil et al. 1998; Ahuatzi et al. 2004). Therefore, the main role of Hxk2 in glucose repression is possibly inhibition of the interaction between Mig1 and Snf1, thereby blocking the phosphorylation of Mig1 which would otherwise relieve glucose repression.

\section{The cAMP-PKA pathway}

The cAMP-PKA pathway plays a major role in the control of metabolism, stress resistance and proliferation, in particular in connection with the available carbon source. In response to a sudden availability of rapidly fermentable sugars, the pathway transiently induces the synthesis of cAMP to boost the activity of the cAMP-dependent protein kinase (PKA). In turn, PKA will affect several downstream targets thereby allowing cells to make the necessary adaptations for fermentative growth. These include the upregulation of glycolysis, the stimulation of cell growth and cell cycle progression, the downregulation of stress resistance and gluconeogenesis, and the mobilization of the reserve carbohydrate glycogen and the stress protectant trehalose (Thevelein et al. 2000; Santangelo 2006; Tamaki 2007; Gancedo 2008).

PKA is a hetero-tetramer composed of two catalytic subunits, redundantly encoded by $T P K 1, T P K 2$ and $T P K 3$ and two regulatory subunits, encoded by $B C Y 1$ (Toda et al. 1987a, b). Binding of the secondary messenger cAMP to the regulatory subunit induces the dissociation of the 
hetero-tetramer and activation of the catalytic subunits (Kuret et al. 1988). PKA activity is critical for yeast since at least one of the three catalytic subunits is necessary for viability (Toda et al. 1987b). This implies as well that there is probably a large overlap in the functions of Tpk1-3, which is further consistent with the high level of protein sequence similarity between the different catalytic subunits (Toda et al. 1987b). Nevertheless, there are several examples of separate, specific functions for the different subunits, such as the induction of pseudohyphal growth, the expression control of genes involved in iron uptake or branched amino acid biosynthesis, or the regulation of mitochondrial enzymes (Robertson and Fink 1998; Pan and Heitman 1999; Robertson et al. 2000; Zhu et al. 2000; Singh et al. 2004; Chevtzoff et al. 2005; Ptacek et al. 2005). Given their central and essential role, the activity of the catalytic subunits is tightly regulated. This is best exemplified by the observation that cells lacking the regulatory subunit Bcy1 display a pleiotropic 'sick' phenotype due to hyperactivation of the Tpk subunits, which includes the inability to grow on carbon sources other than glucose, an abnormally high heat shock sensitivity, the lack of a proper $\mathrm{G}_{1}$-arrest during nutrient starvation and defects in DNA replication and sporulation (Matsumoto et al. 1983; Toda et al. 1987a).

\section{Regulation of the cAMP-PKA pathway}

The cAMP-PKA pathway is under positive control of an intracellular glucose sensing system as well as an extracellular glucose detection system (Fig. 3). The intracellular glucose-sensing system requires the uptake and phosphorylation of glucose, but no further metabolism of the sugar (Beullens et al. 1988; Rolland et al. 2000). In S. cerevisiae, there are three glucose phosphorylating enzymes (Hxk1, Hxk2 and Glk1) and any of these proteins can fulfil this phosphorylation requirement to activate the cAMP-PKA pathway. It is generally believed that the intracellular glucose phosphorylation signal is further transduced to the cAMP-PKA pathway via the Ras proteins, Ras1 and Ras2, which belong to the group of small G proteins. The GTPbound, active Ras proteins stimulate the activity of the adenylate cyclase Cyr1 (also known as Cdc35), the enzyme which catalyses the synthesis of cAMP from ATP (Casperson et al. 1983, 1985; Matsumoto et al. 1983, 1984; Kataoka et al. 1985; Toda et al. 1985; Field et al. 1988). The GDP/GTP exchange on the Ras proteins is controlled by the guanine nucleotide exchange factors (GEF) Cdc25 and Sdc25 (Broek et al. 1987; Camonis and Jacquet 1988; Jones et al. 1991; Camus et al. 1994). The Ira proteins, Ira1 and Ira2, accelerate Ras GTPase activity by acting as GTPase activating proteins (GAP) and, as a result, they keep Ras in the GDP-bound, inactive state (Tanaka et al.

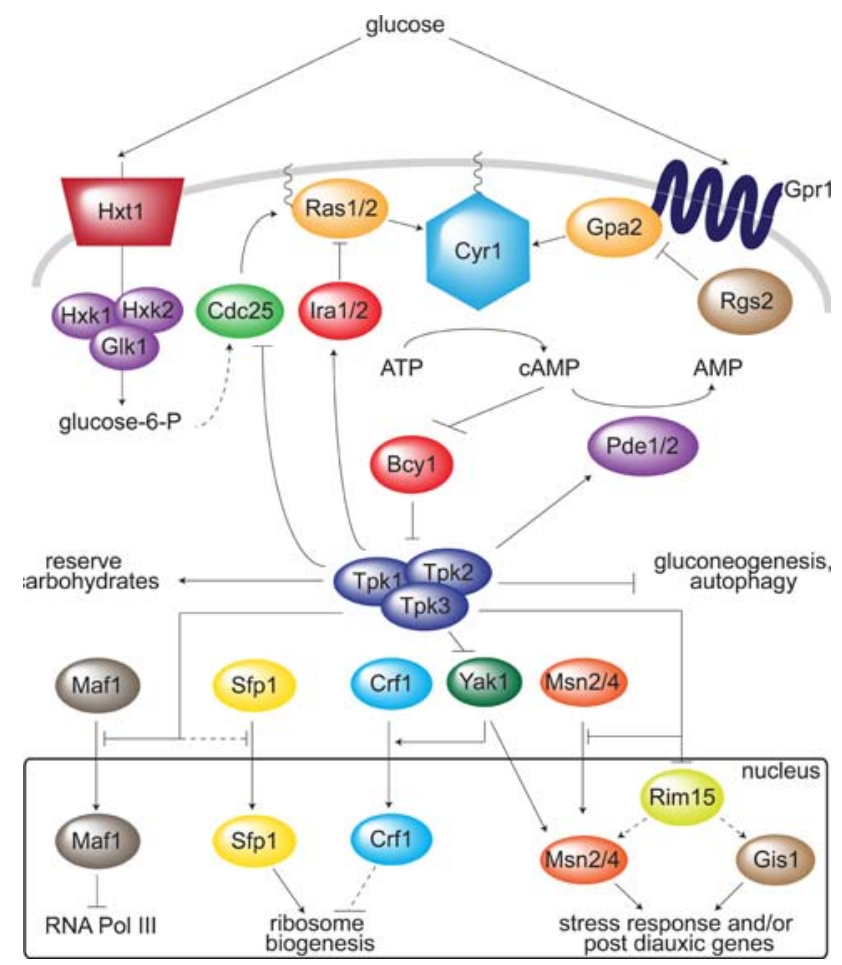

Fig. 3 The cAMP-PKA pathway in $S$. cerevisiae. Addition of glucose to glucose-starved, respiring cells triggers the rapid synthesis of cAMP and, subsequently, the activation of PKA. Glucose-induced cAMP synthesis requires two sensing systems: (i) extracellular detection of glucose via the Gpr1-Gpa2 system and (ii) intracellular detection of glucose, which requires uptake and phosphorylation of the sugar. The intracellular sensing system most probably transduces signals via the GEF protein $\mathrm{Cdc} 25$ and the Ras proteins. Activated PKA mediates the fast transition from respiratory to fermentative growth via the modulation of numerous downstream targets. Arrows and bars represent positive and negative interactions, respectively. Dashed lines represent putative or indirect interactions. See text for further details

1989, 1990a, b, 1991). Both Ras proteins are essential to obtain a normal glucose-induced cAMP signal. Glucose addition to glucose-starved cells triggers a transient increase in the GTP loading of Ras2. This process was shown to require glucose phosphorylation (Mbonyi et al. 1988; Colombo et al. 2004). The mechanism by which glucose phosphorylation affects Ras-GTP loading remains largely to be elucidated. It is known that $\mathrm{Cdc} 25$ is required for the glucose-induced Ras-GTP increase and it was suggested that the intracellular levels of GTP, which quickly respond to nutrient availability, could be the metabolic signal that regulates $\mathrm{Cdc} 25$ activity in response to glucose (Rudoni et al. 2001; Colombo et al. 2004; Cazzaniga et al. 2008). On the other hand, it seems plausible that the Ira proteins are inhibited by the glucose signal, since an iral $\Delta$ ira $2 \Delta$ double deletion mutant displays a severe increase in Ras-GTP levels and no further increase upon glucose addition (Colombo et al. 2004). 
Notably, the Ira proteins are activated by the kelch proteins (see below) (Harashima et al. 2006) and appear to be inhibited by Tfs1, a carboxypeptidase Y inhibitor, originally discovered as a dosage-dependent suppressor of a cdc25 mutation (Robinson and Tatchell 1991; Bruun et al. 1998; Caesar and Blomberg 2004; Chautard et al. 2004). Thus, these proteins are potential transducers of the glucose signal to the Ira proteins.

Extracellular glucose detection occurs through a $G$ protein-coupled receptor (GPCR) system, composed of Gpr1 and Gpa2 (Kraakman et al. 1999a). Gpr1 belongs to the $G$ protein-coupled seven-transmembrane receptor (GPCR) superfamily (Yun et al. 1997; Xue et al. 1998) and $\mathrm{Gpa} 2$ is a member of the heterotrimeric $\mathrm{G}$ protein $\alpha$ subunit $\left(\mathrm{G}_{\alpha}\right)$ protein family (Nakafuku et al. 1988). Addition of glucose to derepressed cells activates Gpr1, which in turn stimulates the exchange of GDP for GTP on Gpa2 (Kraakman et al. 1999a). The Gpr1-Gpa2 couple displays a rather low affinity for glucose, with a halfmaximum response $\left(\mathrm{EC}_{50}\right)$ of $20-75 \mathrm{mM}$, depending on the genetic background tested and the experimental setup (Rolland et al. 2000; Lemaire et al. 2004). This probably ensures that the cAMP-PKA pathway is only fully activated when glucose levels are high enough to switch easily from respiration to fermentation. GTP-bound Gpa2 activates the cAMP-PKA pathway and this is most probably through stimulation of adenylate cyclase (Nakafuku et al. 1988; Kubler et al. 1997; Lorenz and Heitman 1997; Colombo et al. 1998; Rolland et al. 2000; Peeters et al. 2006). Gpa2 interacts with Rgs2, a member of the family of regulators of $G$ protein signalling (RGS), that negatively regulates the Gpa2-GTP signal by stimulating the intrinsic GTPase activity of Gpa2 (Versele et al. 1999). It is unclear whether the $G_{\alpha}$ protein $G p a 2$ also associates with canonical $\mathrm{G}_{\beta}$ and $\mathrm{G}_{\gamma}$ subunits. A recent report suggests that Asc1 functions as the $\mathrm{G}_{\beta}$ subunit for Gpa2 (Zeller et al. 2007). Asc1 has the typical 7-WD domain structure of a canonical $\mathrm{G}_{\beta}$ protein, interacts directly with $\mathrm{Gpa} 2$ in a guanine nucleotide-dependent manner and inhibits Gpa2 guanine nucleotide exchange activity. In addition, Asc1 binds to adenylate cyclase and diminishes the glucose-induced production of cAMP. Another hypothesis states that the kelch-repeat proteins $\mathrm{Krh} 1 / \mathrm{Gpb} 2$ and $\mathrm{Krh} 2 / \mathrm{Gpb} 1$ serve as $\mathrm{G}_{\beta}$ subunit and $\mathrm{Gpg} 1$ as $\mathrm{G}_{\gamma}$ for $\mathrm{Gpa} 2$ (Harashima and Heitman 2002; Batlle et al. 2003). The kelch-repeat proteins interact with Gpa2 and contain seven kelch repeats that mimic the $\beta$ propeller that is formed by seven WD-40 repeats in canonical $\mathrm{G}_{\beta}$ subunits. Phenotypic analysis of gpb1 $\Delta$ gpb2 $\Delta$ double deletion mutants showed that the kelch-repeat proteins act as negative regulators of PKA signalling (Harashima and Heitman 2002; Batlle et al. 2003; Lu and Hirsch 2005). Several mechanisms have been proposed to explain their effect. One report suggests that the kelch-repeat proteins inhibit Gpr1-Gpa2 coupling (Harashima and Heitman 2005). Alternatively, the kelch-repeat proteins were reported to stimulate the interaction between the catalytic and the regulatory subunits of PKA (Peeters et al. 2006). Activated, GTP-bound Gpa2 would relieve this inhibition of PKA by inhibiting the kelch-proteins, thereby bypassing adenylate cyclase to regulate PKA. Finally, it has also been found that the kelch-repeat proteins bind to a conserved C-terminal domain of the Ira proteins and stabilize them (Harashima et al. 2006). As this would decrease Ras-GTP levels, it means that the Gpr1-Gpa2 couple could possibly modulate the activity of adenylate cyclase and PKA via the Ras proteins. It should be stressed that intracellular sensing of glucose is a prerequisite for the extracellular glucose detection system to further activate cAMP synthesis (Rolland et al. 2000), but how the signals of both sensing systems are exactly integrated to control adenylate cyclase activity remains to be resolved.

A strong negative feedback mechanism ensures that the glucose-induced increase in cAMP levels and PKA activity are transient and can only be triggered in glucose-derepressed cells. PKA itself is involved in this mechanism since basal cAMP levels are dramatically increased in strains with reduced activity of the kinase (Nikawa et al. 1987a; Mbonyi et al. 1990). cAMP is hydrolyzed by the low- and high-affinity phosphodiesterases, respectively, encoded by PDE1 and PDE2 (Sass et al. 1986; Nikawa et al. 1987b; Wilson and Tatchell 1988). The high-affinity phosphodiesterase Pde2 appears to control basal cAMP levels, which is important to prevent undesirable PKA activity during stationary phase (Park et al. 2005). The lowaffinity phosphodiesterase Pde1, however, was shown to be specifically involved in the feedback inhibition of glucoseinduced cAMP signalling and is probably activated by PKA itself (Casamayor et al. 1999). The Ras proteins are also involved in the negative feedback control of the activated cAMP-PKA pathway. The glucose-induced increase of Ras-GTP loading is only transient and in a PKA-attenuated strain a severe increase in basal Ras-GTP levels was observed (Colombo et al. 2004). Whether the Ras proteins or rather one of their regulators are the targets of the feedback-inhibition mechanism is not clear. Another target for feedback regulation could be adenylate cyclase itself (Nikawa et al. 1987a). Furthermore, feedback regulation may involve other carbon source-dependent pathways as well, for instance the main glucose repression pathway, since no glucose-induced cAMP increase was observed in a snfl $\Delta$ mutant (Arguelles et al. 1990). Finally, it is important to note that PKA activity is further finetuned by modulation of its subcellular localization, phosphorylation state and abundance (Werner-Washburne et al. 1991; Griffioen et al. 2000, 2001; Schmelzle et al. 2004; 
Portela and Moreno 2006). However, compared to cAMPmediated control, this regulation of PKA appears to be less important for short-term signalling events.

\section{Targets of cAMP-activated PKA}

cAMP-activated PKA has a major impact on gene expression, which is well-illustrated by the observation that $90 \%$ of the transcriptional changes upon glucose addition to glucose-starved cells could be mimicked by artificial activation of PKA (Wang et al. 2004). Accordingly, several of the known PKA targets affect gene transcript levels, either directly or indirectly (Fig. 3). Two of those are the transcription factors Msn2 and Msn4, which mediate the transcription of the so-called stress response element (STRE)-controlled genes (Estruch and Carlson 1993; Martinez-Pastor et al. 1996; Schmitt and McEntee 1996). STRE genes are involved in a wide variety of processes, including protection against diverse types of stress such as heat, oxidative and osmotic stress, carbohydrate metabolism and growth regulation (Mai and Breeden 1997; Moskvina et al. 1998; Smith et al. 1998; Gasch et al. 2000). Msn2 and Msn4 are inhibited by PKA and, notably, deletion of both MSN2 and MSN4 rescues the lethality of a tpk null strain (Boy-Marcotte et al. 1998; Smith et al. 1998). During growth on glucose, Msn2 and Msn4 are phosphorylated and reside in the cytosol. Upon glucose exhaustion, they are hyperphosphorylated and translocated to the nucleus, where they induce expression of the STREcontrolled genes. PKA inhibits nuclear import of Msn2/4, probably through direct phosphorylation of their nuclear localization signal (Gorner et al. 1998, 2002; Garreau et al. 2000). A second mechanism for PKA-mediated regulation of STRE-controlled gene expression involves the Ccr4-Not complex, a global transcriptional regulator that affects genes positively and negatively. It was proposed that this complex contributes to the downregulation of Msn2/4driven transcription and this through direct interaction with Tpk2 and by modulation of the phosphorylation status of Msn2 via the Bud14-Glc7 protein phosphatase (Lenssen et al. 2002, 2005). Moreover, PKA seems to additionally inhibit the function of Msn2 and Msn4 via the protein kinases Yak1 and Rim15. Both kinases are under negative control of PKA, supposedly by direct phosphorylation, and deletion of $Y A K 1$ or RIM15, like deletion of both MSN2 and MSN4, can suppress the lethality caused by loss of PKA activity (Garrett and Broach 1989; Garrett et al. 1991; Reinders et al. 1998; Griffioen et al. 2001; Moriya et al. 2001; Zappacosta et al. 2002). A recent report suggests that Yak1 phosphorylates and thereby activates Msn2 through a still unknown mechanism, which apparently does not implicate the control of Msn2 subcellular localization (Lee et al. 2008a). Since the $Y A K 1$ gene itself is induced by
Msn2/4, this would generate a positive feedback loop (Smith et al. 1998). In the same study, Yak1 was also found to stimulate the activity of Hsf1, another transcriptional activator of stress response genes that was recently shown to be under negative control of PKA (Hahn et al. 2004; Ferguson et al. 2005; Lee et al. 2008a). Rim15 was initially identified as an activator of meiotic gene expression (Vidan and Mitchell 1997). Later, this protein kinase was shown to be essential for the accumulation of both the reserve carbohydrate glycogen and the stress protectant trehalose, the induction of several stress response genes, the induction of thermotolerance and proper $\mathrm{G}_{1}$-arrest upon nutrient starvation (Reinders et al. 1998; Cameroni et al. 2004; Zhang et al. 2009). Genome-wide expression analyses confirmed that the Rim15-controlled expression program following glucose limitation at the diauxic shift is almost entirely mediated by the three transcription factors Msn2, Msn4 and Gis1 (Cameroni et al. 2004; Roosen et al. 2005). The latter is a transcription factor that induces expression of stress response genes containing so-called post diauxic shift (PDS) elements in their promoter regions, some of which are required during respiratory growth (Pedruzzi et al. 2000; Cameroni et al. 2004; Roosen et al. 2005; Zhang et al. 2009). Together, the above-described data indicate that PKA exerts a dual control on gene expression, first by regulation of its downstream protein kinases Rim15 and Yak1, and second by direct regulation of their presumed effectors, i.e. the transcription factors Msn2, Msn4, and likely also Gis1.

PKA activates the transcription of ribosomal protein genes as well (Herruer et al. 1987; Kraakman et al. 1993; Griffioen et al. 1994). It was reported that PKA promotes nuclear localization and binding of the transcriptional activator Sfp1 to the promoters of ribosomal protein genes (Marion et al. 2004). In addition, PKA appears to induce transcription of ribosomal protein genes also by inhibition of Yak1, which in turn is required to promote the activity of the transcriptional corepressor Crf1 (Martin et al. 2004). As will be discussed in more detail below, PKA further stimulates protein synthesis indirectly by inhibiting nuclear import of Maf1, which represses 5S rRNA and tRNAs transcription by RNA Polymerase III (Moir et al. 2006; Willis and Moir 2007).

In addition to the control of gene expression and protein synthesis, PKA directly modulates the activity of metabolic enzymes. PKA-dependent phosphorylation inhibits the activity of fructose-1,6-bisphosphatase (Fbp1) and stimulates the activity of 6-phosphofructo-2-kinase (Pfk2) and of both isoforms of pyruvate kinase (Pyk1 and Pyk2) (Gancedo et al. 1983; Rittenhouse et al. 1987; Cytrynska et al. 2001; Vaseghi et al. 2001; Portela et al. 2002; Dihazi et al. 2003). Together, these modifications result in the stimulation of glycolysis and the inhibition of 


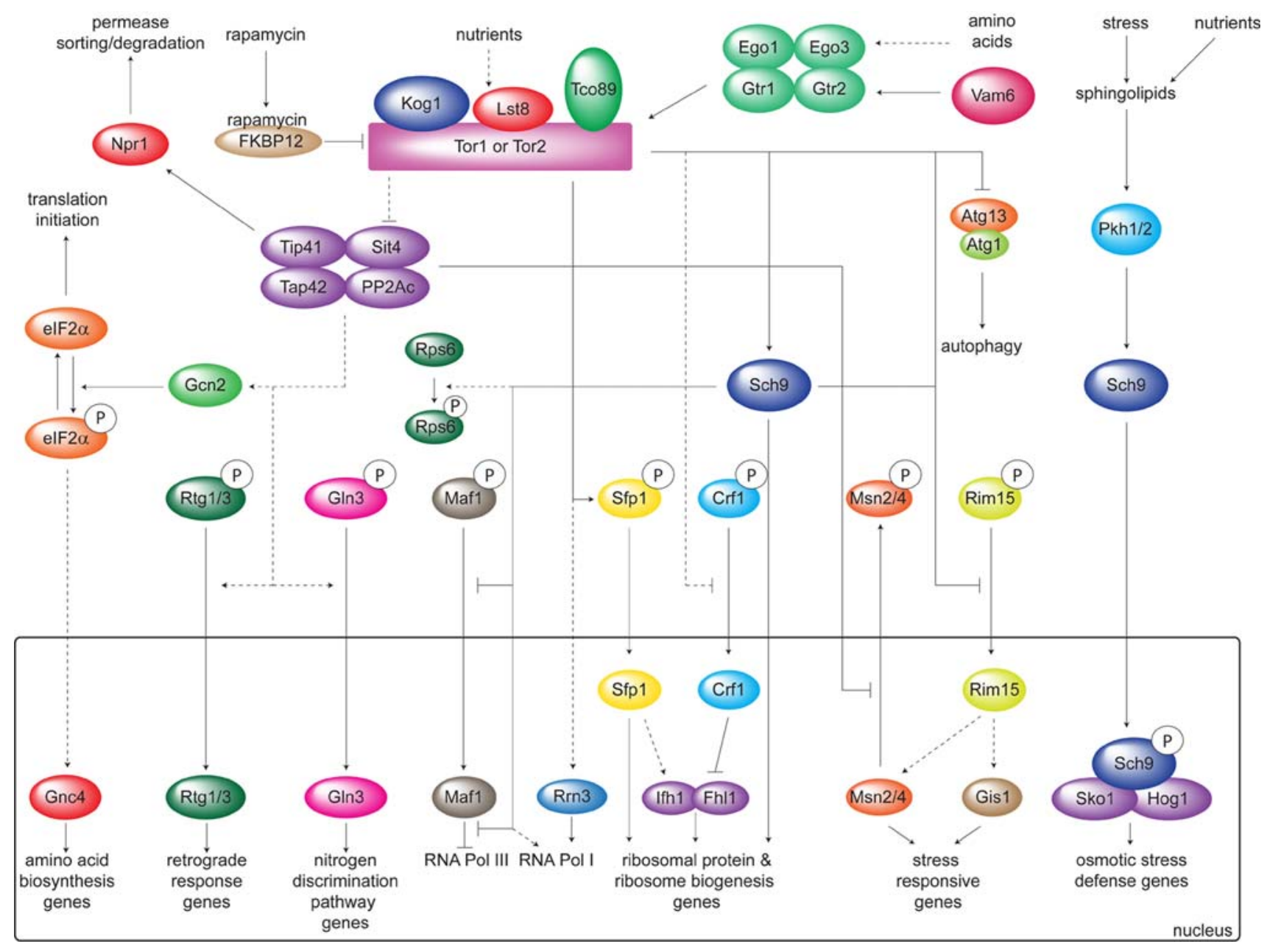

Fig. 4 The TORC1 pathway in $S$. cerevisiae. Nutrients activate TORC1, resulting in the stimulation of protein synthesis and the inhibition of stress response genes, autophagy and several pathways that allow growth on poor nitrogen sources. A major part of these processes is regulated by the rapamycin-sensitive TORC 1 complex either via the Tap42-Sit4/PPA2c or the recently identified Sch9 branches. The activity of Sch9 is additionally regulated by Pkh1 and Pkh2. Note that Sch9 functions both in the cytoplasm and the nucleus. See text for further details. Arrows and bars represent positive and negative interactions, respectively. Dashed lines represent putative or indirect interactions

confirmed that PKA phosphorylation negatively controls the recruitment of Atg1 to the sites of autophagosome formation upon nutrient limitation (Budovskaya et al. 2005).

\section{The TOR pathway}

The Target $O$ f Rapamycin (TOR), a highly conserved Ser/ Thr protein kinase, is the central component of a major regulatory signalling network that controls cell growth in diverse eukaryotic organisms, ranging from yeast to man. The TOR proteins were first identified in yeast as the targets of the antifungal and immunosuppressive agent rapamycin, hence their name (Heitman et al. 1991). In contrast to most eukaryotes, yeast contains two TOR homologues, Tor1 and Tor2. Two functionally and structurally distinct 
TOR multiprotein complexes exist: TOR complex 1 (TORC1) and TOR complex 2 (TORC2) (Zheng et al. 1995; Loewith et al. 2002); however, only TORC1 is specifically inhibited by rapamycin (Fig. 4). The addition of rapamycin induces dramatic phenotypic changes such as cell cycle arrest and entry into $G_{0}$, general downregulation of protein synthesis, accumulation of the reserve carbohydrate glycogen and the stress protectant trehalose, upregulation of stress response genes, autophagy and alterations in nitrogen and carbon metabolism (De Virgilio and Loewith 2006a, b; Rohde et al. 2008). Hence, it appears that TORC1 signalling controls the temporal aspects of cell growth in response to the quality of the available nitrogen and carbon sources. On the other hand, TORC2, which is insensitive to rapamycin and is less wellcharacterized in comparison to TORC1, is thought to regulate the spatial aspects of growth, such as the control of actin polarization (De Virgilio and Loewith 2006a, b; Rohde et al. 2008). Here, we will focus on TORC1, as only this complex modulates nutrient-induced signalling in response to mainly nitrogen sources and to some extent glucose.

\section{Structural aspects and localization of the TOR protein complexes}

TOR1 and TOR2 encode two large $(\sim 280 \mathrm{kDa})$ and homologous $(67 \%$ identical) proteins that belong to a family of phosphatidylinositol kinase-related kinases (PIKKs) (Cafferkey et al. 1993; Kunz et al. 1993; Helliwell et al. 1994; Keith and Schreiber 1995). Despite their resemblance to lipid kinases, they are thought to function solely as Ser/Thr protein kinases. Both Tor1 as well as Tor2 can be found in the multiprotein TORC1 together with Lst8, Kog1 and Tco89. A separate pool of Tor2 also associates with Lst8, Avo1, Avo2, Avo3, Bit61 and Bit2 to form TORC2 (Loewith et al. 2002; Chen and Kaiser 2003; Wedaman et al. 2003; Reinke et al. 2004; Araki et al. 2005; Fadri et al. 2005). The precise function of these TORinteracting proteins is not known yet. They might play a role in the binding of the TOR complexes to their substrates, be the receivers of upstream signals and/or determine the localization of the complexes. The TOR complexes are likely dimeric built on a TOR-TOR dimer (Wullschleger et al. 2005). Only TORC1 can bind FKBP12-rapamycin while in TORC2, the Tor2 FKBP12rapamycin binding domain is probably not exposed for binding (Loewith et al. 2002), explaining why only TORC1 signalling is sensitive to rapamycin treatment. Interestingly, the constitution of TORC1 appears to be unaffected by rapamycin, implying that rapamycin does not inhibit TORC1 signalling by interfering with TORC1 stability (Loewith et al. 2002). Both TOR complexes are essential for viability, since deletion of TOR2 (inactivation of TORC2) or deletion of both TOR1 and TOR2, or rapamycin treatment (inactivation of TORC1) are lethal to yeast (Heitman et al. 1991; Kunz et al. 1993). Deletion of TOR1 alone, however, is not lethal, indicating that Tor1 and Tor2 have a redundant role in TORC1 signalling.

Several studies investigated the localization of TORC1 and TORC2. Various different localization patterns were observed, which is possibly a reflection of the fact that TOR signalling controls a multitude of processes. In general, the TOR complexes were found to associate with membranes ranging from the plasma membrane to the vacuolar membrane and internal membranes of the protein secretory pathway (Cardenas and Heitman 1995; Kunz et al. 2000; Wedaman et al. 2003; Aronova et al. 2007; Sturgill et al. 2008; Berchtold and Walther 2009). TORC2 appears to be predominantly localized in discrete dots at the plasma membrane (Cardenas and Heitman 1995; Kunz et al. 2000; Sturgill et al. 2008), while TORC1 is mainly found at the vacuolar membrane, which is intriguing knowing that the vacuole is a reservoir of nutrients and that TORC1 signalling is believed to be regulated by nutrients (Cardenas and Heitman 1995; Aronova et al. 2007; Sturgill et al. 2008). According to a recent study, TORC1 is also targeted to the nucleus where it induces 35S rRNA synthesis under favourable growth conditions (Li et al. 2006).

\section{Rapamycin-sensitive signalling via TORC1}

Rapamycin has proven to be a good drug for yeast researchers to study TORC1 signalling. Thanks to the fact that it rapidly and specifically inhibits TORC1, numerous proteins involved in a wide range of processes could be identified whose activity is modified by TORC1 activity. Especially, the transcriptional regulation exerted by TORC1 is well-described and many transcription factors were found to be under control of TORC1 signalling (Fig. 4).

The precise mechanism how TORC1 regulates its downstream effectors are often not well-understood. As will be discussed in the section below, several TORC1mediated processes involve the protein kinase Sch9 (Urban et al. 2007). Others appear to be regulated via the PP2A and the PP2A-related protein phosphatases. These phosphatases consist of heteromeric protein complexes (Duvel and Broach 2004). The PP2A holoenzyme contains one of the two redundant catalytic subunits (PP2Ac), Pph21, Pph22 (Sneddon et al. 1990; Ronne et al. 1991), a scaffolding subunit, Tpd3 (van Zyl et al. 1992), and one of the two regulatory subunits, Cdc55 or Rts1 (Healy et al. 1991; Zhao et al. 1997). The PP2A-related phosphatase is mainly found as a complex between the catalytic subunit, Sit4 (Arndt et al. 1989), and one of the four regulatory subunits, 
Sap4, Sap155, Sap185 and Sap190 (Luke et al. 1996). TORC1 controls the activity of these phosphatases via Tap42. When Tap42 is phosphorylated by TORC1, it will compete for binding the catalytic subunits of the phosphatases leading to the exclusion of other subunits of the phosphatase holoenzymes (Di Como and Arndt 1996; Jiang and Broach 1999). Thereby, TORC1 stimulates the formation of a Tap42-associated phosphatase complex that further includes either one of the regulatory proteins $\operatorname{Rrd} 1$ or Rrd2, both of which are known to confer phosphotyrosyl phosphatase activity to the catalytic phosphatase subunits in vitro (Zabrocki et al. 2002; Zheng and Jiang 2005). Tap42 as well as Rrd1 and Rrd2 may redirect the substrate specificity of the catalytic phosphatase subunits, and as such, it is not surprising that the proteins have been attributed both inhibitory as well as activatory roles, dependent on the substrate being studied (Van Hoof et al. 2001; Cherkasova and Hinnebusch 2003; Duvel et al. 2003; Duvel and Broach 2004). In actively growing cells, the Tap42-associated phosphatase complexes reside mainly at membranes where they associate with TORC1. Rapamycin treatment or nitrogen starvation abrogates the TORC1 association and releases the Tap42-associated phosphatase complex into the cytosol (Yan et al. 2006). Once cytoplasmic, this complex then slowly dissociates, presumably concomitant with the dephosphorylation of Tap42 (Zheng and Jiang 2005; Yan et al. 2006). Several studies revealed an important role for yet another player in TORC1dependent regulation of PP2Ac and Sit4, i.e. Tip41. This protein was initially identified as an inhibitor that could specifically interact with dephosphorylated Tap42 (Jacinto et al. 2001). However, more recent data suggest that both Tip41 and Tap42 cooperate in determining the substrate specificity of PP2Ac and Sit4, and that both proteins may fulfil essentially a similar function in TORC1 signalling (Duvel and Broach 2004; Santhanam et al. 2004; Kuepfer et al. 2007).

One of the first described examples where TORC1 signalling involves the regulation of PP2A and the PP2A-like phosphatase Sit4 is the control of nitrogen metabolism. Yeast cells adapt their metabolism to the available nitrogen sources via the nitrogen catabolite repression pathway (NCR) also known as the nitrogen discrimination pathway (NDP) (Magasanik and Kaiser 2002). This pathway ensures that genes encoding proteins required for the usage of poor nitrogen sources are repressed when rich nitrogen sources, such as glutamine, are present in sufficient quantities. Four GATA family zinc-finger transcription factors are involved in the transcriptional control exerted by the NDP: two activators, Gln3 and Gat1, and two repressors, Dal80 and Gzf3 (Minehart and Magasanik 1991; Coffman et al. 1995, 1996, 1997; Cooper 2002). TORC1 inhibits transcription of NDP genes by controlling Gln3 and Gat1 function (Beck et al. 1999; Cardenas et al. 1999; Hardwick et al. 1999; Shamji et al. 2000). Normally, during growth on rich nitrogen sources, Gln3 is phosphorylated and sequestered in the cytoplasm through its binding with the cytoplasmic anchor protein Ure2. Rapamycin treatment, however, rapidly triggers, in a Sit4-dependent manner, the dephosphorylation of Gln3, dissociation from Ure2 and entry into the nucleus, where Gln3 can exert its transcriptional activator function on NDP genes (Beck et al. 1999). Thus, it appears that TORC1 through inhibition of the Tap42-Sit4 phosphatase complex promotes Gln3 phosphorylation, which inhibits Gln3 activity by stimulating its association with Ure2. Nevertheless, recent results indicate that PP2A phosphatase activity is also necessary for Gln3 nuclear import upon rapamycin treatment, although the mechanistic details remain elusive (Tate et al. 2009). Additionally, TORC1 promotes via an unknown mechanism the phosphorylation of Ure2 and this might further modulate the interaction between Gln3-Ure2 (Cardenas et al. 1999; Hardwick et al. 1999). Rapamycin treatment also triggers nuclear import of Gat1 (Beck et al. 1999). How TORC1 regulates this process is unclear, yet it appears to be different from TORC1-dependent Gln3 control and does not involve Ure2 or Sit4 (Kuruvilla et al. 2001; Crespo et al. 2002; Georis et al. 2008).

TORC1 further negatively controls the general amino acid control (GAAC) pathway (Hinnebusch 2005). The central component of this pathway is Gcn4, a transcription factor important for activating transcription of genes needed for amino acid biosynthesis in response to amino acid starvation (Natarajan et al. 2001). The pathway is induced by uncharged tRNAs, which presumably activate the kinase Gcn2. In turn, Gcn2 phosphorylates the $\alpha$ subunit of eIF2 and although this results in a reduction of the general translation initiation, it specifically stimulates the translation of GCN4 mRNA (Dever et al. 1992). TORC1 inhibits Gen2 activity by promoting its phosphorylation at $\mathrm{Ser}^{577}$. This occurs indirectly and involves the inhibition of the PP2A-like phosphatase Sit4 via Tap42. As such, TORC1 enhances translation initiation and antagonizes GCN4 mRNA translation (Valenzuela et al. 2001; Cherkasova and Hinnebusch 2003; Kubota et al. 2003; Rohde et al. 2004). Note that GCN4 is also a target of the NDP (Godard et al. 2007), suggesting that TORC1, via inhibition of NDP gene expression, also inhibits GCN4 transcription.

A third pathway that is involved in nitrogen metabolism and that is subject to TORC1 control is the retrograde response pathway (RTG). Apart from having other functions, this pathway induces the expression of genes whose products are required for the biosynthesis of $\alpha$-ketoglutarate as precursor for glutamate synthesis in cells grown on poor nitrogen sources as well as in respiration-deficient cells (Liu and Butow 2006). Expression of these genes 
requires the transcriptional activators $R \operatorname{tg} 1$ and $R \operatorname{tg} 3$. TORC1 controls the cytoplasmic sequestration of these factors through phosphorylation of Mks1, which thereby forms a complex with the 14-3-3 proteins Bmh1/2 to provide the cytoplasmic anchor for Rtg1 and Rtg3. Rapamycin treatment induces dephosphorylation of Mks1 and causes disassembly of the complex. This directs Mks1 to bind to the positive regulator of the pathway, i.e. Rtg2, thereby relieving the cytoplasmic sequestration and promoting nuclear translocation of Rtg1 and Rtg3 and the induction of the target genes of RTG pathway (Komeili et al. 2000; Dilova et al. 2002, 2004; Tate et al. 2002; Liu et al. 2003). Genome-wide expression analysis revealed that Tap42 is probably also involved in this regulation mechanism (Duvel et al. 2003).

Finally, TORC1 also appears to control the turnover of several amino acid permeases. Depending on the quality and quantity of the nitrogen sources in the medium, yeast cells activate a different set of amino acid permeases. Under nutrient rich conditions, the so-called constitutive permeases, such as the high-affinity tryptophan permease Tat2, are targeted to the plasma membrane, whereas the nitrogen-responsive permeases, such as the general amino acid permease Gap1, are sorted to the vacuole for degradation (Roberg et al. 1997; Beck et al. 1999). During periods of nitrogen limitation, opposite sorting occurs and Gap1 is allowed to reach the plasma membrane, while Tat2 is endocytosed and delivered to the vacuole (Roberg et al. 1997; Beck et al. 1999). The protein kinase Npr1 plays a major role in the sorting of these two classes of permeases. Npr1 is required for stabilization of Gap1 at the plasma membrane and induces the degradation of Tat2, possibly by regulating their ubiquitination (Schmidt et al. 1998; Springael and Andre 1998; De Craene et al. 2001; Helliwell et al. 2001; Soetens et al. 2001; Springael et al. 2002). TORC1 activity, through control of the Tap42-Sit4 phosphatase complex, promotes the phosphorylation of Npr1 (Schmidt et al. 1998; Jacinto et al. 2001; Gander et al. 2008). Presumably, this phosphorylation inhibits Npr1 which would promote Tat2 stabilization and Gap1 degradation. Accordingly, it was found that rapamycin induces Tat2 targeting to the vacuole and that this process depends on Npr1 (Schmidt et al. 1998; Beck et al. 1999). For Gap1, it was initially reported that rapamycin-induced inhibition of TORC1 did not affect its sorting (Chen and Kaiser 2002). More recently, however, it was shown that mutants affected in Lst8 display vacuolar targeting of Gap1 under conditions where the permease should normally be sorted to the plasma membrane. Lst8 is a component of TORC1 and TORC2 and, consistently, the impairment of TOR signalling by treatment with low, sublethal doses of rapamycin triggers a similar missorting of Gap1. As both mutation of Lst8 and rapamycin-induced impairment of
TOR signalling causes a significant increase in intracellular amino acid pools, it was suggested that this increase could act as signal that directs the vacuolar sorting of Gap1 (Chen and Kaiser 2003).

Apart from its controlling function on nitrogen metabolism, TORC1 has a major regulatory role in protein synthesis as it promotes expression of the rRNA and the ribosomal proteins (RP) genes as well as of the so-called ribosome biogenesis (Ribi) regulon (Jorgensen et al. 2004). This regulon contains $\sim 236$ genes encoding for proteins that are also needed for an efficient functioning of the translation apparatus, including translation factors, rRNA and RP modifying and processing enzymes, tRNA synthetases and subunits of RNA polymerases I and III. 35S rRNA, the precursor of $5.8 \mathrm{~S}, 18 \mathrm{~S}$ and $25 \mathrm{~S}$ rRNA, is transcribed by RNA polymerase I (Planta 1997). TORC1 positively affects the interaction between Rrn3 and RNA polymerase I, which is necessary for proper recruitment of the polymerase to the 35S rDNA promoter (Claypool et al. 2004). However, recent data suggest that TORC1 promotes recruitment of the RNA polymerase I to the $r D N A$ locus in a Rrn3-independent way, via a signalling route that requires the TORC1-effector protein kinase Sch9 (see below) (Huber et al. 2009). Tor 1 itself binds to the $35 \mathrm{~S}$ and 5S rDNA chromatin under favourable nutrient conditions and this seems to be essential for the synthesis of $35 \mathrm{~S}$ and 5S rRNA via, respectively, RNA polymerase I and III ( $\mathrm{Li}$ et al. 2006). In addition, the Tor 1 association with $5 \mathrm{~S}$ rDNA chromatin is also required for TORC1 to stimulate the expression of tRNAs by RNA polymerase III (Wei et al. 2009). This regulation of RNA polymerase III expression involves, at least in part, the inhibition of Maf1, a repressor of RNA polymerase III transcription that is also inhibited by PKA (Moir et al. 2006; Oficjalska-Pham et al. 2006; Roberts et al. 2006; Wei et al. 2009). Apparently, 5S rDNA-associated TORC1 phosphorylates Maf1, thereby inhibiting the nucleoplasm-to-nucleolus translocation of Maf1 and the concomitant binding of Maf1 with RNA polymerase III-transcribed genes (Wei et al. 2009). Interestingly, most recent data suggest that TORC1 mediates phosphorylation of Maf1 indirectly via Sch9 (Huber et al. 2009).

Concerning the regulation of RP gene transcription by RNA polymerase II, it was found that TORC1 promotes complex formation between Fhl1, a forkhead-like transcription factor that binds to the promoter of RP genes, and its co-activator Ifh1 (Lee et al. 2002; Martin et al. 2004; Schawalder et al. 2004; Wade et al. 2004; Rudra et al. 2005). This Fhl1-Ifh1 complex then promotes the expression of RP genes. Depending on the genetic background, Fhl1 can also act alone or in complex with the corepressor Crf1, but then it mediates repression of the RP genes (Martin et al. 2004; Zhao et al. 2006). How TORC1 exactly 
interferes with Fhl1 complex formation and activity is unclear. It was suggested that Yak1 phosphorylates Crf1 to promote its nuclear entry and that TORC1, possibly via PKA, inhibits Yak1 (Martin et al. 2004). When TORC1 is active, Crf1 would then remain in the cytoplasm and the Fhl1-Ifh1 complex could promote RP expression, whereas under less favourable conditions, Yak1-activated Crf1 enters the nucleus and displaces Ifh1 from Fhl1 to repress RP expression. Note, however, that it is generally believed that TORC1 and PKA operate in parallel and therefore the hypothesis that TORC1 activates the PKA pathway needs further testing. Furthermore, the role of Crf1 as corepressor of RP gene expression appears to depend on the genetic background of the strains under study (Zhao et al. 2006) and other mechanisms of TORC1-dependent control of the Fhl1 complex have been suggested. One such mechanism seems to involve the stress- and nutrient-sensitive transcription factor Sfp1. TORC1 regulates, probably via direct phosphorylation, the nucleocytoplasmic distribution and the promoter binding of Sfp1. In exponentially growing cells, Sfp1 is localized in the nucleus where it promotes both RP as well as Ribi gene expression, but upon TORC1 inactivation Sfp1 translocates to the cytoplasm (Jorgensen et al. 2004; Marion et al. 2004; Lempiainen et al. 2009). Sfp1, in turn, appears to affect the localization of the Fhl1Ifh1 complex. In the absence of nutrients or Sfp1, both Fhl1 and Ifh1 remain nuclear but relocalize to the nucleolar regions, which occurs concomitant with reduced RP gene transcription (Jorgensen et al. 2004). In the nucleolus, Fhl1 and Ifh1 were proposed to have additional functions, such as repressing rRNA transcription, which would provide an interesting link between rRNA and RP synthesis. Different studies indicated that Sch9 should be involved in the regulation of RP and Ribi gene expression and it was proposed that this protein kinase could be the effector allowing for TORC1 control independent of Fhl1 and Sfp1 (Crauwels et al. 1997a; Jorgensen et al. 2004; Roosen et al. 2005; see also below). Another protein involved in TORC1-mediated transcriptional control of ribosome biosynthesis is Hmo1. This protein is a member of the HMG protein family that encompasses architectural proteins that bind to DNA with low sequence specificity. Hmol associates with RP gene promoters and with the rDNA region and this association requires TORC1 activity (Hall et al. 2006; Berger et al. 2007). By regulating Hmo1, TORC1 probably ensures that rRNA and RP expression are well-coordinated.

TORC1 also regulates protein synthesis at the posttranscriptional level. It was recently shown that TORC1 controls the nucleocytoplasmic shuttling of Dim2 and Rrp12, two 40S ribosome synthesis factors that are involved in ribosome assembly and the nucleocytoplasmic translocation of pre-ribosomes (Vanrobays et al. 2008). Furthermore, TORC1 was found to be essential for translation initiation (Barbet et al. 1996). Based on the fact that deletion of $C D C 33$, encoding for the translation initiation factor eIF4E, results in a similar phenotype as observed when TORC1 is inactivated, it was proposed that TORC1 might control translation initiation via eIF4E (Barbet et al. 1996; Danaie et al. 1999). In addition, TORC1 was shown to have a positive effect on the stability of translation initiation factor eIF4G that binds to eIF4E (Berset et al. 1998). A third translation initiation factor that is regulated by TORC1 is eIF2. However, as mentioned above, the regulation of eIF2 by TORC1 is indirect and mediated through the kinase Gcn2, of which the phosphorylation status is controlled via the Tap42 effector branch. Phosphorylated Gen2 in turn prevents phosphorylation of the $\alpha$ subunit of eIF2 and thereby the inhibition of translation initiation (Cherkasova and Hinnebusch 2003; Kubota et al. 2003; Hinnebusch 2005).

Next, TORC 1 exerts a major impact on the transcription of stress response genes. Here, TORC1 has a dual control. On the one hand, it prevents nuclear translocation of the protein kinase Rim15, thereby ensuring that this kinase is maintained inactive through PKA-mediated phosphorylation (Pedruzzi et al. 2003; Urban et al. 2007; Wanke et al. 2008). Since this control involves Sch9, it will be discussed in more detail in the section below. On the other hand, TORC1 inhibits the transcription of stress-responsive genes via a Rim15-independent, but Tap42-PP2A-dependent route, thereby promoting the phosphorylation and cytoplasmic retention of Msn2 (Beck and Hall 1999; Duvel et al. 2003; Santhanam et al. 2004). It is important to note that the latter is independent of the PKA-mediated phosphorylation of the Msn2/4 nuclear localization signal (Gorner et al. 1998, 2002; Garreau et al. 2000; Santhanam et al. 2004).

Finally, TORC1 is also a known negative regulator of autophagy (Chang et al. 2009). TORC1 activity controls the phosphorylation status of Atg13. When TORC1 is active, Atg13 is hyperphosphorylated, whereas rapamycin addition induces a rapid dephosphorylation of Atg13 (Kamada et al. 2000). The latter apparently stimulates the affinity of Atg13 for Atg1 and promotes Atg1-Atg13 complex formation which is a requirement for autophagy (Funakoshi et al. 1997; Kamada et al. 2000). It is possible that PP2A is involved in TORC1-dependent regulation of Atg13 phosphorylation, since it was recently shown that autophagy is negatively regulated by the Tap42-PP2A pathway (Yorimitsu et al. 2009).

Recently, a label-free quantitative phosphoproteomic screen revealed more than 100 novel TORC1-dependent phosphorylation events, which were only partially dependent on the two known direct downstream effectors of TORC1, i.e. Sch9 and Tap42. This suggests the existence of additional but yet unidentified direct targets of TORC1 
(Huber et al. 2009). The authors described possible new links between TORC1 and filamentous growth through the Ksp1 protein kinase (Bharucha et al. 2008) and between TORC1 and the DNA damage response through Pin4, a protein involved in G2/M progression, and Rph1, a histone demethylase (Kim et al. 2002; Pike et al. 2004). Furthermore, they described additional links between TORC1 and ribosome biogenesis through regulation of Stb3, Dot6 and Tod6, three transcriptional repressors of ribi gene expression (Liko et al. 2007; Badis et al. 2008; Zhu et al. 2009).

\section{Rapamycin-insensitive signalling via TORC2}

TORC2 signalling is less well-characterized than TORC1 signalling due to the absence of a rapamycin equivalent for TORC2. The Cell Wall Integrity (CWI) pathway that regulates cell wall synthesis and actin polarization was the first pathway that could be connected to TORC2 signalling (Schmidt et al. 1996; Levin 2005). Overexpression of components of the CWI pathway could restore viability and actin polarization defects of mutants compromised in their TORC2 function (Schmidt et al. 1996; Bickle et al. 1998; Helliwell et al. 1998). These results suggest that TORC2 functions upstream or in parallel to the CWI pathway to regulate actin polarization. Additionally, it was found that the protein kinases, Ypk1 and Ypk2, and the $\mathrm{PH}$ domain proteins, $\operatorname{Sim} 1$ and $\operatorname{SIm} 2$, which also play a role in actin polarization, are downstream targets of TORC2 signalling (Audhya et al. 2004; Fadri et al. 2005; Kamada et al. 2005). Interestingly, Ypk1/2 and Slm1/2 appear to be upstream regulators of the CWI pathway and might, therefore, provide a mechanistic link between TORC2 and the CWI pathway (Schmelzle et al. 2002; Ho et al. 2008). Since both Ypk1/2 and Slm1/2 were also shown to be regulated by sphingolipids, these proteins also couple TORC2 to sphingolipid metabolism and signalling (Aronova et al. 2008).

\section{How is TOR signalling regulated?}

Rapamycin treatment, transfer of yeast cells from good- to poor-quality carbon or nitrogen sources, or starvation for carbon or nitrogen all elicit very similar responses indicating that TORC1 is regulated by the abundance and/or quality of the available carbon and nitrogen source. While it is still largely unknown which metabolite(s) may regulate TORC1, glutamine appears to play a particularly important role in TORC1 activation (Crespo et al. 2002). Notably, glutamine can be readily converted to $\alpha$-ketoglutarate (for use in the TCA cycle) or serve as a precursor for the biosynthesis of other amino acids, nucleotides and nitrogen containing molecules ( $\mathrm{such}$ as $\mathrm{NAD}^{+}$). It is, therefore, not only a key intermediate in nitrogen metabolism, but also an important indicator of the cell's general nutrient status (Magasanik and Kaiser 2002). In line with the idea that glutamine acts upstream of TORC1, glutamine starvation phenocopies the effects of TORC1 inactivation inasmuch as it causes nuclear localization and activation of Gln3 and Rtg1/Rtg3 (Crespo et al. 2002; Butow and Avadhani 2004). Nevertheless, since other TORC1 readouts, such as for instance the subcellular distribution of $\mathrm{Msn} 2$, remain unaffected by glutamine starvation, TORC1 is likely to respond to additional nutrients and to elicit nutrient-specific responses. Understanding of how nutrients (including amino acids such as glutamine) are sensed and how this information is transmitted to TORC 1 still remains one of the major challenges in the TORC1 field.

In this context, the vacuolar membrane-associated EGO (exit from rapamycin-induced growth arrest) protein complex (EGOC) (Dubouloz et al. 2005), which consists of Ego1/Meh1/Gse2, Ego3/Nir1/Slm4/Gse1, Gtr1, and Gtr2, has been proposed to function as a critical hub that directly relays an amino acid signal to TORC1 (De Virgilio and Loewith 2006a, b; Gao and Kaiser 2006; Piper 2006). This initial idea has recently been bolstered by the finding that the EGOC subunit Gtr1, which is homologous to mammalian Rag GTPases, directly interacts with and activates TORC1 in an amino acid-sensitive and nucleotide-dependent manner (Binda et al. 2009). Accordingly, expression of a constitutively active (GTP-bound) Gtr1 ${ }^{\mathrm{GTP}}$, which interacted strongly with TORC1, rendered TORC1 partially resistant to leucine deprivation, while expression of a growth inhibitory GDP-bound Gtr $1^{\text {GDP }}$ caused constitutively low TORC1 activity. In line with this proposed model in yeast, two complementary studies in Drosophila and mammalian cells have also reported that the conserved Rag GTPases act as upstream regulators of TORC1 and play important roles in coupling amino acid-derived signals to TORC1 (Kim et al. 2008; Sancak et al. 2008).

Interestingly, a genome-wide synthetic genetic interaction screen revealed that tor $1 \Delta$ cells were particularly sick, or not viable, in the absence of individual subunits of either of two protein complexes, namely the EGO complex and the homotypic fusion and vacuole protein sorting (HOPS/ class C-Vps) complex (Zurita-Martinez et al. 2007). These and additional genetic data indicated that the class $\mathrm{C}-\mathrm{Vps} /$ HOPS complex may, like EGOC, directly or indirectly control TORC1 signalling in response to amino acids. Notably, the HOPS complex is thought to facilitate the transition from tethering to trans-SNARE pairing during fusion at the vacuole in part by nucleotide exchange on the GTPase Ypt7, which is exerted by the HOPS complex subunit Vam6 (Wurmser et al. 2000). Intriguingly, recent genetic and biochemical data indicate that Vam6 may in fact control TORC1 function rather directly by regulating the nucleotide-binding status of the EGOC subunit Gtr1 
(Binda et al. 2009). This suggests that Vam6 may actually integrate amino acid signals to coordinate the control of TORC1 activity and vacuolar fusion events. While the discovery of the EGOC as an activator of TORC1 signalling represents an important step in deciphering the molecular events that signal nutrient availability to TORC1, an exciting question that remains to be addressed is how amino acid availability is sensed and communicated to Vam6 and/or the EGOC.

In addition to the abundance and/or quality of nutrients, TORC1 activity also appears to be sensitive to stress cues, but the mechanisms by which these cues are sensed and how this is communicated to TORC1 are presently unknown (De Virgilio and Loewith 2006a). Finally, the Golgi $\mathrm{Ca}^{2+} / \mathrm{Mn}^{2+}$ ATPase Pmr1 has recently also been implicated in TORC1 regulation (Devasahayam et al. 2006). Accordingly, loss of Pmr1 increased rapamycin resistance, while addition of $\mathrm{Mn}^{2+}$ to the growth medium restored rapamycin sensitivity to pmrl $\Delta$ cells. Together with genetic epistasis analyses that placed Pmr1 upstream of TORC1, it was suggested that manganese within the Golgi lumen might, via a yet unidentified mechanism, inhibit TORC1 activity (Devasahayam et al. 2007).

The upstream signals that regulate TORC2 remain currently elusive, but may possibly include nutrients and/or diverse stresses. Given the importance of cell polarization during mitosis (Pruyne and Bretscher 2000a, b), an interesting additional or alternative model is that the cell cycle machinery may impinge on TORC2.

The protein kinase Sch9

As indicated above, the serine/threonine protein kinase Sch9 plays a central role in nutrient-mediated signalling. This kinase was originally identified through a screen aiming to isolate multi-copy suppressors of the growth defect at high temperatures of a cAMP-PKA signallingdeficient $c d c 25^{t s}$ strain (Toda et al. 1988). It was then also shown that the typical phenotypes associated with the loss of Sch9 activity, such as slow growth, reduced cell size and small colony formation, can all be suppressed by overactivation of the PKA pathway, an observation that was subsequently confirmed in several studies (Toda et al. 1988; Hartley et al. 1994; Jorgensen et al. 2002). Later, it was reported that the deletion of GPR1, GPA2 or RAS2, which all encode proteins involved in the upstream activation of the cAMP-PKA pathway, results in a synthetic growth defect when combined with the deletion of $\mathrm{SCH} 9$ (Kraakman et al. 1999b; Lorenz et al. 2000). Thus, there appears to be an intimate relationship between Sch9 and PKA as both kinases seem to have overlapping functions. Subsequently, Sch9 was reported to be essential for the proper nutritional regulation of PKA-dependent phenotypes in glucose-repressed cells, such as the activation of trehalase, the repression of stress response genes and the induction of ribosomal protein genes (Crauwels et al. 1997a). These findings led to the concept of the socalled Fermentable Growth Medium (FGM) pathway that is believed to ensure the maintenance of PKA-dependent phenotypes of yeast cells growing on medium containing a rapidly fermented sugar and all essential nutrients, after the transient activation of the cAMP-PKA pathway that occurs during lag phase when cells prepare themselves for fermentative growth (Thevelein 1994; Crauwels et al. 1997a). As the FGM pathway appeared to operate independent of cAMP, it was postulated that Sch9 could control the activity of PKA at the level of the free catalytic Tpk subunits (Thevelein 1994; Crauwels et al. 1997a). More recently, however, it was found that PKA and Sch9 act in parallel (Roosen et al. 2005). For instance, both kinases have an additive effect for the expression of proteins required for nucleotide metabolism but they exert opposite effects on the expression on proteins involved in detoxification or proteolysis (Roosen et al. 2005). In addition, they independently determine the sensitivity of yeast cells for the ATP-analogue 1NM-PP1 as illustrated by the observation that a mutant with combined analogue-sensitive sch $9^{a s}$ tpk $1^{\text {as }}$ tpk $2^{\text {as }}$ tpk $3^{\text {as }}$ alleles is more sensitive than the single sch $9^{a s}$ mutant or the tpk $1^{\text {as }}$ tpk2 $2^{a s} t p k 3^{a s}$ strain (Yorimitsu et al. 2007; Huber et al. 2009; Lee et al. 2009).

$\mathrm{Sch}$ 9 is homologous to the mammalian protein kinase $\mathrm{B}$ (PKB/Akt). Alignment of Sch9 and PKB revealed $44 \%$ identity and $68 \%$ similarity over 397 residues and showed that the homology between Sch9 and PKB is most pronounced at the catalytic domain and the C-terminus (Geyskens et al. 2001). Furthermore, Sch9 and PKB are not only structurally, but also functionally related since expression of PKB rescues the slow growth and small colony phenotype of a sch9 $\Delta$ deletion mutant (Geyskens et al. 2001). PKB was originally discovered as an oncogene and is involved in the regulation of cell survival, cell cycle progression and metabolism. The PKB kinase contains a pleckstrin homology ( $\mathrm{PH}$ ) domain which binds to the lipid second messenger phosphatidylinositol-3,4,5-trisphosphate (PIP3). PIP3 is produced by phosphorylation of phosphatidylinositol-4,5-bisphosphate via the phosphoinositide-3kinase $\mathrm{PI} 3 \mathrm{~K}$, which is activated by receptor tyrosine kinases, such as the insulin receptor. After binding to PIP3 via its $\mathrm{PH}$ domain, $\mathrm{PKB}$ is localized at the plasma membrane where it is phosphorylated, and thereby activated, by the phosphoinositide-dependent kinase PDK1, which also contains a PH domain, and by mammalian TORC2 (Fayard et al. 2005; Corradetti and Guan 2006). Yeast contains two PDK1 orthologs, Pkh1 and Pkh2, which, however, contain no $\mathrm{PH}$ domain and are apparently activated by sphingolipids rather than by phosphoinositides (Casamayor et al. 
1999; Friant et al. 2001; Liu et al. 2005a, b). Sch9 also contains a PDK1 consensus site and it was found that phosphorylation of this site by $\mathrm{Pkh} 1 / 2$ activated Sch9 in vitro (Liu et al. 2005a; Urban et al. 2007). Moreover, phosphorylation of the PDK1 site appears to be essential for Sch9 to function in vivo for the control of cell growth control and stress resistance (Roelants et al. 2004). To date, there are no data that show that Sch9 is a target of the rapamycin-insensitive TORC2. In contrast, Sch9 is directly phosphorylated by TORC1 on at least five residues in the C-terminal half and these phosphorylation events are critical for its catalytic activity (Urban et al. 2007). As already described above and illustrated in Fig. 4, the phosphorylation of Sch9 allows TORC1 to prevent the induction of typical $G_{0}$ traits as well as to stimulate ribosomal biogenesis and translation initiation (Urban et al. 2007; Huber et al. 2009). A recent report indicates that TORC1-dependent phosphorylation of Sch9 is subject to feedback control since it is negatively regulated by $\mathrm{Sfp} 1$, a transcriptional activator of ribosomal protein and ribi gene expression, which itself is activated by TORC1 (Lempiainen et al. 2009). Note that in addition to the Pkh- and TORC1dependent phosphorylation sites, Sch9 appears to be phosphorylated at many additional residues, indicating that yet unidentified protein kinases may control Sch9 function (Urban et al. 2007). Like TORC1, Sch9 is predominantly localized at the vacuolar membrane (Jorgensen et al. 2004; Urban et al. 2007). In this context, it should be mentioned that Sch9 possesses no $\mathrm{PH}$ domain but instead contains a calcium-dependent $\mathrm{C} 2$ domain at its $\mathrm{N}$-terminus. While the role of this domain for Sch9 function remains to be determined, it may possibly serve to regulate the subcellular localization of Sch9, as C2 domains can bind phospholipids and are known to serve as membrane-targeting domains in other proteins (Lemmon 2008). A fraction of the Sch9 pool appears also to be localized in the nucleus as co-immunoprecipitation analysis showed that Sch9 is recruited to the chromatin of osmostress-responsive genes (Pascual-Ahuir and Proft 2007).

One major role of $\mathrm{Sch} 9$ is to regulate translation in function of nutrient availability and the growth potential. As such, Sch9 controls the expression of RP genes and of the Ribi regulon, by interfering with the transcriptional processes conducted by the RNA polymerases I, II and III (Crauwels et al. 1997a, b; Jorgensen et al. 2004; Roosen et al. 2005; Urban et al. 2007; Smets et al. 2008; Huber et al. 2009). Concerning RNA polymerase I transcription, Sch9 appears to be required to maintain the optimal activity of the polymerase, presumably by promoting the recruitment of the catalytic subunit Rpa190 to the rDNA locus. In addition, Sch9 is essential for the proper processing of the $35 \mathrm{~S}$ transcript into the $25 \mathrm{~S}, 18 \mathrm{~S}$ and $5.8 \mathrm{~S}$ rRNA and at least one component of the processome, i.e.
Rps6, was shown to be phosphorylated by Sch9. The latter led to the conclusion that Sch9 should be considered as the orthologue of the mammalian kinase S6K1, rather than being the yeast counterpart of PKB (Urban et al. 2007; Huber et al. 2009). Possibly, Sch9 may still combine the functions of S6K and PKB and thus represent the ancestor from which both kinases have evolved. For processes mediated by the RNA polymerase II, Sch9 phosphorylates and inhibits the activity of the transcriptional repressors Stb3 and Dot6/Tod6, which, respectively, bind the RRPE and PAC elements in the promoters of ribi genes (Huber et al. 2009). For RNA polymerase III-dependent transcription, the downstream target of Sch9 is Maf1, the repressor that is also regulated by PKA and TORC1. Here, Sch9 was first reported to phosphorylate Maf1 at a subset of the sites that are also recognized by PKA (Lee et al. 2009). Most recently, it was shown that Sch9 phosphorylates Maf1 at seven distinct sites in vitro and that it thereby can not only partially inhibit nuclear accumulation of Maf1 after rapamycin treatment, but also completely block the repressive association between Maf1 and the RNA Pol III subunit Rpc82 (Huber et al. 2009). In addition to ribosome biogenesis, Sch9 controls the expression of different tRNA synthetases, proteins involved in amino acid metabolism as well as translation initiation and elongation factors (Crauwels et al. 1997b; Roosen et al. 2005) and recent evidence suggests that Sch9 also controls the phosphorylation status of eIF $2 \alpha$ (Urban et al. 2007). Hence, Sch9 functions as a central coordinator of protein synthesis and this may explain why sch $9 \Delta$ cells are characterized by a small cell size, since, indeed, the translational capacity of a cell is tightly coupled to the size threshold at which cells commit to cell division (Jorgensen et al. 2002, 2004).

Several studies implicated Sch9 in the regulation of the cellular response to stress. Best studied is its role in the regulation of the protein kinase Rim15, which in turn controls the expression of stress-responsive genes through the transcriptional activators Gis1 and Msn2/4 that, respectively, bind to the PDS and STRE elements (Crauwels et al. 1997a; Pedruzzi et al. 2003; Cameroni et al. 2004; Roosen et al. 2005). Sch9 phosphorylates $\operatorname{Rim} 15$ at $\operatorname{Ser}^{1061}$ in vitro and this phosphorylation event is necessary for normal cytoplasmic retention of Rim15 (Pedruzzi et al. 2003; Wanke et al. 2008). Mechanistically, phosphorylated $\mathrm{Ser}^{1061}$ in Rim15, together with phosphorylated $\mathrm{Thr}^{1075}$ by the Pho85-Pho80 kinase complex (see also below), may allow Rim15 to engage in binding the two monomeric subunits within a single 14-3-3 (Bmh2) protein dimer (Wanke et al. 2005, 2008) and thereby guarantee optimal sequestration of Rim 15 in the cytoplasm (Fig. 5). As expected, the regulation of Rim15 localization by Sch9 was also found to be dependent on TORC1 signalling as rapamycin treatment causes dephosphorylation 
Fig. 5 The Rim15 protein kinase acts as a nutritional integrator in $S$. cerevisiae. Rim15 is regulated by at least four nutrient signalling protein kinases. In response to glucose, PKA directly phosphorylates and thereby inactivates the kinase activity of Rim15. Active TORC1 and Sch9 promote cytoplasmic retention of Rim15. Notably, TORC1 favours phosphorylation of Rim15 at both $\mathrm{Ser}^{1061}$ (via activation of Sch9) and $\mathrm{Thr}^{1075}$ (via inhibiting a yet unidentified protein phosphatase) to promote the association of Rim15 with a 14-3-3/Bmh2-protein dimer for its optimal sequestration in the cytoplasm. Inactivation of TORC1 and Sch9 results in the nuclear translocation of Rim 15 where this kinase controls the expression of Msn2/4- and Gis1-dependent genes. Rim15 is subject to autophosphorylation, which apparently stimulates nuclear export. Also Pho85Pho80, which phosphorylates Rim15 at $\mathrm{Thr}^{1075}$, controls the nuclear export of Rim15. PDS post-diauxic shift, STRE stressresponsive element

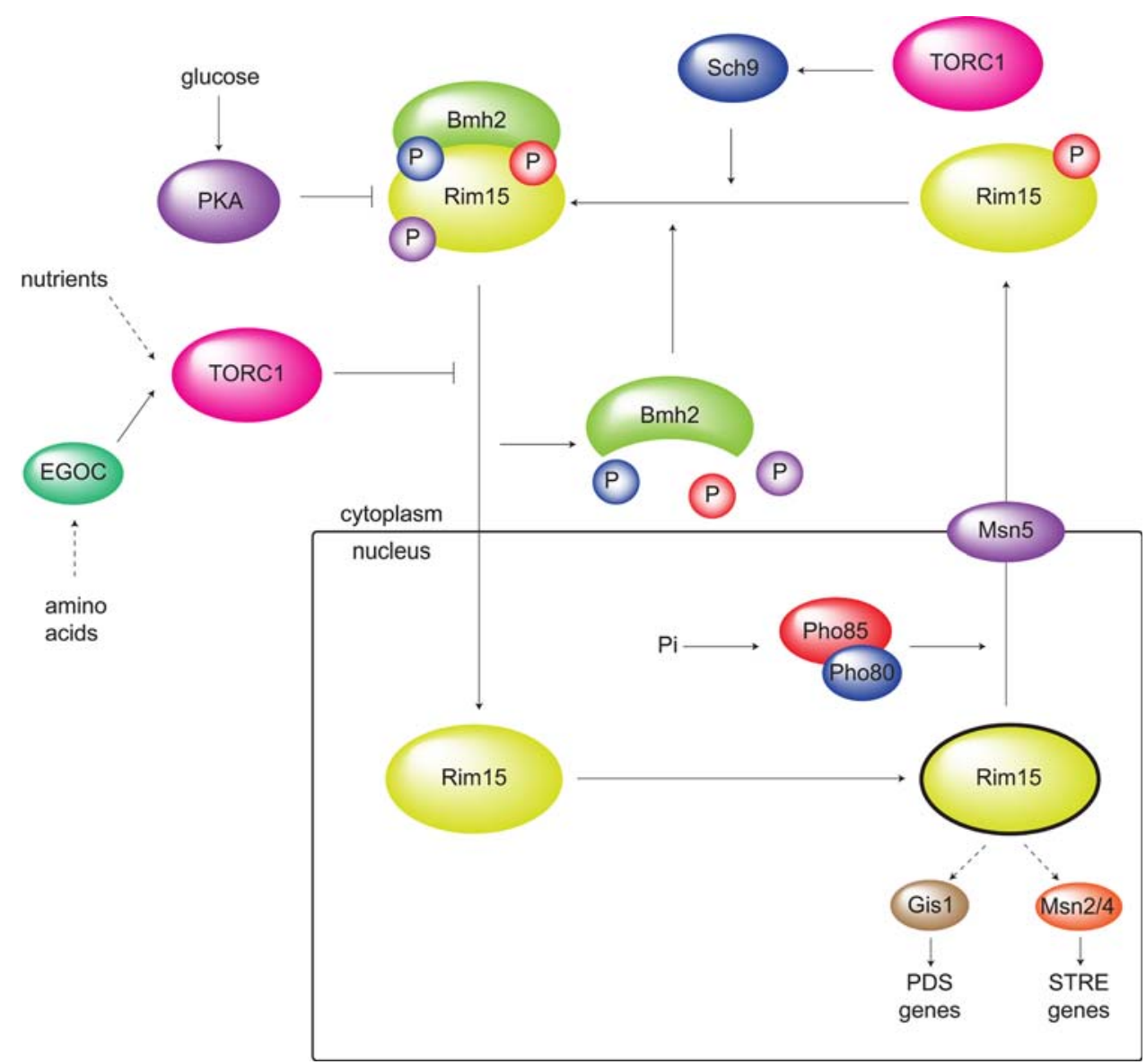

of the 14-3-3-binding site and enforces nuclear accumulation of Rim15 (Pedruzzi et al. 2003; Wanke et al. 2005; Urban et al. 2007). In addition to control via Rim15, TORC1 and Sch9 independently regulate the effectors Msn2/4 and Gis1. As mentioned above, TORC1 controls the phosphorylation and cytoplasmic retention of Msn2 via the Tap42-PP2A-dependent route (Beck and Hall 1999; Duvel et al. 2003; Santhanam et al. 2004). Sch9, on the other hand, is essential to maintain the Gis1 activity, which explains why Sch9 and TORC1 exert essentially opposed effects for the expression of the PDS genes at the diauxic shift (Roosen et al. 2005; Smets et al. 2008). How Sch9 stimulates Gis1 is not known, but it is tempting to speculate that it may involve a function of Sch9 that was only recently uncovered. Indeed, for the induction of osmostress-responsive genes, Sch9 appears to act as a chromatin-associated transcriptional activator since it is recruited to the promoter region of these genes when yeast is exposed to osmotic stress (Pascual-Ahuir and Proft 2007). This recruitment is independent of TORC1 but requires Sko1, a transcriptional activator of osmostress genes, and Hog1, a mitogen-activated protein kinase (MAPK) that is part of osmoregulatory signalling cascade. In vitro experiments demonstrated that Sch9 interacts with both Sko1 and Hog1 and that Sch9 is able to phosphorylate Sko1 (Hohmann et al. 2007; Pascual-Ahuir and Proft 2007). Moreover, a recent genome-wide transcriptional analysis revealed other genes that require Sch9 for their optimal expression, while being negatively regulated by TORC1 (Smets et al. 2008). These include several genes encoding mitochondrial functions, such as proteins involved in the tricarboxylic acid cycle, the fatty acid metabolism as well as mitochondrial ribosomal proteins. The same study also showed that Sch9 acts independent of TORC1 to reduce the basal expression of NDP target genes, such as GAP1, which encodes the general amino acid permease, as well as genes regulated by GAAC pathway and its central transcription factor Gen4.

Finally, the role of Sch9 for the induction of autophagy was studied in more detail. These studies revealed that autophagy is induced in yeast cells upon the simultaneous inactivation of Sch9 and PKA (Yorimitsu et al. 2007). This induction required the Atg1 kinase complex and was only in part dependent on the presence of Rim15 and Msn2/4. Interestingly, neither Rim15 nor Msn2/4 seemed to be essential for rapamycin-induced autophagy and the 
Fig. 6 Central role of Pho85Pho80 in Pi-signalling and Pi-dependent stress responses in $S$. cerevisiae. Activation of the PHO pathway in response to $\mathrm{Pi}$-limiting conditions requires inhibition of Pho85-Pho80 by Pho81 and subsequent transcription of the PHO genes via interaction of $\mathrm{Pho} 2$ and Pho4. Inositol phosphate metabolism and adenosine nucleotide metabolism both influence Pi-dependent responses on different levels. Additionally, Pho85-Pho80 also negatively regulates Rim 15 and Crz1. Dashed lines represent putative or indirect interactions. See text for further details. $P D S$ post-diauxic shift, CDRE calcineurin-dependent response element

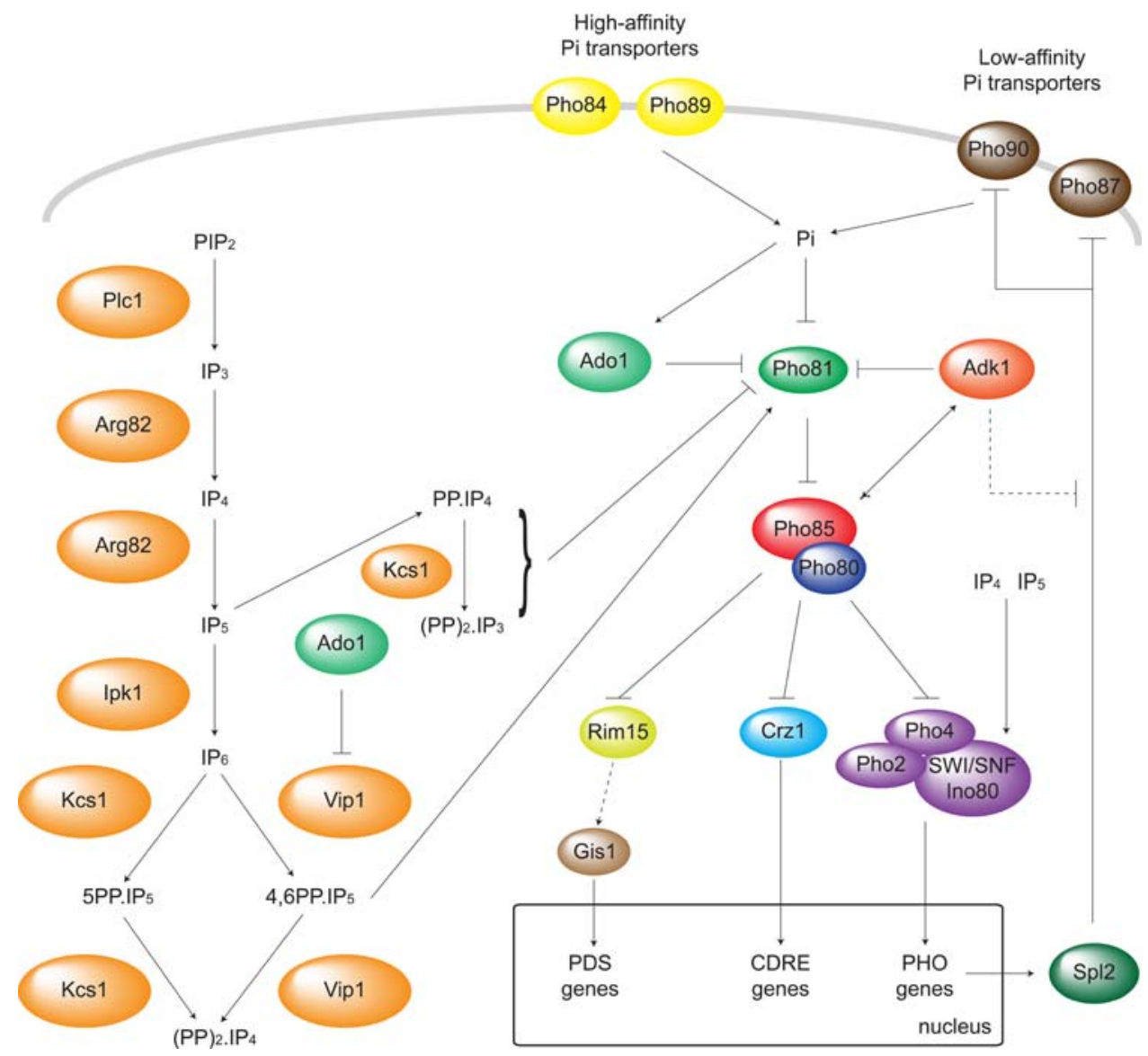

combined inactivation of Sch9 and PKA appeared to additively stimulate autophagy, indicating that also for autophagy Sch9 and PKA act, at least in part, in parallel to the TORC1 pathways (Yorimitsu et al. 2007).

The Pho85-Pho80 kinase complex

Pho85 is a cyclin-dependent kinase (CDK) in S. cerevisiae with distinct functions in several pathways, which is confirmed by the pleiotropic phenotype of a pho85 $\Delta$ strain. Deletion of PHO85 results in slow growth with a $\mathrm{G}_{1}$-delay on rich medium and a severe growth defect on poor carbon and nitrogen sources (Lee et al. 2000). More specifically, mutant pho85 4 cells display a background-dependent hyperaccumulation of glycogen (Timblin et al. 1996; Lee et al. 2000), morphology and polarity defects (Measday et al. 1997; Tennyson et al. 1998), constitutive expression of phosphate-responsive or so-called PHO genes, CWI defects and hypersensitivity to stress conditions (Huang et al. 2002), sporulation defects (Gilliquet and Berben 1993), aberrant expression profiles during the diauxic shift (Nishizawa et al. 2004) and a hyperinduction of nutrient starvation-induced autophagy (Wang et al. 2001). Consistent with its multiple functions, Pho85 can interact with ten different cyclins that can be divided into two different subfamilies according to their sequence similarities (Measday et al. 1997). The first so-called Pcl1,2 subfamily includes the cyclins Pcl1, Pcl2, Pcl5, Pcl9 and Clg1. The second subfamily is denoted as the Pho80 subfamily and includes Pcl6, Pcl7, Pcl8, Pcl10 and Pho80. The interaction of Pho85 with its corresponding cyclin is essential for its activity and to confer substrate specificity. In this review, we will focus on Pho80, which is the major cyclin involved in phosphate metabolism and regulation of proper entry into $\mathrm{G}_{0}$ under phosphate starving conditions. For the other cyclins, we refer to a recent review (Huang et al. 2007a).

\section{The role of Pho85-Pho80 kinase complex in phosphate metabolism and phosphate signalling}

The Pho85-Pho80 kinase complex plays a central role in the PHO pathway, which allows cells to properly respond to changes in extra- and/or intracellular phosphate levels, as outlined in Fig. 6. Pho85-Pho80 controls the localization of the Pho4 transcription factor, which is essential for induction of the PHO genes (O'Neill et al. 1996; Ogawa et al. 2000), leading to optimized phosphate acquisition (see further). Under phosphate limiting conditions, the 
low-phosphate signal activates the PHO pathway by triggering activation of the CDK-inhibitor (CKI) Pho81 (Lenburg and O'Shea 1996). In turn, the active Pho81 maintains the Pho85-Pho80 kinase complex in its inactive form and thereby Pho81 prevents that the kinase complex would hyperphosphorylate Pho4 (O’Neill et al. 1996). Under these conditions, Pho4 can interact with its nuclear import factor Pse1 and translocate into the nucleus, where it activates the transcription of the PHO genes (Kaffman et al. 1998b). However, transcriptional activation occurs only in the presence of the transcription cofactor Pho2, which binds to a Pho4 dimer to form a stabilized heterotrimeric protein complex (Magbanua et al. 1997; Shao et al. 1998). Pho 2 must be phosphorylated at $\operatorname{Ser}^{230}$ in order to bind unphosphorylated dimeric Pho4 and it appears that this phosphorylation is also regulated by phosphate availability (Xia and Ao 1999; Liu et al. 2000). The proteins that control phosphorylation of Pho2 under physiological conditions have not been identified, but it is known that the Cdc28 is able to phosphorylate Pho2 in vitro (Liu et al. 2000). Note that the function of Pho 2 is not restricted to phosphate signalling, as this cofactor is also involved in mating-type switching, through its interaction with Swi5 (Bhoite and Stillman 1998; Bhoite et al. 2002), as well as in one-carbon metabolism and especially adenine synthesis, through interaction with Bas1 (Zhang et al. 1997; Bhoite et al. 2002; Subramanian et al. 2005). The latter is of particular interest since it provides a link between phosphate signalling and adenylic nucleotide synthesis as will be discussed below.

When phosphate is abundant, Pho81 is inactivated and as a result the Pho85-Pho80 kinase complex becomes active, which can now phosphorylate Pho4 resulting in the disassembly of the Pho4-Pho2 heterotrimeric protein complex and the repression of the PHO genes. Phosphorylated Pho4 then interacts with the export factor Msn5 to be excluded from the nucleus (Kaffman et al. 1998a). The first step in activation or repression of the PHO pathway thus occurs via modulation of the activity of the Pho81 CKI. Pho81 is constitutively localized in the nucleus where it is bound to the Pho80 cyclin under high- and low-Pi conditions. Similarly, Pho81 is able to inhibit the Pho85Pcl7 kinase complex in response to low-phosphate levels via direct interaction with the Pcl7 cyclin (Lee et al. 2000). The Pho81 protein consists of 1,179 amino acids, but only the so-called minimum domain, located between the amino acid 644 to 723, is essential for inhibition of Pho85-Pho80 towards Pho4 (Huang et al. 2001). Other domains of Pho81 have multiple functions towards non-Pho4 targets of the Pho85-Pho80 kinase or inhibit other Pho85-cyclin complexes (Huang et al. 2007b; Swinnen et al. 2005). Since Pho81 always interacts with the Pho80 cyclin, but only inhibits the Pho85-Pho80 kinase under phosphate limiting conditions, Pho81 may be regulated by post-translational or allosteric activations. Recent evidence shows that inositol polyphosphate species play a particular role in this regulation. More specifically, isoform synthesized by Vip1 was found to bind non-covalently with Pho80-Pho85-Pho81, thereby inducing additional interactions between Pho81 and Pho80-Pho85 that prevent substrates from accessing the kinase active site (Lee et al. 2007; Lee et al. 2008b). Intriguingly, under phosphate starvation conditions, Pho4dependent antisense and intragenic RNA transcription in the KCS1 locus induces downregulation of the Kcs1 activity, leading to a positive feedback loop for activation of the PHO genes (Nishizawa et al. 2008a).

Activation of the PHO pathway results in increased expression or breakdown of proteins involved in the uptake and storage of phosphate (Ogawa et al. 2000). For the uptake of phosphate, the regulation occurs both by Pho4dependent transcriptional and post-transcriptional processes. S. cerevisiae encodes for two different phosphate transporter systems: a low-affinity system consisting of Pho87, Pho90 and Pho91 and a high-affinity system containing Pho84 and Pho89. Under phosphate limiting conditions, genes encoding for high-affinity phosphate transporters, i.e. PHO84 and PHO89, are induced. In contrast, the expression of the genes encoding the lowaffinity system is independent of Pho4 and phosphate availability (Auesukaree et al. 2003). Nonetheless, Pho4 may control the low-affinity system via the induction of Spl2 (Wykoff et al. 2007). Spl2, which was originally discovered as a multi-copy suppressor of plc1 $\Delta$ (Flick and Thorner 1998), appears to limit the phosphate-uptake velocity of Pho87 and Pho90 in vivo through its interaction with the SPX domain of these low-affinity phosphate transporters (Hurlimann et al. 2009). This provides yet another feedback loop for the control of the PHO pathway. Thus, while the low-affinity phosphate transporters Pho87 and Pho90 are active at the plasma membrane under highphosphate conditions, the high-affinity system takes over the phosphate uptake function of Pho87 and Pho90 under phosphate limiting conditions. The activity of Pho91 was shown to be independent of Pho4 and Spl2 (Wykoff et al. 2007) and Pho91 was identified as a vacuolar phosphate transporter essential for proper polyphosphate accumulation (Hurlimann et al. 2007). For storage of phosphate, the products of the PHM1 to PHM5 genes are important. These proteins are involved in orthophosphate and polyphosphate accumulation and their expression is induced under phosphate limiting conditions (Ogawa et al. 2000; Auesukaree et al. 2004). This may seem to be contradictory since polyphosphate is consumed under phosphate limiting conditions. However, the increased intracellular phosphate levels obtained by high-affinity phosphate uptake have to be stored as polyphosphate in the vacuole to avoid negative 
feedback, in particular to the Pho84 transporter, sustaining in this way a high rate of phosphate uptake under phosphate limiting conditions. In addition, several repressible acid phosphatases, encoded by $\mathrm{PHO}$, $\mathrm{PHO} 11$ and $\mathrm{PHO} 2$ (rAPases) as well as the repressible alkaline phosphatase PHO8 (rALPases), are induced (Persson et al. 2003). The acid phosphatases are secreted into the periplasmic space where they act on a multitude of phospho-ester substrates, while the alkaline phosphatase Pho8, localized at the vacuole, acts on other phosphate-containing substrates to liberate free phosphate (Klionsky and Emr 1989). Genes involved in catabolism of alternative phosphorous sources (GIT1, GDE1 and HOR2) are also induced under phosphate limiting conditions (Ogawa et al. 2000; Almaguer et al. 2003). Finally, PHO81 is itself induced under these conditions, comprising a third positive feedback loop for constitutive activation of the PHO pathway. Several other PHO genes undergo Pho4-dependent induction under lowphosphate conditions (Ogawa et al. 2000), but for most of them no clear function in phosphate metabolism or phosphate signalling has been identified. Recently, ChIP-onChIP analysis revealed 18 novel PHO-type genes with no apparent functional relationship to phosphate metabolism (Nishizawa et al. 2008a). Since most of them have already been identified as upregulated during nitrogen starvation and entry into stationary phase, it can be concluded that Pho4 has a possible role in a cross-talk between phosphate starvation and other nutrient starvation-induced stress conditions.

Apart from the main function of Pho4 to induce the PHO genes under phosphate limiting conditions, this transcription factor has been shown to be involved in other cellular processes. Two major phenotypes of a pho85 4 strain are the absence of growth on poor nutrient sources (Lee et al. 2000) and vacuolar dysfunction (Huang et al. 2002) and involvement of Pho4 appears to play a role in both processes. The additional deletion of $\mathrm{PHO}_{4}$ can rescue the growth defects of a pho854 strain on non-fermentable carbon sources and proline as sole nitrogen source (Nishizawa et al. 1999; Popova Iu et al. 2000). However, this phenotype is not only dependent on the Pho80 cyclin but also seems to involve the cyclins Pcl6 and Pcl7 (Lee et al. 2000), though a possible link between Pcl6 and Pcl7 and Pho4 was never investigated. Secondly, a pho854 and a pho804 strain show hypersensitivity to vacuolar stress conditions, such as high osmolarity, salt stress and elevated $\mathrm{Ca}^{2+}$ levels, and this is due to severe abnormalities in vacuolar structure and function (Cohen et al. 1999; Huang et al. 2002). These vacuolar phenotypes are completely suppressed by additional deletion of PHO4 or VTC4 (PHM3), a Pho4-activated gene involved in polyphosphate metabolism as discussed above (Ogawa et al. 2000). Pho4dependent hyperinduction of Vtc4 thus leads to vacuolar dysfunction and sensitivity to various environmental stress conditions. Interestingly, the ChIP-on-Chip analysis, mentioned above, revealed phosphate independent but Pho4dependent transcription of several genes, providing additional evidence that a nuclear pool of Pho4 exists that can bind to a promoter and control transcription under high phosphate conditions (Nishizawa et al. 2008a). In this way, Pho4 was shown to act as a transcriptional repressor as it negatively regulates the transcription of CIS3, YPS3 and SNZ1 (Nishizawa et al. 2008a, b). Additionally, a role for Pho4 in $\mathrm{G}_{1}$-arrest caused by DNA damage has also been reported (Wysocki et al. 2006).

\section{The role of the Pho85-Pho80 kinase complex in phosphate starvation-induced stress responses}

Inorganic phosphate is an essential nutrient for all organisms required for biosynthesis of nucleotides, phospholipids and metabolites, making it an important messenger to signal a growth limiting metabolic state and reduced developmental capacities of the cell. Similar to glucose or nitrogen starvation conditions, the depletion of phosphorous sources forces yeast cells to enter the quiescent $\mathrm{G}_{0}$-state (Swinnen et al. 2006).

Thorough investigation of phosphate starvation-induced stress responses uncovered a central role for the Pho81 CKI in the activation of Rim15, the kinase that is essential for the accumulation of the reserve carbohydrate glycogen and the stress protectant trehalose and the expression of stressresponsive genes under glucose starvation conditions (Reinders et al. 1998; Cameroni et al. 2004; Roosen et al. 2005). Indeed, in a pho81 $\Delta$ mutant strain, like in a rim15 strain, the accumulation of trehalose and the expression of PDS genes, like SSA3 and GRE1, are clearly delayed and reduced under phosphate starving conditions, while an effect on the expression of STRE genes appears less obvious (Swinnen et al. 2005). Interestingly, deletion of PHO85 reverted all of the observed phenotypes in a pho814 strain, but deletion of $P H O 80$, while fully reverting the defect in PDS-driven gene expression, only partially reverted the trehalose accumulation defect in a pho814 strain. This indicates that additional Pho85-associated cyclins are required to maintain proper trehalose levels. Note that the regulation of PDS genes particularly requires the protein kinase Sch9, and, therefore, it may not come as a surprise that also this kinase plays a role in controlling these genes in response to phosphate availability, which is further reflected by the fact that the combined deletion of $\mathrm{PHO} 85$ and $\mathrm{SCH} 9$ is synthetic lethal (Swinnen et al. 2005). As discussed above, Pho81 gets activated when phosphate becomes limiting and this results in nuclear translocation of Pho4 and the activation of the PHO genes. For this process, the minimum domain of 
Pho81 is sufficient (Huang et al. 2001). In contrast, the control of Rim15-dependent phenotypes requires fulllength Pho81, providing evidence that Pho81 is able to discriminate between different effectors of the same Pho85-Pho80 kinase (Swinnen et al. 2005). The molecular mechanism underlying this discrimination is still largely elusive, but several phosphorylation sites on Pho81 (Knight et al. 2004) and an involvement of inositol polyphosphates (Lee et al. 2008b) could be essential.

Meanwhile, it is known that Pho85-Pho80 promotes the nuclear exclusion of Rim 15 when phosphate is abundantly available (Wanke et al. 2005). This is mediated by Pho80Pho85-dependent phosphorylation of Rim15 on $\mathrm{Thr}^{1075}$, which favours the association of Rim15 with the 14-3-3 protein Bmh2 in the cytoplasm (Wanke et al. 2005). Conversely, TORC1 inactivation triggers (likely due to the activation of protein phosphatases) dephosphorylation of Rim15 at $\mathrm{Thr}^{1075}$, thereby favouring accumulation of Rim15 in the nucleus. Since Pho85-Pho80 is mainly localized within the nucleus and TORC1 is predominantly associated with the vacuolar membrane (Kaffman et al. 1998a; Sturgill et al. 2008), Pho85-Pho80 and TORC1 may act on different pools of Rim15. Interestingly, the intrinsic protein kinase activity of Rim15 is also required for its nuclear export (Wanke et al. 2005).

\section{The role of the Pho85-Pho80 kinase complex in $\mathrm{Ca}^{2+}$ signalling and alkaline stress response}

The third in vivo effector of the Pho85-Pho80 kinase is the Calcineurin Responsive Zinc finger transcription factor 1, Crz1. This protein was identified via a synthetic dosage lethality screen in a pho85 4 and a pho80 $\Delta$ strain and localization and phosphorylation studies confirmed that Pho85-Pho80 promotes nuclear exclusion of Crz1 via direct phosphorylation (Sopko et al. 2006). Crz1 is known to be activated via dephosphorylation by the serine/threonine protein phosphatase Calcineurin, consisting of two catalytic subunits $\mathrm{Cna} 1$ and $\mathrm{Cna} 2$ and a regulatory subunit $\mathrm{Cnb} 1$, in response to ion stress involving $\mathrm{Li}^{+}, \mathrm{Na}^{+}, \mathrm{Mn}^{2+}$ and $\mathrm{Ca}^{2+}$. Activation of Calcineurin promotes nuclear translocation of Crz1 via interaction with its import factor Nmd5 (Polizotto and Cyert 2001), thereby inducing transcriptional activation of the "calcineurin-dependent response element" (CDRE) genes such as the $\mathrm{Na}^{+}$-ATPase ENA1/PMR2, the $\mathrm{Ca}^{2+}$-ATPases PMCl and PMRI and the catalytic subunit of the $\beta-1-3$ glucan synthase FKS2 (Matheos et al. 1997; Stathopoulos and Cyert 1997; Stathopoulos-Gerontides et al. 1999). Ion stress responses are often transient and after adaptation the subsequent nuclear export of Crz1 occurs via interaction with its export factor Msn5 (Boustany and Cyert 2002). Additional finetuning of the Crz1-dependent response occurs via regulation by two other kinases. Hrr25, a yeast casein kinase type 1 (CK1) homologue, stimulates nuclear exclusion of Crz1 (Kafadar et al. 2003), while PKA inhibits nuclear import of Crz1 (Kafadar and Cyert 2004), both of which occur through direct phosphorylation.

A physiological role for the regulation of Crz1 by the Pho85-Pho80 kinase remains elusive. Possibly, Pho85Pho80 regulates expression of the high-affinity phosphate transporter Pho89 under alkaline stress response (Serrano et al. 2002). It was shown that increasing the extracellular $\mathrm{pH}$ to 7.6 leads to induction of PHO84 and PHO89, encoding the high-affinity phosphate transporters, and PHM1, PHM2 and PHM3, encoding the vacuolar polyphosphate synthases. Further investigation revealed a strict Pho4-dependent induction of PHO84, while full induction of PHO89 required both Pho4 and Crz1. Under phosphate starving conditions, however, induction of PHO89 is only Pho4-dependent (Swinnen et al. 2005), providing evidence for a Calcineurin-dependent response under alkaline conditions, which is absent in a low-phosphate environment. Specific domains of Pho81 may inhibit the Pho85-Pho80 kinase towards Crz1 and Pho4, which can lead to full activation of PHO89 in combination with the activation of Calcineurin under alkaline $\mathrm{pH}$ conditions.

\section{Connections between the PHO pathway, the purine pathway and inositol phosphate metabolism}

In yeast, the amount of phosphate in nucleotides resembles the free intracellular orthophosphate concentration, making a co-ordinated regulation of phosphate metabolism and nucleotide synthesis feasible (Gauthier et al. 2008). Furthermore, mutants lacking the genes that encode the adenylate kinase Adk1, catalysing the interconversion of AMP and ATP to ADP (Konrad 1988), or the adenosine kinase Ado1, required for the synthesis of AMP from adenosine and ATP (Lecoq et al. 2001), display a Pho81dependent nuclear translocation of Pho4 and, for instance, constitutive expression of the secreted acid phosphatase Pho5, even under conditions of high extracellular phosphate levels (Auesukaree et al. 2005; Huang and O'Shea 2005; Gauthier et al. 2008). In addition, the expression of PHO genes, i.e. PHO84, appears to be responsive to extracellular adenine (Gauthier et al. 2008). This interconnection of the control of phosphate metabolism and adenylic nucleotides is further reflected in a common requirement of the Pho2 transcriptional cofactor. Indeed, apart from playing a crucial role in the control of phosphate homeostasis, Pho2 together with the transcription factor Bas1 co-regulates the expression of the so-called ADE regulon that includes genes involved in the de novo synthesis of purines (Daignan-Fornier and Fink 1992). Consistently, a recent transcriptome analysis revealed that the 
metabolic intermediate AICAR (5'-phosphoribosyl-5amino-4-imidazole carboxamide), which was previously identified as a transcriptional regulator of the purine pathway genes (Rebora et al. 2001; Rebora et al. 2005), also mediates the expression of several PHO genes (Pinson et al. 2009). These authors reported that Pho4 and Bas1 compete for Pho2 binding and that AICAR stimulates the interaction between either Pho4 or Bas1 with Pho2.

As AICAR is known to stimulate the activity of the AMP-dependent protein kinase in mammalian cells, it was analysed whether the list of AICAR-responsive genes also includes known Snf1 targets. However, no such genes were found, suggesting that regulation of genes targeted by $\mathrm{Pho} 2$ does not involve AICAR activation of Snf1 (Pinson et al. 2009).

Several studies also established a link between phosphate signalling and inositol phosphate metabolism. Strains deleted for PLC1, ARG82 and KCS1 were found to exhibit constitutive expression and activity secreted phosphatases such as Pho5. This phenotype is dependent on a functional Pho81 and corresponds with the inability of these deletion mutants to synthesize PP.IP 4 and $(\mathrm{PP})_{2} \cdot \mathrm{IP}_{3}$ (Auesukaree et al. 2005). Both PP.IP $P_{4}$ and $(\mathrm{PP})_{2} \cdot \mathrm{IP}_{3}$ can apparently inhibit Pho81 and thereby repress the PHO genes under high-phosphate conditions. In contrast, full induction of the PHO genes under phosphate-limiting conditions requires $\mathrm{IP}_{4}$ and $\mathrm{IP}_{5}$. These molecules appear to modulate the activity of the SWI/SNF and INO80 chromatin remodelling complexes, thereby affecting the induction of transcription of some phosphate-responsive genes (Steger et al. 2003). Thus, inositol polyphosphates and inositol pyrophosphates modulate the expression of the PHO genes at different levels and in opposite ways.

\section{Conclusion: integration of nutrient-induced responses}

For both unicellular and multicellular organisms, nutrients are the essential building blocks to make the necessary cellular components and metabolites. As outlined above, nutrients fulfil also regulatory functions since they act as triggers for several signalling pathways. Initial experimental work started from the concept of linear pathways acting in parallel, but along the road this concept changed towards a nutrient-dependent signalling network with extensive cross-talk between pathways at different levels. Furthermore, it is now clear that pathways converge on common effectors. As a consequence, one should bear in mind that the phenotype observed when changing a particular nutritional stimulus, or when the flow through a specific pathway is genetically modified, reflects the action of a signalling network and thus that the propagation of a signal can be enhanced, blocked or redirected dependent on the overall nutrient availability and metabolic status of the yeast cell. Therefore, it is not surprising that central signalling components can exert additive or opposed effects dependent on the target being studied. Perhaps a good way to picture signalling is by the principle of 'gating', which was first reported by Iyengar in 1996 (Iyengar 1996; Jordan and Iyengar 1998). He described that cAMP-activated PKA acts as a gatekeeper to control the flow through several signal transduction cascades in mammalian cells. This phenomenon has been recognized in yeast as well (Roosen et al. 2005). Although both papers concentrated on the gatekeeper function of PKA, it obviously is also applicable to other central kinases and phosphatases operating in a signalling network.

Our insight into the constitution of the nutrient signalling network has been advanced tremendously ever since the whole yeast genome was fully sequenced and new methods became available to study signalling events on a genome-wide scale. Despite all the efforts, there are still crucial gaps to be filled. For instance, we do not know how the intracellular and extracellular glucose sensing systems connect to each other to control the activity of adenylate cyclase and PKA. Neither do we know how nutrients are being sensed to drive the activation of TORC1 and Sch9. One theme that is starting to emerge is the fine-tuning of signalling by intracellular metabolic intermediates, such as the influence of inositol phosphates and intermediates formed by the purine biosynthesis pathway on phosphate signalling. Without doubt there is still a lot to be discovered, certainly when it comes to analysis of the concerted action of different nutritional stimuli. Hence, it can be expected that novel interconnection between individual pathways will be found in the coming years.

Acknowledgments We like to thank the Katholieke Universiteit Leuven, IWT-Vlaanderen and FWO-Vlaanderen for their support to JW and the Swiss National Science Foundation for support to CDV. We also gratefully acknowledge the Leenaards Foundation, and the Canton of Fribourg.

\section{References}

Ahuatzi D, Herrero P, de la Cera T, Moreno F (2004) The glucoseregulated nuclear localization of hexokinase 2 in Saccharomyces cerevisiae is Mig1-dependent. J Biol Chem 279:14440-14446

Ahuatzi D, Riera A, Pelaez R, Herrero P, Moreno F (2007) Hxk2 regulates the phosphorylation state of Mig1 and therefore its nucleocytoplasmic distribution. J Biol Chem 282:4485-4493

Almaguer C, Mantella D, Perez E, Patton-Vogt J (2003) Inositol and phosphate regulate GIT1 transcription and glycerophosphoinositol incorporation in Saccharomyces cerevisiae. Eukaryot Cell 2:729-736

Araki T, Uesono Y, Oguchi T, Toh EA (2005) LAS24/KOG1, a component of the TOR complex 1 (TORC1), is needed for resistance to local anesthetic tetracaine and normal distribution of actin cytoskeleton in yeast. Genes Genet Syst 80:325-343 
Arguelles JC, Mbonyi K, Van Aelst L, Vanhalewyn M, Jans AW, Thevelein JM (1990) Absence of glucose-induced cAMP signaling in the Saccharomyces cerevisiae mutants cat1 and cat3 which are deficient in derepression of glucose-repressible proteins. Arch Microbiol 154:199-205

Arndt KT, Styles CA, Fink GR (1989) A suppressor of a HIS4 transcriptional defect encodes a protein with homology to the catalytic subunit of protein phosphatases. Cell 56:527-537

Aronova S, Wedaman K, Anderson S, Yates J 3rd, Powers T (2007) Probing the membrane environment of the TOR kinases reveals functional interactions between TORC1, actin, and membrane trafficking in Saccharomyces cerevisiae. Mol Biol Cell 18:2779_ 2794

Aronova S, Wedaman K, Aronov PA, Fontes K, Ramos K, Hammock BD, Powers T (2008) Regulation of ceramide biosynthesis by TOR complex 2. Cell Metab 7:148-158

Audhya A, Loewith R, Parsons AB, Gao L, Tabuchi M, Zhou H, Boone C, Hall MN, Emr SD (2004) Genome-wide lethality screen identifies new PI4, 5P2 effectors that regulate the actin cytoskeleton. EMBO J 23:3747-3757

Auesukaree C, Homma T, Kaneko Y, Harashima S (2003) Transcriptional regulation of phosphate-responsive genes in low-affinity phosphate-transporter-defective mutants in Saccharomyces cerevisiae. Biochem Biophys Res Commun 306:843-850

Auesukaree C, Homma T, Tochio H, Shirakawa M, Kaneko Y, Harashima S (2004) Intracellular phosphate serves as a signal for the regulation of the PHO pathway in Saccharomyces cerevisiae. J Biol Chem 279:17289-17294

Auesukaree C, Tochio H, Shirakawa M, Kaneko Y, Harashima S (2005) Plc1p, Arg82p, and Kcs1p, enzymes involved in inositol pyrophosphate synthesis, are essential for phosphate regulation and polyphosphate accumulation in Saccharomyces cerevisiae. J Biol Chem 280:25127-25133

Badis G, Chan ET, van Bakel H, Pena-Castillo L, Tillo D, Tsui K, Carlson CD, Gossett AJ, Hasinoff MJ, Warren CL, Gebbia M, Talukder S, Yang A, Mnaimneh S, Terterov D, Coburn D, Li Yeo A, Yeo ZX, Clarke ND, Lieb JD, Ansari AZ, Nislow C, Hughes TR (2008) A library of yeast transcription factor motifs reveals a widespread function for Rsc3 in targeting nucleosome exclusion at promoters. Mol Cell 32:878-887

Barbet NC, Schneider U, Helliwell SB, Stansfield I, Tuite MF, Hall MN (1996) TOR controls translation initiation and early G1 progression in yeast. Mol Biol Cell 7:25-42

Batlle M, Lu A, Green DA, Xue Y, Hirsch JP (2003) Krh1p and Krh2p act downstream of the Gpa2p G(alpha) subunit to negatively regulate haploid invasive growth. J Cell Sci 116:701-710

Beck T, Hall MN (1999) The TOR signalling pathway controls nuclear localization of nutrient-regulated transcription factors. Nature 402:689-692

Beck T, Schmidt A, Hall MN (1999) Starvation induces vacuolar targeting and degradation of the tryptophan permease in yeast. J Cell Biol 146:1227-1238

Berchtold D, Walther TC (2009) TORC2 plasma membrane localization is essential for cell viability and restricted to a distinct domain. Mol Biol Cell 20:1565-1575

Berger AB, Decourty L, Badis G, Nehrbass U, Jacquier A, Gadal O (2007) Hmol is required for TOR-dependent regulation of ribosomal protein gene transcription. Mol Cell Biol 27:8015-8026

Berset C, Trachsel H, Altmann M (1998) The TOR (target of rapamycin) signal transduction pathway regulates the stability of translation initiation factor eIF4G in the yeast Saccharomyces cerevisiae. Proc Natl Acad Sci USA 95:4264-4269

Bertram PG, Choi JH, Carvalho J, Chan TF, Ai W, Zheng XF (2002) Convergence of TOR-nitrogen and Snf1-glucose signaling pathways onto Gln3. Mol Cell Biol 22:1246-1252
Beullens M, Mbonyi K, Geerts L, Gladines D, Detremerie K, Jans AW, Thevelein JM (1988) Studies on the mechanism of the glucose-induced cAMP signal in glycolysis and glucose repression mutants of the yeast Saccharomyces cerevisiae. Eur J Biochem 172:227-231

Bharucha N, Ma J, Dobry CJ, Lawson SK, Yang Z, Kumar A (2008) Analysis of the yeast kinome reveals a network of regulated protein localization during filamentous growth. Mol Biol Cell 19:2708-2717

Bhoite LT, Stillman DJ (1998) Residues in the Swi5 zinc finger protein that mediate cooperative DNA binding with the Pho2 homeodomain protein. Mol Cell Biol 18:6436-6446

Bhoite LT, Allen JM, Garcia E, Thomas LR, Gregory ID, Voth WP, Whelihan K, Rolfes RJ, Stillman DJ (2002) Mutations in the pho2 (bas2) transcription factor that differentially affect activation with its partner proteins bas1, pho4, and swi5. J Biol Chem 277:37612-37618

Bickle M, Delley PA, Schmidt A, Hall MN (1998) Cell wall integrity modulates RHO1 activity via the exchange factor ROM2. EMBO J 17:2235-2245

Binda M, Peli-Gulli MP, Bonfils G, Panchaud N, Urban J, Sturgill TW, Loewith R, De Virgilio C (2009) The Vam6 GEF controls TORC1 by activating the EGO complex. Mol Cell 35:563-573

Boustany LM, Cyert MS (2002) Calcineurin-dependent regulation of Crz1p nuclear export requires Msn5p and a conserved calcineurin docking site. Genes Dev 16:608-619

Boy-Marcotte E, Perrot M, Bussereau F, Boucherie H, Jacquet M (1998) Msn2p and Msn4p control a large number of genes induced at the diauxic transition which are repressed by cyclic AMP in Saccharomyces cerevisiae. J Bacteriol 180:1044-1052

Broek D, Toda T, Michaeli T, Levin L, Birchmeier C, Zoller M, Powers S, Wigler M (1987) The S. cerevisiae CDC25 gene product regulates the RAS/adenylate cyclase pathway. Cell 48:789-799

Bruun AW, Svendsen I, Sorensen SO, Kielland-Brandt MC, Winther JR (1998) A high-affinity inhibitor of yeast carboxypeptidase Y is encoded by TFS1 and shows homology to a family of lipid binding proteins. Biochemistry 37:3351-3357

Budovskaya YV, Stephan JS, Reggiori F, Klionsky DJ, Herman PK (2004) The Ras/cAMP-dependent protein kinase signaling pathway regulates an early step of the autophagy process in Saccharomyces cerevisiae. J Biol Chem 279:20663-20671

Budovskaya YV, Stephan JS, Deminoff SJ, Herman PK (2005) An evolutionary proteomics approach identifies substrates of the cAMP-dependent protein kinase. Proc Natl Acad Sci USA 102:13933-13938

Butow RA, Avadhani NG (2004) Mitochondrial signaling: the retrograde response. Mol Cell 14:1-15

Caesar R, Blomberg A (2004) The stress-induced Tfs1p requires NatB-mediated acetylation to inhibit carboxypeptidase $\mathrm{Y}$ and to regulate the protein kinase A pathway. J Biol Chem 279:3853238543

Cafferkey R, Young PR, McLaughlin MM, Bergsma DJ, Koltin Y, Sathe GM, Faucette L, Eng WK, Johnson RK, Livi GP (1993) Dominant missense mutations in a novel yeast protein related to mammalian phosphatidylinositol 3-kinase and VPS34 abrogate rapamycin cytotoxicity. Mol Cell Biol 13:6012-6023

Cameroni E, Hulo N, Roosen J, Winderickx J, De Virgilio C (2004) The novel yeast PAS kinase Rim 15 orchestrates G0-associated antioxidant defense mechanisms. Cell Cycle 3:462-468

Camonis JH, Jacquet M (1988) A new RAS mutation that suppresses the CDC25 gene requirement for growth of Saccharomyces cerevisiae. Mol Cell Biol 8:2980-2983

Camus C, Boy-Marcotte E, Jacquet M (1994) Two subclasses of guanine exchange factor (GEF) domains revealed by comparison of activities of chimeric genes constructed from CDC25, SDC25 
and BUD5 in Saccharomyces cerevisiae. Mol Gen Genet 245:167-176

Cardenas ME, Heitman J (1995) FKBP12-rapamycin target TOR2 is a vacuolar protein with an associated phosphatidylinositol-4 kinase activity. EMBO J 14:5892-5907

Cardenas ME, Cutler NS, Lorenz MC, Di Como CJ, Heitman J (1999) The TOR signaling cascade regulates gene expression in response to nutrients. Genes Dev 13:3271-3279

Casamayor A, Torrance PD, Kobayashi T, Thorner J, Alessi DR (1999) Functional counterparts of mammalian protein kinases PDK1 and SGK in budding yeast. Curr Biol 9:186-197

Casperson GF, Walker N, Brasier AR, Bourne HR (1983) A guanine nucleotide-sensitive adenylate cyclase in the yeast Saccharomyces cerevisiae. J Biol Chem 258:7911-7914

Casperson GF, Walker N, Bourne HR (1985) Isolation of the gene encoding adenylate cyclase in Saccharomyces cerevisiae. Proc Natl Acad Sci USA 82:5060-5063

Cazzaniga P, Pescini D, Besozzi D, Mauri G, Colombo S, Martegani E (2008) Modeling and stochastic simulation of the Ras/cAMP/ PKA pathway in the yeast Saccharomyces cerevisiae evidences a key regulatory function for intracellular guanine nucleotides pools. J Biotechnol 133:377-385

Celenza JL, Carlson M (1989) Mutational analysis of the Saccharomyces cerevisiae SNF1 protein kinase and evidence for functional interaction with the SNF4 protein. Mol Cell Biol 9:5034-5044

Celenza JL, Eng FJ, Carlson M (1989) Molecular analysis of the SNF4 gene of Saccharomyces cerevisiae: evidence for physical association of the SNF4 protein with the SNF1 protein kinase. Mol Cell Biol 9:5045-5054

Chang YY, Juhasz G, Goraksha-Hicks P, Arsham AM, Mallin DR, Muller LK, Neufeld TP (2009) Nutrient-dependent regulation of autophagy through the target of rapamycin pathway. Biochem Soc Trans 37:232-236

Chautard H, Jacquet M, Schoentgen F, Bureaud N, Benedetti H (2004) Tfs1p, a member of the PEBP family, inhibits the Ira2p but not the Ira1p Ras GTPase-activating protein in Saccharomyces cerevisiae. Eukaryot Cell 3:459-470

Chen EJ, Kaiser CA (2002) Amino acids regulate the intracellular trafficking of the general amino acid permease of Saccharomyces cerevisiae. Proc Natl Acad Sci USA 99:14837-14842

Chen EJ, Kaiser CA (2003) LST8 negatively regulates amino acid biosynthesis as a component of the TOR pathway. J Cell Biol $161: 333-347$

Cherkasova VA, Hinnebusch AG (2003) Translational control by TOR and TAP42 through dephosphorylation of eIF2alpha kinase GCN2. Genes Dev 17:859-872

Chevtzoff C, Vallortigara J, Averet N, Rigoulet M, Devin A (2005) The yeast cAMP protein kinase Tpk $3 p$ is involved in the regulation of mitochondrial enzymatic content during growth. Biochim Biophys Acta 1706:117-125

Claypool JA, French SL, Johzuka K, Eliason K, Vu L, Dodd JA, Beyer AL, Nomura M (2004) Tor pathway regulates Rrn3pdependent recruitment of yeast RNA polymerase $\mathrm{I}$ to the promoter but does not participate in alteration of the number of active genes. Mol Biol Cell 15:946-956

Coffman JA, Rai R, Cooper TG (1995) Genetic evidence for Gln3pindependent, nitrogen catabolite repression-sensitive gene expression in Saccharomyces cerevisiae. J Bacteriol 177:69106918

Coffman JA, Rai R, Cunningham T, Svetlov V, Cooper TG (1996) Gat1p, a GATA family protein whose production is sensitive to nitrogen catabolite repression, participates in transcriptional activation of nitrogen-catabolic genes in Saccharomyces cerevisiae. Mol Cell Biol 16:847-858
Coffman JA, Rai R, Loprete DM, Cunningham T, Svetlov V, Cooper TG (1997) Cross regulation of four GATA factors that control nitrogen catabolic gene expression in Saccharomyces cerevisiae. J Bacteriol 179:3416-3429

Cohen A, Perzov N, Nelson H, Nelson N (1999) A novel family of yeast chaperons involved in the distribution of V-ATPase and other membrane proteins. J Biol Chem 274:26885-26893

Colombo S, Ma P, Cauwenberg L, Winderickx J, Crauwels M, Teunissen A, Nauwelaers D, de Winde JH, Gorwa MF, Colavizza D, Thevelein JM (1998) Involvement of distinct Gproteins, Gpa2 and Ras, in glucose- and intracellular acidification-induced cAMP signalling in the yeast Saccharomyces cerevisiae. EMBO J 17:3326-3341

Colombo S, Ronchetti D, Thevelein JM, Winderickx J, Martegani E (2004) Activation state of the Ras 2 protein and glucose-induced signaling in Saccharomyces cerevisiae. J Biol Chem 279:4671546722

Cooper TG (2002) Transmitting the signal of excess nitrogen in Saccharomyces cerevisiae from the Tor proteins to the GATA factors: connecting the dots. FEMS Microbiol Rev 26:223-238

Corradetti MN, Guan KL (2006) Upstream of the mammalian target of rapamycin: do all roads pass through mTOR? Oncogene 25:6347-6360

Crauwels M, Donaton MC, Pernambuco MB, Winderickx J, de Winde JH, Thevelein JM (1997a) The Sch9 protein kinase in the yeast Saccharomyces cerevisiae controls cAPK activity and is required for nitrogen activation of the fermentable-growth-mediuminduced (FGM) pathway. Microbiology 143(Pt 8):2627-2637

Crauwels M, Winderickx J, de Winde JH, Thevelein JM (1997b) Identification of genes with nutrient-controlled expression by PCR-mapping in the yeast Saccharomyces cerevisiae. Yeast 13:973-984

Crespo JL, Powers T, Fowler B, Hall MN (2002) The TOR-controlled transcription activators GLN3, RTG1, and RTG3 are regulated in response to intracellular levels of glutamine. Proc Natl Acad Sci USA 99:6784-6789

Cytrynska M, Frajnt M, Jakubowicz T (2001) Saccharomyces cerevisiae pyruvate kinase Pyk1 is PKA phosphorylation substrate in vitro. FEMS Microbiol Lett 203:223-227

Daignan-Fornier B, Fink GR (1992) Coregulation of purine and histidine biosynthesis by the transcriptional activators BAS1 and BAS2. Proc Natl Acad Sci USA 89:6746-6750

Danaie P, Altmann M, Hall MN, Trachsel H, Helliwell SB (1999) CLN3 expression is sufficient to restore G1-to-S-phase progression in Saccharomyces cerevisiae mutants defective in translation initiation factor eIF4E. Biochem J 340(Pt 1):135-141

De Craene JO, Soetens O, Andre B (2001) The Npr1 kinase controls biosynthetic and endocytic sorting of the yeast Gap1 permease. J Biol Chem 276:43939-43948

De Virgilio C, Loewith R (2006a) Cell growth control: little eukaryotes make big contributions. Oncogene 25:6392-6415

De Virgilio C, Loewith R (2006b) The TOR signalling network from yeast to man. Int J Biochem Cell Biol 38:1476-1481

De Vit MJ, Johnston M (1999) The nuclear exportin Msn5 is required for nuclear export of the Mig1 glucose repressor of Saccharomyces cerevisiae. Curr Biol 9:1231-1241

De Vit MJ, Waddle JA, Johnston M (1997) Regulated nuclear translocation of the Mig1 glucose repressor. Mol Biol Cell 8:1603-1618

De Winde JH, Crauwels M, Hohmann S, Thevelein JM, Winderickx J (1996) Differential requirement of the yeast sugar kinases for sugar sensing in establishing the catabolite-repressed state. Eur J Biochem 241:633-643

Devasahayam G, Ritz D, Helliwell SB, Burke DJ, Sturgill TW (2006) Pmr1, a Golgi $\mathrm{Ca} 2+/ \mathrm{Mn} 2+-\mathrm{ATPase}$, is a regulator of the target 
of rapamycin (TOR) signaling pathway in yeast. Proc Natl Acad Sci USA 103:17840-17845

Devasahayam G, Burke DJ, Sturgill TW (2007) Golgi manganese transport is required for rapamycin signaling in Saccharomyces cerevisiae. Genetics 177:231-238

Dever TE, Feng L, Wek RC, Cigan AM, Donahue TF, Hinnebusch AG (1992) Phosphorylation of initiation factor 2 alpha by protein kinase GCN2 mediates gene-specific translational control of GCN4 in yeast. Cell 68:585-596

Di Como CJ, Arndt KT (1996) Nutrients, via the Tor proteins, stimulate the association of Tap42 with type 2A phosphatases. Genes Dev 10:1904-1916

Dihazi H, Kessler R, Eschrich K (2003) Glucose-induced stimulation of the Ras-cAMP pathway in yeast leads to multiple phosphorylations and activation of 6-phosphofructo-2-kinase. Biochemistry $42: 6275-6282$

Dilova I, Chen CY, Powers T (2002) Mks1 in concert with TOR signaling negatively regulates RTG target gene expression in $S$. cerevisiae. Curr Biol 12:389-395

Dilova I, Aronova S, Chen JC, Powers T (2004) Tor signaling and nutrient-based signals converge on Mks1p phosphorylation to regulate expression of Rtg1.Rtg3p-dependent target genes. J Biol Chem 279:46527-46535

Dubouloz F, Deloche O, Wanke V, Cameroni E, De Virgilio C (2005) The TOR and EGO protein complexes orchestrate microautophagy in yeast. Mol Cell 19:15-26

Duvel K, Broach JR (2004) The role of phosphatases in TOR signaling in yeast. Curr Top Microbiol Immunol 279:19-38

Duvel K, Santhanam A, Garrett S, Schneper L, Broach JR (2003) Multiple roles of Tap42 in mediating rapamycin-induced transcriptional changes in yeast. Mol Cell 11:1467-1478

Entian KD (1980) Genetic and biochemical evidence for hexokinase PII as a key enzyme involved in carbon catabolite repression in yeast. Mol Gen Genet 178:633-637

Entian KD, Zimmermann FK (1980) Glycolytic enzymes and intermediates in carbon catabolite repression mutants of Saccharomyces cerevisiae. Mol Gen Genet 177:345-350

Estruch F, Carlson M (1993) Two homologous zinc finger genes identified by multicopy suppression in a SNF1 protein kinase mutant of Saccharomyces cerevisiae. Mol Cell Biol 13:3872-3881

Estruch F, Treitel MA, Yang X, Carlson M (1992) N-terminal mutations modulate yeast SNF1 protein kinase function. Genetics 132:639-650

Fadri M, Daquinag A, Wang S, Xue T, Kunz J (2005) The pleckstrin homology domain proteins $\operatorname{Slm} 1$ and $\operatorname{Slm} 2$ are required for actin cytoskeleton organization in yeast and bind phosphatidylinositol4,5-bisphosphate and TORC2. Mol Biol Cell 16:1883-1900

Fayard E, Tintignac LA, Baudry A, Hemmings BA (2005) Protein kinase B/Akt at a glance. J Cell Sci 118:5675-5678

Ferguson SB, Anderson ES, Harshaw RB, Thate T, Craig NL, Nelson HC (2005) Protein kinase A regulates constitutive expression of small heat-shock genes in an Msn2/4p-independent and Hsf1p-dependent manner in Saccharomyces cerevisiae. Genetics 169:1203-1214

Field J, Nikawa J, Broek D, MacDonald B, Rodgers L, Wilson IA, Lerner RA, Wigler M (1988) Purification of a RAS-responsive adenylyl cyclase complex from Saccharomyces cerevisiae by use of an epitope addition method. Mol Cell Biol 8:2159-2165

Flick JS, Thorner J (1998) An essential function of a phosphoinositide-specific phospholipase $\mathrm{C}$ is relieved by inhibition of a cyclin-dependent protein kinase in the yeast Saccharomyces cerevisiae. Genetics 148:33-47

Forsberg H, Ljungdahl PO (2001) Sensors of extracellular nutrients in Saccharomyces cerevisiae. Curr Genet 40:91-109

Friant S, Lombardi R, Schmelzle T, Hall MN, Riezman H (2001) Sphingoid base signaling via $\mathrm{Pkh}$ kinases is required for endocytosis in yeast. EMBO J 20:6783-6792
Funakoshi T, Matsuura A, Noda T, Ohsumi Y (1997) Analyses of APG13 gene involved in autophagy in yeast, Saccharomyces cerevisiae. Gene 192:207-213

Gancedo JM (1998) Yeast carbon catabolite repression. Microbiol Mol Biol Rev 62:334-361

Gancedo JM (2008) The early steps of glucose signalling in yeast. FEMS Microbiol Rev 32:673-704

Gancedo JM, Mazon MJ, Gancedo C (1983) Fructose 2,6-bisphosphate activates the cAMP-dependent phosphorylation of yeast fructose-1,6-bisphosphatase in vitro. J Biol Chem 258:5998 5999

Gander S, Bonenfant D, Altermatt P, Martin DE, Hauri S, Moes S, Hall MN, Jenoe P (2008) Identification of the rapamycinsensitive phosphorylation sites within the Ser/Thr-rich domain of the yeast Npr1 protein kinase. Rapid Commun Mass Spectrom 22:3743-3753

Gao M, Kaiser CA (2006) A conserved GTPase-containing complex is required for intracellular sorting of the general amino-acid permease in yeast. Nat Cell Biol 8:657-667

Garreau H, Hasan RN, Renault G, Estruch F, Boy-Marcotte E, Jacquet M (2000) Hyperphosphorylation of Msn2p and Msn4p in response to heat shock and the diauxic shift is inhibited by cAMP in Saccharomyces cerevisiae. Microbiology $146(\mathrm{Pt}$ 9):2113-2120

Garrett S, Broach J (1989) Loss of Ras activity in Saccharomyces cerevisiae is suppressed by disruptions of a new kinase gene, YAKI, whose product may act downstream of the cAMPdependent protein kinase. Genes Dev 3:1336-1348

Garrett S, Menold MM, Broach JR (1991) The Saccharomyces cerevisiae YAK1 gene encodes a protein kinase that is induced by arrest early in the cell cycle. Mol Cell Biol 11:4045-4052

Gasch AP, Spellman PT, Kao CM, Carmel-Harel O, Eisen MB, Storz G, Botstein D, Brown PO (2000) Genomic expression programs in the response of yeast cells to environmental changes. Mol Biol Cell 11:4241-4257

Gauthier S, Coulpier F, Jourdren L, Merle M, Beck S, Konrad M, Daignan-Fornier B, Pinson B (2008) Co-regulation of yeast purine and phosphate pathways in response to adenylic nucleotide variations. Mol Microbiol 68:1583-1594

Georis I, Tate JJ, Cooper TG, Dubois E (2008) Tor pathway control of the nitrogen-responsive DAL5 gene bifurcates at the level of Gln3 and Gat1 regulation in Saccharomyces cerevisiae. J Biol Chem 283:8919-8929

Geyskens I, Kumara SHMC, Donaton MCV, Bergsma JCT, Thevelein JM, Wera S (2001) Expression of mammalian PKB complements deletion of the yeast protein kinase Sch9. Nato Sci Ser A316:117-126

Gilliquet V, Berben G (1993) Positive and negative regulators of the Saccharomyces cerevisiae 'PHO system' participate in several cell functions. FEMS Microbiol Lett 108:333-339

Godard P, Urrestarazu A, Vissers S, Kontos K, Bontempi G, van Helden J, Andre B (2007) Effect of 21 different nitrogen sources on global gene expression in the yeast Saccharomyces cerevisiae. Mol Cell Biol 27:3065-3086

Gorner W, Durchschlag E, Martinez-Pastor MT, Estruch F, Ammerer G, Hamilton B, Ruis H, Schuller C (1998) Nuclear localization of the $\mathrm{C} 2 \mathrm{H} 2$ zinc finger protein Msn2p is regulated by stress and protein kinase A activity. Genes Dev 12:586-597

Gorner W, Durchschlag E, Wolf J, Brown EL, Ammerer G, Ruis H, Schuller C (2002) Acute glucose starvation activates the nuclear localization signal of a stress-specific yeast transcription factor. EMBO J 21:135-144

Griffioen G, Mager WH, Planta RJ (1994) Nutritional upshift response of ribosomal protein gene transcription in Saccharomyces cerevisiae. FEMS Microbiol Lett 123:137-144

Griffioen G, Anghileri P, Imre E, Baroni MD, Ruis H (2000) Nutritional control of nucleocytoplasmic localization of 
cAMP-dependent protein kinase catalytic and regulatory subunits in Saccharomyces cerevisiae. J Biol Chem 275:1449-1456

Griffioen G, Branduardi P, Ballarini A, Anghileri P, Norbeck J, Baroni MD, Ruis H (2001) Nucleocytoplasmic distribution of budding yeast protein kinase A regulatory subunit Bcy1 requires Zds1 and is regulated by Yak1-dependent phosphorylation of its targeting domain. Mol Cell Biol 21:511-523

Hahn JS, Thiele DJ (2004) Activation of the Saccharomyces cerevisiae heat shock transcription factor under glucose starvation conditions by Snf1 protein kinase. J Biol Chem 279:51695176

Hahn JS, Hu Z, Thiele DJ, Iyer VR (2004) Genome-wide analysis of the biology of stress responses through heat shock transcription factor. Mol Cell Biol 24:5249-5256

Hall DB, Wade JT, Struhl K (2006) An HMG protein, Hmo1, associates with promoters of many ribosomal protein genes and throughout the rRNA gene locus in Saccharomyces cerevisiae. Mol Cell Biol 26:3672-3679

Harashima T, Heitman J (2002) The Galpha protein Gpa2 controls yeast differentiation by interacting with kelch repeat proteins that mimic Gbeta subunits. Mol Cell 10:163-173

Harashima T, Heitman J (2005) Galpha subunit Gpa2 recruits kelch repeat subunits that inhibit receptor-G protein coupling during cAMP-induced dimorphic transitions in Saccharomyces cerevisiae. Mol Biol Cell 16:4557-4571

Harashima T, Anderson S, Yates JR 3rd, Heitman J (2006) The kelch proteins Gpb1 and Gpb2 inhibit Ras activity via association with the yeast RasGAP neurofibromin homologs Ira1 and Ira2. Mol Cell 22:819-830

Hardie DG (2007) AMP-activated/SNF1 protein kinases: conserved guardians of cellular energy. Nat Rev Mol Cell Biol 8:774-785

Hardwick JS, Kuruvilla FG, Tong JK, Shamji AF, Schreiber SL (1999) Rapamycin-modulated transcription defines the subset of nutrient-sensitive signaling pathways directly controlled by the Tor proteins. Proc Natl Acad Sci USA 96:14866-14870

Hardy TA, Roach PJ (1993) Control of yeast glycogen synthase-2 by COOH-terminal phosphorylation. J Biol Chem 268:2379923805

Hartley AD, Ward MP, Garrett S (1994) The Yak1 protein kinase of Saccharomyces cerevisiae moderates thermotolerance and inhibits growth by an Sch9 protein kinase-independent mechanism. Genetics 136:465-474

Healy AM, Zolnierowicz S, Stapleton AE, Goebl M, DePaoli-Roach AA, Pringle JR (1991) CDC55, a Saccharomyces cerevisiae gene involved in cellular morphogenesis: identification, characterization, and homology to the B subunit of mammalian type $2 \mathrm{~A}$ protein phosphatase. Mol Cell Biol 11:5767-5780

Hedbacker K, Carlson M (2006) Regulation of the nucleocytoplasmic distribution of Snf1-Gal83 protein kinase. Eukaryot Cell 5:1950 1956

Hedbacker K, Carlson M (2008) SNF1/AMPK pathways in yeast. Front Biosci 13:2408-2420

Hedbacker K, Hong SP, Carlson M (2004) Pak1 protein kinase regulates activation and nuclear localization of Snf1-Gal83 protein kinase. Mol Cell Biol 24:8255-8263

Hedges D, Proft M, Entian KD (1995) CAT8, a new zinc clusterencoding gene necessary for derepression of gluconeogenic enzymes in the yeast Saccharomyces cerevisiae. Mol Cell Biol 15:1915-1922

Heitman J, Movva NR, Hall MN (1991) Targets for cell cycle arrest by the immunosuppressant rapamycin in yeast. Science 253:905-909

Helliwell SB, Wagner P, Kunz J, Deuter-Reinhard M, Henriquez R, Hall MN (1994) TOR1 and TOR2 are structurally and functionally similar but not identical phosphatidylinositol kinase homologues in yeast. Mol Biol Cell 5:105-118
Helliwell SB, Schmidt A, Ohya Y, Hall MN (1998) The Rho1 effector Pkc1, but not Bni1, mediates signalling from Tor2 to the actin cytoskeleton. Curr Biol 8:1211-1214

Helliwell SB, Losko S, Kaiser CA (2001) Components of a ubiquitin ligase complex specify polyubiquitination and intracellular trafficking of the general amino acid permease. J Cell Biol 153:649-662

Herrero P, Martinez-Campa C, Moreno F (1998) The hexokinase 2 protein participates in regulatory DNA-protein complexes necessary for glucose repression of the SUC2 gene in Saccharomyces cerevisiae. FEBS Lett 434:71-76

Herruer MH, Mager WH, Woudt LP, Nieuwint RT, Wassenaar GM, Groeneveld P, Planta RJ (1987) Transcriptional control of yeast ribosomal protein synthesis during carbon-source upshift. Nucleic Acids Res 15:10133-10144

Hiesinger M, Roth S, Meissner E, Schuller HJ (2001) Contribution of Cat8 and Sip4 to the transcriptional activation of yeast gluconeogenic genes by carbon source-responsive elements. Curr Genet 39:68-76

Hinnebusch AG (2005) Translational regulation of GCN4 and the general amino acid control of yeast. Annu Rev Microbiol 59:407-450

Ho HL, Lee HY, Liao HC, Chen MY (2008) Involvement of Saccharomyces cerevisiae Avo3p/Tsc11p in maintaining TOR complex 2 integrity and coupling to downstream signaling. Eukaryot Cell 7:1328-1343

Hohmann S, Winderickx J, de Winde JH, Valckx D, Cobbaert P, Luyten K, de Meirsman C, Ramos J, Thevelein JM (1999) Novel alleles of yeast hexokinase PII with distinct effects on catalytic activity and catabolite repression of SUC2. Microbiology 145(Pt 3):703-714

Hohmann S, Krantz M, Nordlander B (2007) Yeast osmoregulation. Methods Enzymol 428:29-45

Holsbeeks I, Lagatie O, Van Nuland A, Van de Velde S, Thevelein JM (2004) The eukaryotic plasma membrane as a nutrientsensing device. Trends Biochem Sci 29:556-564

Hong SP, Momcilovic M, Carlson M (2005) Function of mammalian LKB1 and $\mathrm{Ca} 2+/$ calmodulin-dependent protein kinase kinase alpha as Snf1-activating kinases in yeast. J Biol Chem 280:21804-21809

Huang S, O'Shea EK (2005) A systematic high-throughput screen of a yeast deletion collection for mutants defective in PHO5 regulation. Genetics 169:1859-1871

Huang D, Chun KT, Goebl MG, Roach PJ (1996) Genetic interactions between REG1/HEX2 and GLC7, the gene encoding the protein phosphatase type 1 catalytic subunit in Saccharomyces cerevisiae. Genetics 143:119-127

Huang S, Jeffery DA, Anthony MD, O'Shea EK (2001) Functional analysis of the cyclin-dependent kinase inhibitor Pho81 identifies a novel inhibitory domain. Mol Cell Biol 21:6695-6705

Huang D, Moffat J, Andrews B (2002) Dissection of a complex phenotype by functional genomics reveals roles for the yeast cyclin-dependent protein kinase Pho85 in stress adaptation and cell integrity. Mol Cell Biol 22:5076-5088

Huang D, Friesen H, Andrews B (2007a) Pho85, a multifunctional cyclin-dependent protein kinase in budding yeast. Mol Microbiol 66:303-314

Huang K, Ferrin-O'Connell I, Zhang W, Leonard GA, O'Shea EK, Quiocho FA (2007b) Structure of the Pho85-Pho80 CDK-cyclin complex of the phosphate-responsive signal transduction pathway. Mol Cell 28:614-623

Huber A, Bodenmiller B, Uotila A, Stahl M, Wanka S, Gerrits B, Aebersold R, Loewith R (2009) Characterization of the rapamycin-sensitive phosphoproteome reveals that Sch9 is a central coordinator of protein synthesis. Genes Dev 23:1929 1943 
Hurlimann HC, Stadler-Waibel M, Werner TP, Freimoser FM (2007) Pho91 Is a vacuolar phosphate transporter that regulates phosphate and polyphosphate metabolism in Saccharomyces cerevisiae. Mol Biol Cell 18:4438-4445

Hurlimann HC, Pinson B, Stadler-Waibel M, Zeeman SC, Freimoser FM (2009) The SPX domain of the yeast low-affinity phosphate transporter Pho90 regulates transport activity. EMBO Rep 10:1003-1008

Iyengar R (1996) Gating by cyclic AMP: expanded role for an old signaling pathway. Science 271:461-463

Jacinto E, Guo B, Arndt KT, Schmelzle T, Hall MN (2001) TIP41 interacts with TAP42 and negatively regulates the TOR signaling pathway. Mol Cell 8:1017-1026

Jiang Y, Broach JR (1999) Tor proteins and protein phosphatase 2A reciprocally regulate Tap42 in controlling cell growth in yeast. EMBO J 18:2782-2792

Jiang R, Carlson M (1996) Glucose regulates protein interactions within the yeast SNF1 protein kinase complex. Genes Dev 10:3105-3115

Jiang R, Carlson M (1997) The Snf1 protein kinase and its activating subunit, Snf4, interact with distinct domains of the Sip1/Sip2/ Gal83 component in the kinase complex. Mol Cell Biol 17:2099-2106

Jones S, Vignais ML, Broach JR (1991) The CDC25 protein of Saccharomyces cerevisiae promotes exchange of guanine nucleotides bound to ras. Mol Cell Biol 11:2641-2646

Jordan JD, Iyengar R (1998) Modes of interactions between signaling pathways. Biochem Pharmacol 55:1347-1352

Jorgensen P, Nishikawa JL, Breitkreutz BJ, Tyers M (2002) Systematic identification of pathways that couple cell growth and division in yeast. Science 297:395-400

Jorgensen P, Rupes I, Sharom JR, Schneper L, Broach JR, Tyers M (2004) A dynamic transcriptional network communicates growth potential to ribosome synthesis and critical cell size. Genes Dev 18:2491-2505

Kafadar KA, Cyert MS (2004) Integration of stress responses: modulation of calcineurin signaling in Saccharomyces cerevisiae by protein kinase A. Eukaryot Cell 3:1147-1153

Kafadar KA, Zhu H, Snyder M, Cyert MS (2003) Negative regulation of calcineurin signaling by Hrr25p, a yeast homolog of casein kinase I. Genes Dev 17:2698-2708

Kaffman A, Rank NM, O’Neill EM, Huang LS, O'Shea EK (1998a) The receptor Msn5 exports the phosphorylated transcription factor Pho4 out of the nucleus. Nature 396:482-486

Kaffman A, Rank NM, O'Shea EK (1998b) Phosphorylation regulates association of the transcription factor Pho4 with its import receptor Pse1/Kap121. Genes Dev 12:2673-2683

Kamada Y, Funakoshi T, Shintani T, Nagano K, Ohsumi M, Ohsumi Y (2000) Tor-mediated induction of autophagy via an Apg1 protein kinase complex. J Cell Biol 150:1507-1513

Kamada Y, Fujioka Y, Suzuki NN, Inagaki F, Wullschleger S, Loewith R, Hall MN, Ohsumi Y (2005) Tor2 directly phosphorylates the AGC kinase Ypk2 to regulate actin polarization. Mol Cell Biol 25:7239-7248

Kataoka T, Broek D, Wigler M (1985) DNA sequence and characterization of the $S$. cerevisiae gene encoding adenylate cyclase. Cell 43:493-505

Keith CT, Schreiber SL (1995) PIK-related kinases: DNA repair, recombination, and cell cycle checkpoints. Science 270:50-51

Keleher CA, Redd MJ, Schultz J, Carlson M, Johnson AD (1992) Ssn6-Tup1 is a general repressor of transcription in yeast. Cell 68:709-719

Kim EM, Jang YK, Park SD (2002) Phosphorylation of Rph1, a damage-responsive repressor of PHR1 in Saccharomyces cerevisiae, is dependent upon Rad53 kinase. Nucleic Acids Res 30:643-648
Kim MD, Hong SP, Carlson M (2005) Role of Tos3, a Snf1 protein kinase kinase, during growth of Saccharomyces cerevisiae on nonfermentable carbon sources. Eukaryot Cell 4:861-866

Kim E, Goraksha-Hicks P, Li L, Neufeld TP, Guan KL (2008) Regulation of TORC1 by Rag GTPases in nutrient response. Nat Cell Biol 10:935-945

Klionsky DJ, Emr SD (1989) Membrane protein sorting: biosynthesis, transport and processing of yeast vacuolar alkaline phosphatase. EMBO J 8:2241-2250

Knight JP, Daly TM, Bergman LW (2004) Regulation by phosphorylation of Pho81p, a cyclin-dependent kinase inhibitor in Saccharomyces cerevisiae. Curr Genet 46:10-19

Komeili A, Wedaman KP, O'Shea EK, Powers T (2000) Mechanism of metabolic control. Target of rapamycin signaling links nitrogen quality to the activity of the Rtg1 and Rtg 3 transcription factors. J Cell Biol 151:863-878

Konrad M (1988) Analysis and in vivo disruption of the gene coding for adenylate kinase (ADK1) in the yeast Saccharomyces cerevisiae. J Biol Chem 263:19468-19474

Kraakman LS, Griffioen G, Zerp S, Groeneveld P, Thevelein JM, Mager WH, Planta RJ (1993) Growth-related expression of ribosomal protein genes in Saccharomyces cerevisiae. Mol Gen Genet 239:196-204

Kraakman L, Lemaire K, Ma P, Teunissen AW, Donaton MC, Van Dijck P, Winderickx J, de Winde JH, Thevelein JM (1999a) A Saccharomyces cerevisiae G-protein coupled receptor, Gpr1, is specifically required for glucose activation of the cAMP pathway during the transition to growth on glucose. Mol Microbiol 32:1002-1012

Kraakman LS, Winderickx J, Thevelein JM, De Winde JH (1999b) Structure-function analysis of yeast hexokinase: structural requirements for triggering cAMP signalling and catabolite repression. Biochem J 343:159-168

Kubler E, Mosch HU, Rupp S, Lisanti MP (1997) Gpa2p, a G-protein alpha-subunit, regulates growth and pseudohyphal development in Saccharomyces cerevisiae via a cAMP-dependent mechanism. J Biol Chem 272:20321-20323

Kubota H, Obata T, Ota K, Sasaki T, Ito T (2003) Rapamycininduced translational derepression of GCN4 mRNA involves a novel mechanism for activation of the eIF2 alpha kinase GCN2. J Biol Chem 278:20457-20460

Kuepfer L, Peter M, Sauer U, Stelling J (2007) Ensemble modeling for analysis of cell signaling dynamics. Nat Biotechnol 25:10011006

Kunz J, Henriquez R, Schneider U, Deuter-Reinhard M, Movva NR, Hall MN (1993) Target of rapamycin in yeast, TOR2, is an essential phosphatidylinositol kinase homolog required for G1 progression. Cell 73:585-596

Kunz J, Schneider U, Howald I, Schmidt A, Hall MN (2000) HEAT repeats mediate plasma membrane localization of Tor $2 p$ in yeast. J Biol Chem 275:37011-37020

Kuret J, Johnson KE, Nicolette C, Zoller MJ (1988) Mutagenesis of the regulatory subunit of yeast cAMP-dependent protein kinase. Isolation of site-directed mutants with altered binding affinity for catalytic subunit. J Biol Chem 263:9149-9154

Kuruvilla FG, Shamji AF, Schreiber SL (2001) Carbon- and nitrogenquality signaling to translation are mediated by distinct GATAtype transcription factors. Proc Natl Acad Sci USA 98:72837288

Lecoq K, Belloc I, Desgranges C, Daignan-Fornier B (2001) Role of adenosine kinase in Saccharomyces cerevisiae: identification of the ADO1 gene and study of the mutant phenotypes. Yeast $18: 335-342$

Lee M, O'Regan S, Moreau JL, Johnson AL, Johnston LH, Goding CR (2000) Regulation of the Pcl7-Pho85 cyclin-cdk complex by Pho81. Mol Microbiol 38:411-422 
Lee TI, Rinaldi NJ, Robert F, Odom DT, Bar-Joseph Z, Gerber GK, Hannett NM, Harbison CT, Thompson CM, Simon I, Zeitlinger J, Jennings EG, Murray HL, Gordon DB, Ren B, Wyrick JJ, Tagne JB, Volkert TL, Fraenkel E, Gifford DK, Young RA (2002) Transcriptional regulatory networks in Saccharomyces cerevisiae. Science 298:799-804

Lee YS, Mulugu S, York JD, O'Shea EK (2007) Regulation of a cyclin-CDK-CDK inhibitor complex by inositol pyrophosphates. Science 316:109-112

Lee P, Cho BR, Joo HS, Hahn JS (2008a) Yeast Yak1 kinase, a bridge between PKA and stress-responsive transcription factors, Hsf1 and Msn2/Msn4. Mol Microbiol 70:882-895

Lee YS, Huang K, Quiocho FA, O'Shea EK (2008b) Molecular basis of cyclin-CDK-CKI regulation by reversible binding of an inositol pyrophosphate. Nat Chem Biol 4:25-32

Lee J, Moir RD, Willis IM (2009) Regulation of RNA polymerase III transcription involves SCH9-dependent and -independent branches of the TOR pathway. J Biol Chem 284:12604-12608

Lemaire K, Van de Velde S, Van Dijck P, Thevelein JM (2004) Glucose and sucrose act as agonist and mannose as antagonist ligands of the $\mathrm{G}$ protein-coupled receptor Gpr1 in the yeast Saccharomyces cerevisiae. Mol Cell 16:293-299

Lemmon MA (2008) Membrane recognition by phospholipid-binding domains. Nat Rev Mol Cell Biol 9:99-111

Lempiainen H, Uotila A, Urban J, Dohnal I, Ammerer G, Loewith R, Shore D (2009) Sfp1 interaction with TORC1 and Mrs6 reveals feedback regulation on TOR signaling. Mol Cell 33:704-716

Lenburg ME, O'Shea EK (1996) Signaling phosphate starvation. Trends Biochem Sci 21:383-387

Lenssen E, Oberholzer U, Labarre J, De Virgilio C, Collart MA (2002) Saccharomyces cerevisiae Ccr4-not complex contributes to the control of Msn2p-dependent transcription by the Ras/ cAMP pathway. Mol Microbiol 43:1023-1037

Lenssen E, James N, Pedruzzi I, Dubouloz F, Cameroni E, Bisig R, Maillet L, Werner M, Roosen J, Petrovic K, Winderickx J, Collart MA, De Virgilio C (2005) The Ccr4-Not complex independently controls both Msn2-dependent transcriptional activation-via a newly identified Glc7/Bud14 type I protein phosphatase module-and TFIID promoter distribution. Mol Cell Biol 25:488-498

Lesage P, Yang X, Carlson M (1996) Yeast SNF1 protein kinase interacts with SIP4, a C6 zinc cluster transcriptional activator: a new role for SNF1 in the glucose response. Mol Cell Biol 16:1921-1928

Levin DE (2005) Cell wall integrity signaling in Saccharomyces cerevisiae. Microbiol Mol Biol Rev 69:262-291

Li H, Tsang CK, Watkins M, Bertram PG, Zheng XF (2006) Nutrient regulates Tor1 nuclear localization and association with rDNA promoter. Nature 442:1058-1061

Liko D, Slattery MG, Heideman W (2007) Stb3 binds to ribosomal RNA processing element motifs that control transcriptional responses to growth in Saccharomyces cerevisiae. J Biol Chem 282:26623-26628

Liu Z, Butow RA (2006) Mitochondrial retrograde signaling. Annu Rev Genet 40:159-185

Liu C, Yang Z, Yang J, Xia Z, Ao S (2000) Regulation of the yeast transcriptional factor $\mathrm{PHO} 2$ activity by phosphorylation. J Biol Chem 275:31972-31978

Liu Z, Sekito T, Spirek M, Thornton J, Butow RA (2003) Retrograde signaling is regulated by the dynamic interaction between $R \operatorname{tg} 2 p$ and Mks1p. Mol Cell 12:401-411

Liu K, Zhang X, Lester RL, Dickson RC (2005a) The sphingoid long chain base phytosphingosine activates AGC-type protein kinases in Saccharomyces cerevisiae including Ypk1, Ypk2, and Sch9. J Biol Chem 280:22679-22687
Liu K, Zhang X, Sumanasekera C, Lester RL, Dickson RC (2005b) Signalling functions for sphingolipid long-chain bases in Saccharomyces cerevisiae. Biochem Soc Trans 33:1170-1173

Lo WS, Duggan L, Emre NC, Belotserkovskya R, Lane WS, Shiekhattar R, Berger SL (2001) Snf1-a histone kinase that works in concert with the histone acetyltransferase Gcn5 to regulate transcription. Science 293:1142-1146

Loewith R, Jacinto E, Wullschleger S, Lorberg A, Crespo JL, Bonenfant D, Oppliger W, Jenoe P, Hall MN (2002) Two TOR complexes, only one of which is rapamycin sensitive, have distinct roles in cell growth control. Mol Cell 10:457-468

Lorenz MC, Heitman J (1997) Yeast pseudohyphal growth is regulated by GPA2, a $\mathrm{G}$ protein alpha homolog. EMBO J 16:7008-7018

Lorenz MC, Pan X, Harashima T, Cardenas ME, Xue Y, Hirsch JP, Heitman J (2000) The G protein-coupled receptor gpr1 is a nutrient sensor that regulates pseudohyphal differentiation in Saccharomyces cerevisiae. Genetics 154:609-622

Lu A, Hirsch JP (2005) Cyclic AMP-independent regulation of protein kinase A substrate phosphorylation by Kelch repeat proteins. Eukaryot Cell 4:1794-1800

Ludin K, Jiang R, Carlson M (1998) Glucose-regulated interaction of a regulatory subunit of protein phosphatase 1 with the Snf1 protein kinase in Saccharomyces cerevisiae. Proc Natl Acad Sci USA 95:6245-6250

Luke MM, Della Seta F, Di Como CJ, Sugimoto H, Kobayashi R, Arndt KT (1996) The SAP, a new family of proteins, associate and function positively with the SIT4 phosphatase. Mol Cell Biol 16:2744-2755

Lundin M, Nehlin JO, Ronne H (1994) Importance of a flanking ATrich region in target site recognition by the GC box-binding zinc finger protein MIG1. Mol Cell Biol 14:1979-1985

Ma H, Bloom LM, Walsh CT, Botstein D (1989) The residual enzymatic phosphorylation activity of hexokinase II mutants is correlated with glucose repression in Saccharomyces cerevisiae. Mol Cell Biol 9:5643-5649

Magasanik B, Kaiser CA (2002) Nitrogen regulation in Saccharomyces cerevisiae. Gene 290:1-18

Magbanua JP, Ogawa N, Harashima S, Oshima Y (1997) The transcriptional activators of the $\mathrm{PHO}$ regulon, Pho4p and Pho2p, interact directly with each other and with components of the basal transcription machinery in Saccharomyces cerevisiae. $\mathrm{J}$ Biochem 121:1182-1189

Mai B, Breeden L (1997) Xbp1, a stress-induced transcriptional repressor of the Saccharomyces cerevisiae Swi4/Mbp1 family. Mol Cell Biol 17:6491-6501

Marion RM, Regev A, Segal E, Barash Y, Koller D, Friedman N, O'Shea EK (2004) Sfp1 is a stress- and nutrient-sensitive regulator of ribosomal protein gene expression. Proc Natl Acad Sci USA 101:14315-14322

Martin DE, Soulard A, Hall MN (2004) TOR regulates ribosomal protein gene expression via PKA and the Forkhead transcription factor FHL1. Cell 119:969-979

Martinez-Pastor MT, Marchler G, Schuller C, Marchler-Bauer A, Ruis H, Estruch F (1996) The Saccharomyces cerevisiae zinc finger proteins Msn2p and Msn4p are required for transcriptional induction through the stress response element (STRE). EMBO J 15:2227-2235

Matheos DP, Kingsbury TJ, Ahsan US, Cunningham KW (1997) Tcn1p/Crz1p, a calcineurin-dependent transcription factor that differentially regulates gene expression in Saccharomyces cerevisiae. Genes Dev 11:3445-3458

Matsumoto K, Uno I, Ishikawa T (1983) Initiation of meiosis in yeast mutants defective in adenylate cyclase and cyclic AMP-dependent protein kinase. Cell 32:417-423 
Matsumoto K, Uno I, Ishikawa T (1984) Identification of the structural gene and nonsense alleles for adenylate cyclase in Saccharomyces cerevisiae. J Bacteriol 157:277-282

Mayordomo I, Sanz P (2001) Hexokinase PII: structural analysis and glucose signalling in the yeast Saccharomyces cerevisiae. Yeast 18:923-930

Mayordomo I, Estruch F, Sanz P (2002) Convergence of the target of rapamycin and the Snf1 protein kinase pathways in the regulation of the subcellular localization of Msn2, a transcriptional activator of STRE (Stress Response Element)-regulated genes. J Biol Chem 277:35650-35656

Mbonyi K, Beullens M, Detremerie K, Geerts L, Thevelein JM (1988) Requirement of one functional RAS gene and inability of an oncogenic ras variant to mediate the glucose-induced cyclic AMP signal in the yeast Saccharomyces cerevisiae. Mol Cell Biol 8:3051-3057

Mbonyi K, van Aelst L, Arguelles JC, Jans AW, Thevelein JM (1990) Glucose-induced hyperaccumulation of cyclic AMP and defective glucose repression in yeast strains with reduced activity of cyclic AMP-dependent protein kinase. Mol Cell Biol 10:45184523

McCartney RR, Schmidt MC (2001) Regulation of Snf1 kinase. Activation requires phosphorylation of threonine 210 by an upstream kinase as well as a distinct step mediated by the Snf4 subunit. J Biol Chem 276:36460-36466

McCartney RR, Rubenstein EM, Schmidt MC (2005) Snf1 kinase complexes with different beta subunits display stress-dependent preferences for the three Snf1-activating kinases. Curr Genet 47:335-344

Measday V, Moore L, Retnakaran R, Lee J, Donoviel M, Neiman AM, Andrews B (1997) A family of cyclin-like proteins that interact with the Pho85 cyclin-dependent kinase. Mol Cell Biol 17:1212-1223

Minehart PL, Magasanik B (1991) Sequence and expression of GLN3, a positive nitrogen regulatory gene of Saccharomyces cerevisiae encoding a protein with a putative zinc finger DNAbinding domain. Mol Cell Biol 11:6216-6228

Mitchelhill KI, Stapleton D, Gao G, House C, Michell B, Katsis F, Witters LA, Kemp BE (1994) Mammalian AMP-activated protein kinase shares structural and functional homology with the catalytic domain of yeast Snf1 protein kinase. J Biol Chem 269:2361-2364

Moir RD, Lee J, Haeusler RA, Desai N, Engelke DR, Willis IM (2006) Protein kinase A regulates RNA polymerase III transcription through the nuclear localization of Maf1. Proc Natl Acad Sci USA 103:15044-15049

Momcilovic M, Iram SH, Liu Y, Carlson M (2008) Roles of the glycogen-binding domain and Snf4 in glucose inhibition of SNF1 protein kinase. J Biol Chem 283:19521-19529

Moriya H, Shimizu-Yoshida Y, Omori A, Iwashita S, Katoh M, Sakai A (2001) Yak1p, a DYRK family kinase, translocates to the nucleus and phosphorylates yeast Pop2p in response to a glucose signal. Genes Dev 15:1217-1228

Moskvina E, Schuller C, Maurer CT, Mager WH, Ruis H (1998) A search in the genome of Saccharomyces cerevisiae for genes regulated via stress response elements. Yeast 14:1041-1050

Nakafuku M, Obara T, Kaibuchi K, Miyajima I, Miyajima A, Itoh H, Nakamura S, Arai K, Matsumoto K, Kaziro Y (1988) Isolation of a second yeast Saccharomyces cerevisiae gene (GPA2) coding for guanine nucleotide-binding regulatory protein: studies on its structure and possible functions. Proc Natl Acad Sci USA 85:1374-1378

Natarajan K, Meyer MR, Jackson BM, Slade D, Roberts C, Hinnebusch AG, Marton MJ (2001) Transcriptional profiling shows that Gen $4 p$ is a master regulator of gene expression during amino acid starvation in yeast. Mol Cell Biol 21:4347-4368
Nehlin JO, Ronne H (1990) Yeast MIG1 repressor is related to the mammalian early growth response and Wilms' tumour finger proteins. EMBO J 9:2891-2898

Niederacher D, Entian KD (1991) Characterization of Hex2 protein, a negative regulatory element necessary for glucose repression in yeast. Eur J Biochem 200:311-319

Nikawa J, Cameron S, Toda T, Ferguson KM, Wigler M (1987a) Rigorous feedback control of cAMP levels in Saccharomyces cerevisiae. Genes Dev 1:931-937

Nikawa J, Sass P, Wigler M (1987b) Cloning and characterization of the low-affinity cyclic AMP phosphodiesterase gene of Saccharomyces cerevisiae. Mol Cell Biol 7:3629-3636

Nishizawa M, Kanaya Y, Toh EA (1999) Mouse cyclin-dependent kinase $(\mathrm{Cdk}) 5$ is a functional homologue of a yeast Cdk, pho85 kinase. J Biol Chem 274:33859-33862

Nishizawa M, Katou Y, Shirahige K, Toh-e A (2004) Yeast Pho85 kinase is required for proper gene expression during the diauxic shift. Yeast 21:903-918

Nishizawa M, Komai T, Katou Y, Shirahige K, Ito T, Toh EA (2008a) Nutrient-regulated antisense and intragenic RNAs modulate a signal transduction pathway in yeast. PLoS Biol 6:2817-2830

Nishizawa M, Komai T, Morohashi N, Shimizu M, Toh-e A (2008b) Transcriptional repression by the Pho4 transcription factor controls the timing of SNZ1 expression. Eukaryot Cell 7:949957

O'Neill EM, Kaffman A, Jolly ER, O'Shea EK (1996) Regulation of PHO4 nuclear localization by the PHO80-PHO85 cyclin-CDK complex. Science 271:209-212

Oficjalska-Pham D, Harismendy O, Smagowicz WJ, Gonzalez de Peredo A, Boguta M, Sentenac A, Lefebvre O (2006) General repression of RNA polymerase III transcription is triggered by protein phosphatase type 2A-mediated dephosphorylation of Maf1. Mol Cell 22:623-632

Ogawa N, DeRisi J, Brown PO (2000) New components of a system for phosphate accumulation and polyphosphate metabolism in Saccharomyces cerevisiae revealed by genomic expression analysis. Mol Biol Cell 11:4309-4321

Pan X, Heitman J (1999) Cyclic AMP-dependent protein kinase regulates pseudohyphal differentiation in Saccharomyces cerevisiae. Mol Cell Biol 19:4874-4887

Panek AC, de Araujo PS, Moura Neto V, Panek AD (1987) Regulation of the trehalose-6-phosphate synthase complex in Saccharomyces. I. Interconversion of forms by phosphorylation. Curr Genet 11:459-465

Papamichos-Chronakis M, Gligoris T, Tzamarias D (2004) The Snf1 kinase controls glucose repression in yeast by modulating interactions between the Mig1 repressor and the Cyc8-Tup1 co-repressor. EMBO Rep 5:368-372

Park JI, Grant CM, Dawes IW (2005) The high-affinity cAMP phosphodiesterase of Saccharomyces cerevisiae is the major determinant of cAMP levels in stationary phase: involvement of different branches of the Ras-cyclic AMP pathway in stress responses. Biochem Biophys Res Commun 327:311-319

Pascual-Ahuir A, Proft M (2007) The Sch9 kinase is a chromatinassociated transcriptional activator of osmostress-responsive genes. EMBO J 26:3098-3108

Pedruzzi I, Burckert N, Egger P, De Virgilio C (2000) Saccharomyces cerevisiae Ras/cAMP pathway controls post-diauxic shift element-dependent transcription through the zinc finger protein Gis1. EMBO J 19:2569-2579

Pedruzzi I, Dubouloz F, Cameroni E, Wanke V, Roosen J, Winderickx J, De Virgilio C (2003) TOR and PKA signaling pathways converge on the protein kinase Rim15 to control entry into G0. Mol Cell 12:1607-1613

Peeters T, Louwet W, Gelade R, Nauwelaers D, Thevelein JM, Versele M (2006) Kelch-repeat proteins interacting with the 
Galpha protein Gpa2 bypass adenylate cyclase for direct regulation of protein kinase A in yeast. Proc Natl Acad Sci USA 103:13034-13039

Persson BL, Lagerstedt JO, Pratt JR, Pattison-Granberg J, Lundh K, Shokrollahzadeh S, Lundh F (2003) Regulation of phosphate acquisition in Saccharomyces cerevisiae. Curr Genet 43:225244

Pike BL, Yongkiettrakul S, Tsai MD, Heierhorst J (2004) Mdt1, a novel Rad53 FHA1 domain-interacting protein, modulates DNA damage tolerance and G(2)/M cell cycle progression in Saccharomyces cerevisiae. Mol Cell Biol 24:2779-2788

Pinson B, Vaur S, Sagot I, Coulpier F, Lemoine S, Daignan-Fornier B (2009) Metabolic intermediates selectively stimulate transcription factor interaction and modulate phosphate and purine pathways. Genes Dev 23:1399-1407

Piper RC (2006) Successful transporter gets an EGO boost. Dev Cell 11:6-7

Planta RJ (1997) Regulation of ribosome synthesis in yeast. Yeast 13:1505-1518

Polizotto RS, Cyert MS (2001) Calcineurin-dependent nuclear import of the transcription factor Crz1p requires Nmd5p. J Cell Biol 154:951-960

Popova Iu G, Padkina MV, Sambuk EV (2000) Effect of mutations in PHO85 and PHO4 genes on utilization of proline in Saccharomyces cerevisiae yeasts. Genetika 36:1622-1628

Portela P, Moreno S (2006) Glucose-dependent activation of protein kinase A activity in Saccharomyces cerevisiae and phosphorylation of its TPK1 catalytic subunit. Cell Signal 18:1072-1086

Portela P, Howell S, Moreno S, Rossi S (2002) In vivo and in vitro phosphorylation of two isoforms of yeast pyruvate kinase by protein kinase A. J Biol Chem 277:30477-30487

Pruyne D, Bretscher A (2000a) Polarization of cell growth in yeast. J Cell Sci 113(Pt 4):571-585

Pruyne D, Bretscher A (2000b) Polarization of cell growth in yeast. I. Establishment and maintenance of polarity states. J Cell Sci 113(Pt 3):365-375

Ptacek J, Devgan G, Michaud G, Zhu H, Zhu X, Fasolo J, Guo H, Jona G, Breitkreutz A, Sopko R, McCartney RR, Schmidt MC, Rachidi N, Lee SJ, Mah AS, Meng L, Stark MJ, Stern DF, De Virgilio C, Tyers M, Andrews B, Gerstein M, Schweitzer B, Predki PF, Snyder M (2005) Global analysis of protein phosphorylation in yeast. Nature 438:679-684

Rahner A, Scholer A, Martens E, Gollwitzer B, Schuller HJ (1996) Dual influence of the yeast Cat1p (Snflp) protein kinase on carbon source-dependent transcriptional activation of gluconeogenic genes by the regulatory gene CAT8. Nucleic Acids Res 24:2331-2337

Randez-Gil F, Bojunga N, Proft M, Entian KD (1997) Glucose derepression of gluconeogenic enzymes in Saccharomyces cerevisiae correlates with phosphorylation of the gene activator Cat8p. Mol Cell Biol 17:2502-2510

Randez-Gil F, Herrero P, Sanz P, Prieto JA, Moreno F (1998) Hexokinase PII has a double cytosolic-nuclear localisation in Saccharomyces cerevisiae. FEBS Lett 425:475-478

Rebora K, Desmoucelles C, Borne F, Pinson B, Daignan-Fornier B (2001) Yeast AMP pathway genes respond to adenine through regulated synthesis of a metabolic intermediate. Mol Cell Biol 21:7901-7912

Rebora K, Laloo B, Daignan-Fornier B (2005) Revisiting purinehistidine cross-pathway regulation in Saccharomyces cerevisiae: a central role for a small molecule. Genetics 170:61-70

Reinders A, Burckert N, Boller T, Wiemken A, De Virgilio C (1998) Saccharomyces cerevisiae cAMP-dependent protein kinase controls entry into stationary phase through the Rim15p protein kinase. Genes Dev 12:2943-2955
Reinke A, Anderson S, McCaffery JM, Yates J 3rd, Aronova S, Chu S, Fairclough S, Iverson C, Wedaman KP, Powers T (2004) TOR complex 1 includes a novel component, Tco89p (YPL180w), and cooperates with Ssd1p to maintain cellular integrity in Saccharomyces cerevisiae. J Biol Chem 279:14752-14762

Rittenhouse J, Moberly L, Marcus F (1987) Phosphorylation in vivo of yeast (Saccharomyces cerevisiae) fructose-1,6-bisphosphatase at the cyclic AMP-dependent site. J Biol Chem 262:1011410119

Roberg KJ, Rowley N, Kaiser CA (1997) Physiological regulation of membrane protein sorting late in the secretory pathway of Saccharomyces cerevisiae. J Cell Biol 137:1469-1482

Roberts DN, Wilson B, Huff JT, Stewart AJ, Cairns BR (2006) Dephosphorylation and genome-wide association of Maf1 with Pol III-transcribed genes during repression. Mol Cell 22:633644

Robertson LS, Fink GR (1998) The three yeast A kinases have specific signaling functions in pseudohyphal growth. Proc Natl Acad Sci USA 95:13783-13787

Robertson LS, Causton HC, Young RA, Fink GR (2000) The yeast A kinases differentially regulate iron uptake and respiratory function. Proc Natl Acad Sci USA 97:5984-5988

Robinson LC, Tatchell K (1991) TFS1: a suppressor of cdc25 mutations in Saccharomyces cerevisiae. Mol Gen Genet 230:241-250

Roelants FM, Torrance PD, Thorner J (2004) Differential roles of PDK1- and PDK2-phosphorylation sites in the yeast AGC kinases Ypk1, Pkc1 and Sch9. Microbiology 150:3289-3304

Rohde JR, Campbell S, Zurita-Martinez SA, Cutler NS, Ashe M, Cardenas ME (2004) TOR controls transcriptional and translational programs via Sap-Sit4 protein phosphatase signaling effectors. Mol Cell Biol 24:8332-8341

Rohde JR, Bastidas R, Puria R, Cardenas ME (2008) Nutritional control via Tor signaling in Saccharomyces cerevisiae. Curr Opin Microbiol 11:153-160

Rolland F, De Winde JH, Lemaire K, Boles E, Thevelein JM, Winderickx J (2000) Glucose-induced cAMP signalling in yeast requires both a G-protein coupled receptor system for extracellular glucose detection and a separable hexose kinase-dependent sensing process. Mol Microbiol 38:348-358

Ronne H (1995) Glucose repression in fungi. Trends Genet 11:12-17

Ronne H, Carlberg M, Hu GZ, Nehlin JO (1991) Protein phosphatase 2A in Saccharomyces cerevisiae: effects on cell growth and bud morphogenesis. Mol Cell Biol 11:4876-4884

Roosen J, Oesterhelt C, Pardons K, Swinnen E, Winderickx J (2004) Integration of nutrient signalling pathways in the yeast Saccharomyces cerevisiae. In: Winderickx J, Taylor PM (eds) Topics in current genetics. Nutrient-induced responses in eukaryotic cells, vol 7. Springer, Heidelberg, pp 277-318

Roosen J, Engelen K, Marchal K, Mathys J, Griffioen G, Cameroni E, Thevelein JM, De Virgilio C, De Moor B, Winderickx J (2005) PKA and Sch9 control a molecular switch important for the proper adaptation to nutrient availability. Mol Microbiol 55:862880

Rose M, Albig W, Entian KD (1991) Glucose repression in Saccharomyces cerevisiae is directly associated with hexose phosphorylation by hexokinases PI and PII. Eur J Biochem 199:511-518

Rubenstein EM, McCartney RR, Zhang C, Shokat KM, Shirra MK, Arndt KM, Schmidt MC (2008) Access denied: Snf1 activation loop phosphorylation is controlled by availability of the phosphorylated threonine 210 to the PP1 phosphatase. J Biol Chem 283:222-230

Rudoni S, Colombo S, Coccetti P, Martegani E (2001) Role of guanine nucleotides in the regulation of the Ras/cAMP pathway 
in Saccharomyces cerevisiae. Biochim Biophys Acta 1538:181189

Rudra D, Zhao Y, Warner JR (2005) Central role of Ifh1p-Fhl1p interaction in the synthesis of yeast ribosomal proteins. EMBO J 24:533-542

Sancak Y, Peterson TR, Shaul YD, Lindquist RA, Thoreen CC, BarPeled L, Sabatini DM (2008) The Rag GTPases bind raptor and mediate amino acid signaling to mTORC1. Science 320:14961501

Santangelo GM (2006) Glucose signaling in Saccharomyces cerevisiae. Microbiol Mol Biol Rev 70:253-282

Santhanam A, Hartley A, Duvel K, Broach JR, Garrett S (2004) PP2A phosphatase activity is required for stress and Tor kinase regulation of yeast stress response factor Msn2p. Eukaryot Cell 3:1261-1271

Sanz P, Alms GR, Haystead TA, Carlson M (2000) Regulatory interactions between the Reg1-Glc7 protein phosphatase and the Snf1 protein kinase. Mol Cell Biol 20:1321-1328

Sass P, Field J, Nikawa J, Toda T, Wigler M (1986) Cloning and characterization of the high-affinity cAMP phosphodiesterase of Saccharomyces cerevisiae. Proc Natl Acad Sci USA 83:93039307

Schawalder SB, Kabani M, Howald I, Choudhury U, Werner M, Shore D (2004) Growth-regulated recruitment of the essential yeast ribosomal protein gene activator Ifh1. Nature 432:10581061

Schmelzle T, Helliwell SB, Hall MN (2002) Yeast protein kinases and the RHO1 exchange factor TUS1 are novel components of the cell integrity pathway in yeast. Mol Cell Biol 22:1329-1339

Schmelzle T, Beck T, Martin DE, Hall MN (2004) Activation of the RAS/cyclic AMP pathway suppresses a TOR deficiency in yeast. Mol Cell Biol 24:338-351

Schmidt A, Kunz J, Hall MN (1996) TOR2 is required for organization of the actin cytoskeleton in yeast. Proc Natl Acad Sci USA 93:13780-13785

Schmidt A, Beck T, Koller A, Kunz J, Hall MN (1998) The TOR nutrient signalling pathway phosphorylates NPR1 and inhibits turnover of the tryptophan permease. EMBO J 17:6924-6931

Schmitt AP, McEntee K (1996) Msn2p, a zinc finger DNA-binding protein, is the transcriptional activator of the multistress response in Saccharomyces cerevisiae. Proc Natl Acad Sci USA 93:57775782

Schuller HJ (2003) Transcriptional control of nonfermentative metabolism in the yeast Saccharomyces cerevisiae. Curr Genet 43:139-160

Serrano R, Ruiz A, Bernal D, Chambers JR, Arino J (2002) The transcriptional response to alkaline $\mathrm{pH}$ in Saccharomyces cerevisiae: evidence for calcium-mediated signalling. Mol Microbiol 46:1319-1333

Shamji AF, Kuruvilla FG, Schreiber SL (2000) Partitioning the transcriptional program induced by rapamycin among the effectors of the Tor proteins. Curr Biol 10:1574-1581

Shao D, Creasy CL, Bergman LW (1998) A cysteine residue in helixII of the bHLH domain is essential for homodimerization of the yeast transcription factor Pho4p. Nucleic Acids Res 26:710-714

Singh KK, Rasmussen AK, Rasmussen LJ (2004) Genome-wide analysis of signal transducers and regulators of mitochondrial dysfunction in Saccharomyces cerevisiae. Ann N Y Acad Sci 1011:284-298

Smets B, De Snijder P, Engelen K, Joossens E, Ghillebert R, Thevissen K, Marchal K, Winderickx J (2008) Genome-wide expression analysis reveals TORC1-dependent and -independent functions of Sch9. FEMS Yeast Res 8:1276-1288

Smith A, Ward MP, Garrett S (1998) Yeast PKA represses Msn2p/ Msn4p-dependent gene expression to regulate growth, stress response and glycogen accumulation. EMBO J 17:3556-3564
Smith FC, Davies SP, Wilson WA, Carling D, Hardie DG (1999) The SNF1 kinase complex from Saccharomyces cerevisiae phosphorylates the transcriptional repressor protein Mig1p in vitro at four sites within or near regulatory domain 1. FEBS Lett 453:219-223

Sneddon AA, Cohen PT, Stark MJ (1990) Saccharomyces cerevisiae protein phosphatase $2 \mathrm{~A}$ performs an essential cellular function and is encoded by two genes. EMBO J 9:4339-4346

Soetens O, De Craene JO, Andre B (2001) Ubiquitin is required for sorting to the vacuole of the yeast general amino acid permease, Gap1. J Biol Chem 276:43949-43957

Sopko R, Huang D, Preston N, Chua G, Papp B, Kafadar K, Snyder M, Oliver SG, Cyert M, Hughes TR, Boone C, Andrews B (2006) Mapping pathways and phenotypes by systematic gene overexpression. Mol Cell 21:319-330

Springael JY, Andre B (1998) Nitrogen-regulated ubiquitination of the Gap1 permease of Saccharomyces cerevisiae. Mol Biol Cell 9:1253-1263

Springael JY, Nikko E, Andre B, Marini AM (2002) Yeast Npi3/Bro1 is involved in ubiquitin-dependent control of permease trafficking. FEBS Lett 517:103-109

Stathopoulos AM, Cyert MS (1997) Calcineurin acts through the CRZ1/TCN1-encoded transcription factor to regulate gene expression in yeast. Genes Dev 11:3432-3444

Stathopoulos-Gerontides A, Guo JJ, Cyert MS (1999) Yeast calcineurin regulates nuclear localization of the Crz1p transcription factor through dephosphorylation. Genes Dev 13:798-803

Steger DJ, Haswell ES, Miller AL, Wente SR, O'Shea EK (2003) Regulation of chromatin remodeling by inositol polyphosphates. Science 299:114-116

Sturgill TW, Cohen A, Diefenbacher M, Trautwein M, Martin DE, Hall MN (2008) TOR1 and TOR2 have distinct locations in live cells. Eukaryot Cell 7:1819-1830

Subramanian M, Qiao WB, Khanam N, Wilkins O, Der SD, Lalich JD, Bognar AL (2005) Transcriptional regulation of the onecarbon metabolism regulon in Saccharomyces cerevisiae by Bas1p. Mol Microbiol 57:53-69

Sutherland CM, Hawley SA, McCartney RR, Leech A, Stark MJ, Schmidt MC, Hardie DG (2003) Elm1p is one of three upstream kinases for the Saccharomyces cerevisiae SNF1 complex. Curr Biol 13:1299-1305

Swinnen E, Rosseels J, Winderickx J (2005) The minimum domain of Pho81 is not sufficient to control the Pho85-Rim15 effector branch involved in phosphate starvation-induced stress responses. Curr Genet 48:18-33

Swinnen E, Wanke V, Roosen J, Smets B, Dubouloz F, Pedruzzi I, Cameroni E, De Virgilio C, Winderickx J (2006) Rim15 and the crossroads of nutrient signalling pathways in Saccharomyces cerevisiae. Cell Div 1:3

Tamaki H (2007) Glucose-stimulated cAMP-protein kinase A pathway in yeast Saccharomyces cerevisiae. J Biosci Bioeng 104:245-250

Tanaka K, Matsumoto K, Toh EA (1989) IRA1, an inhibitory regulator of the RAS-cyclic AMP pathway in Saccharomyces cerevisiae. Mol Cell Biol 9:757-768

Tanaka K, Nakafuku M, Satoh T, Marshall MS, Gibbs JB, Matsumoto K, Kaziro Y, Toh-e A (1990a) S. cerevisiae genes IRA1 and IRA2 encode proteins that may be functionally equivalent to mammalian ras GTPase activating protein. Cell 60:803-807

Tanaka K, Nakafuku M, Tamanoi F, Kaziro Y, Matsumoto K, Toh-e A (1990b) IRA2, a second gene of Saccharomyces cerevisiae that encodes a protein with a domain homologous to mammalian ras GTPase-activating protein. Mol Cell Biol 10:4303-4313

Tanaka K, Lin BK, Wood DR, Tamanoi F (1991) IRA2, an upstream negative regulator of RAS in yeast, is a RAS GTPase-activating protein. Proc Natl Acad Sci USA 88:468-472 
Tate JJ, Cox KH, Rai R, Cooper TG (2002) Mks1p is required for negative regulation of retrograde gene expression in Saccharomyces cerevisiae but does not affect nitrogen catabolite repression-sensitive gene expression. J Biol Chem 277:20477-20482

Tate JJ, Georis I, Feller A, Dubois E, Cooper TG (2009) Rapamycininduced Gln3 dephosphorylation is insufficient for nuclear localization: Sit4 and PP2A phosphatases are regulated and function differently. J Biol Chem 284:2522-2534

Tennyson CN, Lee J, Andrews BJ (1998) A role for the Pc19-Pho85 cyclin-cdk complex at the M/G1 boundary in Saccharomyces cerevisiae. Mol Microbiol 28:69-79

Thevelein JM (1994) Signal transduction in yeast. Yeast 10:17531790

Thevelein JM, Cauwenberg L, Colombo S, De Winde JH, Donation M, Dumortier F, Kraakman L, Lemaire K, Ma P, Nauwelaers D, Rolland F, Teunissen A, Van Dijck P, Versele M, Wera S, Winderickx J (2000) Nutrient-induced signal transduction through the protein kinase A pathway and its role in the control of metabolism, stress resistance, and growth in yeast. Enzyme Microb Technol 26:819-825

Timblin BK, Tatchell K, Bergman LW (1996) Deletion of the gene encoding the cyclin-dependent protein kinase Pho85 alters glycogen metabolism in Saccharomyces cerevisiae. Genetics 143:57-66

Toda T, Uno I, Ishikawa T, Powers S, Kataoka T, Broek D, Cameron S, Broach J, Matsumoto K, Wigler M (1985) In yeast, RAS proteins are controlling elements of adenylate cyclase. Cell 40:27-36

Toda T, Cameron S, Sass P, Zoller M, Scott JD, McMullen B, Hurwitz M, Krebs EG, Wigler M (1987a) Cloning and characterization of BCY1, a locus encoding a regulatory subunit of the cyclic AMP-dependent protein kinase in Saccharomyces cerevisiae. Mol Cell Biol 7:1371-1377

Toda T, Cameron S, Sass P, Zoller M, Wigler M (1987b) Three different genes in $S$. cerevisiae encode the catalytic subunits of the cAMP-dependent protein kinase. Cell 50:277-287

Toda T, Cameron S, Sass P, Wigler M (1988) SCH9, a gene of Saccharomyces cerevisiae that encodes a protein distinct from, but functionally and structurally related to, cAMP-dependent protein kinase catalytic subunits. Genes Dev 2:517-527

Treitel MA, Carlson M (1995) Repression by SSN6-TUP1 is directed by MIG1, a repressor/activator protein. Proc Natl Acad Sci USA 92:3132-3136

Treitel MA, Kuchin S, Carlson M (1998) Snf1 protein kinase regulates phosphorylation of the Mig1 repressor in Saccharomyces cerevisiae. Mol Cell Biol 18:6273-6280

Tu J, Carlson M (1994) The GLC7 type 1 protein phosphatase is required for glucose repression in Saccharomyces cerevisiae. Mol Cell Biol 14:6789-6796

Tu J, Carlson M (1995) REG1 binds to protein phosphatase type 1 and regulates glucose repression in Saccharomyces cerevisiae. EMBO J 14:5939-5946

Tung KS, Norbeck LL, Nolan SL, Atkinson NS, Hopper AK (1992) SRN1, a yeast gene involved in RNA processing, is identical to HEX2/REG1, a negative regulator in glucose repression. Mol Cell Biol 12:2673-2680

Uno I, Matsumoto K, Adachi K, Ishikawa T (1983) Genetic and biochemical evidence that trehalase is a substrate of cAMPdependent protein kinase in yeast. J Biol Chem 258:10867-10872

Urban J, Soulard A, Huber A, Lippman S, Mukhopadhyay D, Deloche O, Wanke V, Anrather D, Ammerer G, Riezman H, Broach JR, De Virgilio C, Hall MN, Loewith R (2007) Sch9 is a major target of TORC1 in Saccharomyces cerevisiae. Mol Cell 26:663-674

Valenzuela L, Aranda C, Gonzalez A (2001) TOR modulates GCN4dependent expression of genes turned on by nitrogen limitation. J Bacteriol 183:2331-2334
Van Hoof C, Janssens V, De Baere I, Stark MJ, de Winde JH, Winderickx J, Thevelein JM, Merlevede W, Goris J (2001) The Saccharomyces cerevisiae phosphotyrosyl phosphatase activator proteins are required for a subset of the functions disrupted by protein phosphatase 2A mutations. Exp Cell Res 264:372-387

van Oevelen CJ, van Teeffelen HA, van Werven FJ, Timmers HT (2006) Snf1p-dependent Spt-Ada-Gcn5-acetyltransferase (SAGA) recruitment and chromatin remodeling activities on the HXT2 and HXT4 promoters. J Biol Chem 281:4523-4531

van Zyl W, Huang W, Sneddon AA, Stark M, Camier S, Werner M, Marck C, Sentenac A, Broach JR (1992) Inactivation of the protein phosphatase $2 \mathrm{~A}$ regulatory subunit A results in morphological and transcriptional defects in Saccharomyces cerevisiae. Mol Cell Biol 12:4946-4959

Vanrobays E, Leplus A, Osheim YN, Beyer AL, Wacheul L, Lafontaine DL (2008) TOR regulates the subcellular distribution of DIM2, a $\mathrm{KH}$ domain protein required for cotranscriptional ribosome assembly and pre-40S ribosome export. Rna 14:20612073

Vaseghi S, Macherhammer F, Zibek S, Reuss M (2001) Signal transduction dynamics of the protein kinase-A/phosphofructokinase-2 system in Saccharomyces cerevisiae. Metab Eng 3:163-172

Versele M, de Winde JH, Thevelein JM (1999) A novel regulator of G protein signalling in yeast, Rgs2, downregulates glucose-activation of the cAMP pathway through direct inhibition of Gpa2. EMBO J 18:5577-5591

Vidan S, Mitchell AP (1997) Stimulation of yeast meiotic gene expression by the glucose-repressible protein kinase Rim15p. Mol Cell Biol 17:2688-2697

Vincent O, Carlson M (1998) Sip4, a Snf1 kinase-dependent transcriptional activator, binds to the carbon source-responsive element of gluconeogenic genes. EMBO J 17:7002-7008

Vincent O, Townley R, Kuchin S, Carlson M (2001) Subcellular localization of the Snf1 kinase is regulated by specific beta subunits and a novel glucose signaling mechanism. Genes Dev 15:1104-1114

Wade JT, Hall DB, Struhl K (2004) The transcription factor Ifh1 is a key regulator of yeast ribosomal protein genes. Nature 432:1054-1058

Wang Z, Wilson WA, Fujino MA, Roach PJ (2001) Antagonistic controls of autophagy and glycogen accumulation by Snflp, the yeast homolog of AMP-activated protein kinase, and the cyclindependent kinase Pho85p. Mol Cell Biol 21:5742-5752

Wang Y, Pierce M, Schneper L, Guldal CG, Zhang X, Tavazoie S, Broach JR (2004) Ras and Gpa2 mediate one branch of a redundant glucose signaling pathway in yeast. PLoS Biol 2:E128

Wanke V, Pedruzzi I, Cameroni E, Dubouloz F, De Virgilio C (2005) Regulation of G0 entry by the Pho80-Pho85 cyclin-CDK complex. EMBO J 24:4271-4278

Wanke V, Cameroni E, Uotila A, Piccolis M, Urban J, Loewith R, De Virgilio C (2008) Caffeine extends yeast lifespan by targeting TORC1. Mol Microbiol 69:277-285

Wedaman KP, Reinke A, Anderson S, Yates J 3rd, McCaffery JM, Powers T (2003) Tor kinases are in distinct membrane-associated protein complexes in Saccharomyces cerevisiae. Mol Biol Cell 14:1204-1220

Wei Y, Tsang CK, Zheng XF (2009) Mechanisms of regulation of RNA polymerase III-dependent transcription by TORC1. EMBO J 28:2220-2230

Werner-Washburne M, Brown D, Braun E (1991) Bcy1, the regulatory subunit of cAMP-dependent protein kinase in yeast, is differentially modified in response to the physiological status of the cell. J Biol Chem 266:19704-19709

Willis IM, Moir RD (2007) Integration of nutritional and stress signaling pathways by Maf1. Trends Biochem Sci 32:51-53 
Wilson RB, Tatchell K (1988) SRA5 encodes the low-Km cyclic AMP phosphodiesterase of Saccharomyces cerevisiae. Mol Cell Biol 8:505-510

Wilson WA, Hawley SA, Hardie DG (1996) Glucose repression/ derepression in budding yeast: SNF1 protein kinase is activated by phosphorylation under derepressing conditions, and this correlates with a high AMP:ATP ratio. Curr Biol 6:1426-1434

Winderickx J, Holsbeeks I, Lagatie O, Giots F, Thevelein JM, de Winde H (2003) From feast to famine: adaptation to nutrient availability in yeast. In: Hohmann S, Mager PWH (eds) Topics in current genetics. Yeast stress response, vol 1. Springer, Heidelberg, pp 305-386

Wingender-Drissen R, Becker JU (1983) Regulation of yeast phosphorylase by phosphorylase kinase and cAMP-dependent protein kinase. FEBS Lett 163:33-36

Woods A, Munday MR, Scott J, Yang X, Carlson M, Carling D (1994) Yeast SNF1 is functionally related to mammalian AMPactivated protein kinase and regulates acetyl-CoA carboxylase in vivo. J Biol Chem 269:19509-19515

Wullschleger S, Loewith R, Oppliger W, Hall MN (2005) Molecular organization of target of rapamycin complex 2. J Biol Chem 280:30697-30704

Wurmser AE, Sato TK, Emr SD (2000) New component of the vacuolar class $\mathrm{C}-\mathrm{Vps}$ complex couples nucleotide exchange on the Ypt7 GTPase to SNARE-dependent docking and fusion. J Cell Biol 151:551-562

Wykoff DD, Rizvi AH, Raser JM, Margolin B, O’Shea EK (2007) Positive feedback regulates switching of phosphate transporters in S. cerevisiae. Mol Cell 27:1005-1013

Wysocki R, Javaheri A, Kristjansdottir K, Sha F, Kron SJ (2006) CDK Pho85 targets CDK inhibitor Sic1 to relieve yeast G1 checkpoint arrest after DNA damage. Nat Struct Mol Biol 13:908-914

Xia ZX, Ao SZ (1999) Analysis of interaction between PHO4 and $\mathrm{PHO} 2$ protein by real time BIA. Sheng Wu Hua Xue Yu Sheng Wu Wu Li Xue Bao (Shanghai) 31:145-149

Xue Y, Batlle M, Hirsch JP (1998) GPR1 encodes a putative G protein-coupled receptor that associates with the Gpa2p Galpha subunit and functions in a Ras-independent pathway. EMBO J 17:1996-2007

Yan G, Shen X, Jiang Y (2006) Rapamycin activates Tap42associated phosphatases by abrogating their association with Tor complex 1. EMBO J 25:3546-3555

Yang X, Jiang R, Carlson M (1994) A family of proteins containing a conserved domain that mediates interaction with the yeast SNF1 protein kinase complex. EMBO J 13:5878-5886

Yorimitsu T, Klionsky DJ (2005) Autophagy: molecular machinery for self-eating. Cell Death Differ 12(Suppl 2):1542-1552

Yorimitsu T, Zaman S, Broach JR, Klionsky DJ (2007) Protein kinase A and Sch9 cooperatively regulate induction of autophagy in Saccharomyces cerevisiae. Mol Biol Cell 18:4180-4189

Yorimitsu T, He C, Wang K, Klionsky DJ (2009) Tap42-associated protein phosphatase type $2 \mathrm{~A}$ negatively regulates induction of autophagy. Autophagy 5:616-624
Yun CW, Tamaki H, Nakayama R, Yamamoto K, Kumagai H (1997) G-protein coupled receptor from yeast Saccharomyces cerevisiae. Biochem Biophys Res Commun 240:287-292

Zabrocki P, Van Hoof C, Goris J, Thevelein JM, Winderickx J, Wera S (2002) Protein phosphatase 2A on track for nutrient-induced signalling in yeast. Mol Microbiol 43:835-842

Zaman S, Lippman SI, Zhao X, Broach JR (2008) How Saccharomyces responds to nutrients. Annu Rev Genet 42:27-81

Zappacosta F, Huddleston MJ, Karcher RL, Gelfand VI, Carr SA, Annan RS (2002) Improved sensitivity for phosphopeptide mapping using capillary column HPLC and microionspray mass spectrometry: comparative phosphorylation site mapping from gel-derived proteins. Anal Chem 74:3221-3231

Zeller CE, Parnell SC, Dohlman HG (2007) The RACK1 ortholog Asc1 functions as a G-protein beta subunit coupled to glucose responsiveness in yeast. J Biol Chem 282:25168-25176

Zhang F, Kirouac M, Zhu N, Hinnebusch AG, Rolfes RJ (1997) Evidence that complex formation by Bas1p and Bas2p (Pho2p) unmasks the activation function of Bas $1 \mathrm{p}$ in an adeninerepressible step of ADE gene transcription. Mol Cell Biol 17:3272-3283

Zhang N, Wu J, Oliver SG (2009) Gis1 is required for transcriptional reprogramming of carbon metabolism and the stress response during transition into stationary phase in yeast. Microbiology 155:1690-1698

Zhao Y, Boguslawski G, Zitomer RS, DePaoli-Roach AA (1997) Saccharomyces cerevisiae homologs of mammalian B and B' subunits of protein phosphatase 2A direct the enzyme to distinct cellular functions. J Biol Chem 272:8256-8262

Zhao Y, McIntosh KB, Rudra D, Schawalder S, Shore D, Warner JR (2006) Fine-structure analysis of ribosomal protein gene transcription. Mol Cell Biol 26:4853-4862

Zheng Y, Jiang Y (2005) The yeast phosphotyrosyl phosphatase activator is part of the Tap42-phosphatase complexes. Mol Biol Cell 16:2119-2127

Zheng XF, Florentino D, Chen J, Crabtree GR, Schreiber SL (1995) TOR kinase domains are required for two distinct functions, only one of which is inhibited by rapamycin. Cell 82:121-130

Zhu H, Klemic JF, Chang S, Bertone P, Casamayor A, Klemic KG, Smith D, Gerstein M, Reed MA, Snyder M (2000) Analysis of yeast protein kinases using protein chips. Nat Genet 26:283-289

Zhu C, Byers KJ, McCord RP, Shi Z, Berger MF, Newburger DE, Saulrieta K, Smith Z, Shah MV, Radhakrishnan M, Philippakis AA, Hu Y, De Masi F, Pacek M, Rolfs A, Murthy T, Labaer J, Bulyk ML (2009) High-resolution DNA-binding specificity analysis of yeast transcription factors. Genome Res 19:556-566

Zimmermann FK, Scheel I (1977) Mutants of Saccharomyces cerevisiae resistant to carbon catabolite repression. Mol Gen Genet 154:75-82

Zurita-Martinez SA, Puria R, Pan X, Boeke JD, Cardenas ME (2007) Efficient Tor signaling requires a functional class $\mathrm{C}$ Vps protein complex in Saccharomyces cerevisiae. Genetics 176:2139-2150 